\title{
DNREL
}

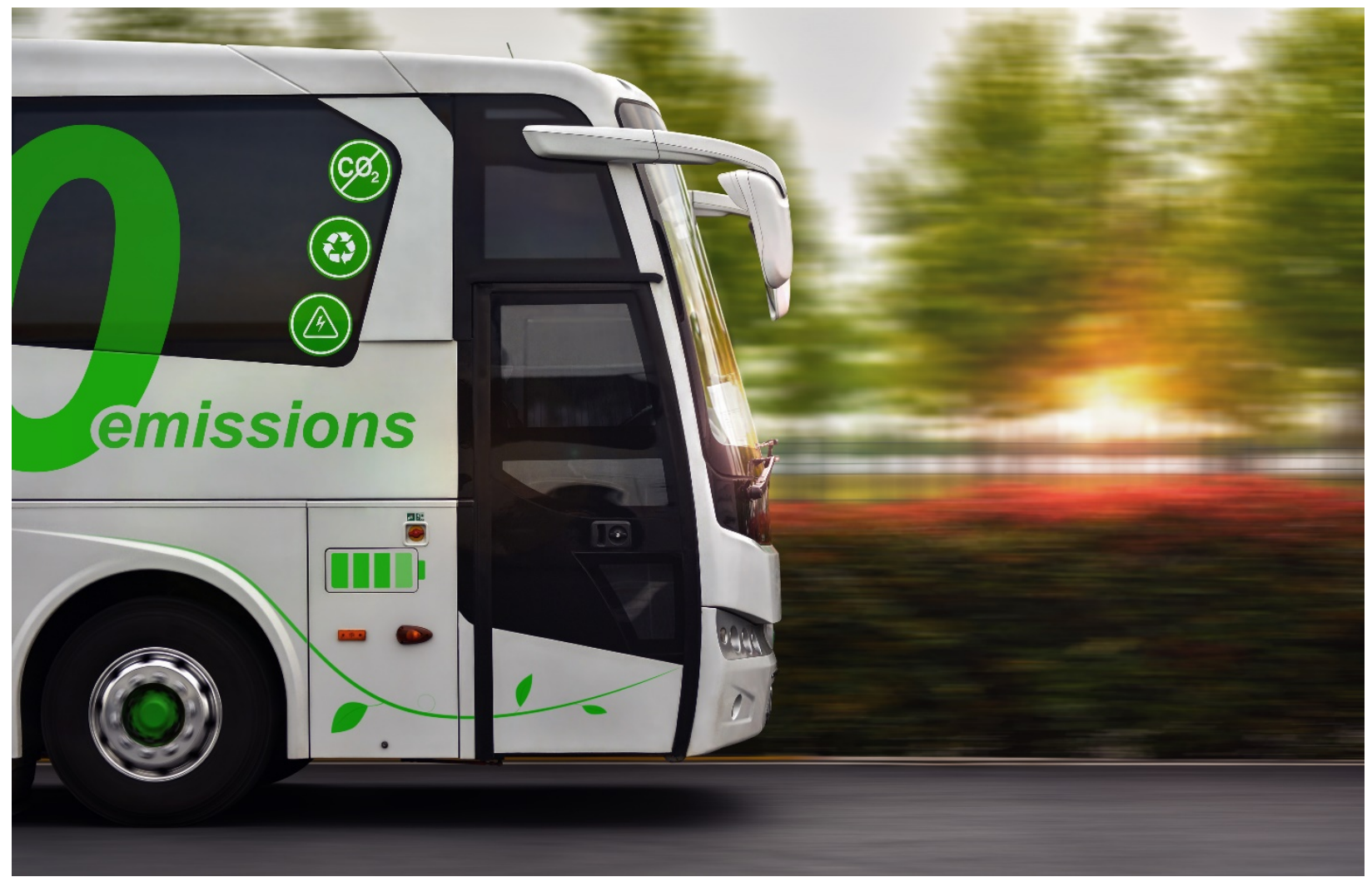

\section{ELECTRIFYING TRANSIT: A GUIDEBOOK FOR IMPLEMENTING BATTERY ELECTRIC BUSES}

Alana Aamodt, Karlynn Cory, and Kamyria Coney National Renewable Energy Laboratory

April 2021

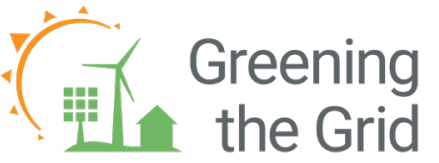

A product of the USAID-NREL Partnership Contract No. IAG-17-2050 


\section{NOTICE}

This work was authored, in part, by the National Renewable Energy Laboratory (NREL), operated by Alliance for Sustainable Energy, LLC, for the U.S. Department of Energy (DOE) under Contract No. DEAC36-08GO28308. Funding provided by the United States Agency for International Development (USAID) under Contract No. IAG-17-2050 as well as the Department of Energy, Office of Science, Office of Workforce Development for Teachers and Scientists, Science Undergraduate Laboratory Internship. The views expressed in this report do not necessarily represent the views of the DOE or the U.S. Government, or any agency thereof, including USAID.

This report is available at no cost from the National Renewable Energy Laboratory (NREL) at www.nrel.gov/publications.

U.S. Department of Energy (DOE) reports produced after 1991 and a growing number of pre-1991 documents are available free via www.OSTI.gov.

Cover photo from iStock 1184915589.

NREL prints on paper that contains recycled content. 


\section{Acknowledgments}

The authors would like to thank Sarah Lawson and Andrew Fang of the U.S. Agency for International Development (USAID) for their review and support for this work. We wish to thank our National Renewable Energy Laboratory (NREL) colleagues, Andrea Watson and Alexandra Aznar, for their support of this report. Other NREL colleagues, including Caley Johnson, Leslie Eudy, and Scott Belding provided invaluable public transit electrification insight for this project. In addition, we would like to thank all case study contributions, including Kenneth Kelly (NREL), Andrew Kotz (NREL), Sanjini U. Nanayakkara (NREL), Carolina Chantrill (Associacion Sustentar), Andres Pisani (Asociacion Sustentar and Universidad Nacional of Rosario), Augustina Krapp (Asociacion Sustentar), Milagros Garros (Bajas Emisiones), and Juan Agullo (Bajas Emisiones). The authors would like to thank and acknowledge Isabel McCan, Liz Craig, and Liz Breazeale for their design and editorial support. 


\section{Executive Summary}

The use of battery electric bus (BEBs) fleets is becoming more attractive to cities seeking to reduce emissions and traffic congestion. While BEB fleets may provide benefits such as lower fuel and maintenance costs, improved performance, lower emissions, and energy security, many challenges need to be overcome to support BEB deployment. These include upfront cost premiums, planning burdens, BEB range, and unfamiliarity with BEB technology. Policymakers, transit agencies, utilities, and other stakeholders have much to consider prior to BEB deployment, and this guidebook is intended to address those considerations.

Well-defined goals for BEB performance and BEB fleet requirements provide a solid basis for planning BEB deployment, but thorough analysis is needed for successful BEB implementation that satisfies the needs of the transit agency and the public. This long-term planning may include developing goals, outlining key performance indicators, engaging stakeholders, and identifying funding sources. Once the plan has been established, it is key to evaluate the available technology and route options in the context of those overall goals.

The three main components of a BEB are bus configuration, battery storage system, and charging infrastructure (also known as electric vehicle supply equipment or EVSE). BEB deployment decisions on these components are tightly interwoven. Battery sizing and charging strategy selections influence each other, as the size of the battery depends on the technology of the charging system. There are several charging methods, including depot charging, on-route charging, and battery swapping. Each option has its benefits, drawbacks, and implications for other elements of BEB project design.

Charging infrastructure also impacts electric utilities and the grid. The power demanded from the grid to charge BEBs requires careful consideration of the electric utility's rate structure, since certain BEB charging strategies may incur additional costs depending on the utility's use of energy charges, demand charges, and time-of-use charges. Transmission and distribution upgrades may be needed if existing infrastructure cannot support the increased load, and these upgrades have their own planning requirements and construction schedules. For these reasons, engaging utilities early is crucial for successful BEB implementation, as BEB refueling requires many considerations that affect the grid, and utility decisions can likewise have a significant impact on the value proposition of BEB investments.

Bus, battery, and EVSE choices also interact with route determination and scheduling. Thorough route analysis can establish range and performance requirements as well as identify important operational variables that may impact other BEB choices. Key route analysis characteristics are described in Table 1. 
Table ES- 1. Sample Bus Route Analysis Variables

\begin{tabular}{|c|c|}
\hline Elements & Characteristics/Variables \\
\hline Bus Route & $\begin{array}{ll}\text { - } & \text { Route length } \\
\text { - } & \text { Start/stop } \\
\text { - } & \text { Grequencies } \\
\text { - } & \text { Road of dimension } \\
\text { - } & \text { Traffic patterns } \\
& \text { and density }\end{array}$ \\
\hline $\begin{array}{c}\text { Bus } \\
\text { Operation }\end{array}$ & $\begin{array}{ll}\text { - } & \text { Bus speeds } \\
\text { - } & \text { Passenger } \\
\text { capacity/bus } \\
\text { ridership } \\
\text { - } \\
\text { Bus size and } \\
\text { weight (loaded and } \\
\text { unloaded) } \\
\text { - Operation } \\
\text { schedules } \\
\text { - } & \text { Deadhead } \\
\text { - } & \text { Susceptibility to } \\
& \text { route interruptions }\end{array}$ \\
\hline $\begin{array}{c}\text { Charging } \\
\text { Stations and } \\
\text { Infrastructure }\end{array}$ & $\begin{array}{l}\text { - } \\
\text { - } \\
\text { Electrical grid } \\
\text { access and } \\
\text { interconnection } \\
\text { - Overlap with other } \\
\text { routes } \\
\text { - Access to land }\end{array}$ \\
\hline Other & $\begin{array}{ll}\text { - } & \text { External } \\
\text { temperature } \\
\text { - } & \text { Weather }\end{array}$ \\
\hline
\end{tabular}

Once technology options have been identified, the route analysis is complete, and bus and range requirements are identified, fleet, route, and infrastructure planning can begin by answering a few key questions:

- What bus size (length) would best suit route characteristics and passenger capacity?

- What is the optimal charging rates, infrastructure, and on-bus battery size combination? How much EVSE is needed at each location? What battery size would satisfy the bus requirements given planned charging infrastructure?

- Does the utility provide different rate structure options? Which rate structure works best for the chosen charging method? Will the EVSE at the same location be used simultaneously for multiple buses, and, if so, what is the impact on electric utility demand charges?

Though costs have been decreasing, BEBs still have high purchase prices (up to $\$ 650,000$, including battery) compared to diesel buses (up to $\$ 400,000$ ) (Quarles, Kockelman, and Mohamed 2020); however, the lower operations and maintenance costs for BEBs (about $\$ 700,000$ vs. $\$ 1.1$ million annually) often lead to net savings over the BEB's lifetime (Johnson et al. 2020). There are also many funding and

${ }^{1}$ Travel without passengers or freight (specifically when the bus is at the depot). 
financing options that support BEB purchases in the United States, including U.S. Federal Transit Administration (FTA) grants, the Volkswagen settlement trust, state incentives, leasing options, green or climate bonds, and utility Pay As You Save (PAYS) tariffs (FTA 2020). ${ }^{2}$

Training transit staff to maintain and operate BEBs will increase safety and allow transit agencies to efficiently transition from diesel buses to electric buses. These trainings also impact economics and operations, as suboptimal operation of BEBs can affect the bus range and charging efficiency. Beyond training, bus tests, charging infrastructure inspection, and emergency preparedness plans are key practices for ensuring safety.

Preparing for BEB deployment can be a lengthy and involved process, but it is important that all considerations are addressed. In addition, once BEBs have been deployed, continued evaluation of the buses can be used to track performance, identify needed improvements, and inform other BEB deployment initiatives.

To assist stakeholders with interest in deploying BEBs, this guidebook describes the decisions and considerations required for successful BEB implementation. After the introduction and background of BEBs, Section 2 describes the benefits and barriers to deployment of BEBs. Section 3 covers the basics of BEBs, batteries, and charging station design. Section 4 addresses the complex relationship between BEB charging infrastructure, the electric grid, and the utilities responsible for the grid. Section 5 covers BEB operation and maintenance. Section 6 describes the costs associated with BEBs, as well as a suite of relevant funding and financing mechanisms for both BEBs and charging infrastructure. Section 7 covers safety concerns and standards. Section 8 addresses project execution factors that arise from the interconnectivity of all these sections.

${ }^{2}$ These options may differ in other jurisdictions. 


\section{List of Acronyms}

ANSI
AVTA
BEB
CNG
CTA
DGE
EV
EVSE
FTA
FY
HVAC
LFP
LTO
MRO
NMC
NREL
OEM
RTA
SAE
SOC
TIGGER
WSDES

American National Standards Institute

Antelope Valley Transit Authority

battery electric bus

compressed natural gas

Chicago Transit Authority

diesel gallon equivalent

electric vehicle

electric vehicle supply equipment

United States Federal Transit Administration

fiscal year

heating, ventilation, and air conditioning

lithium iron phosphate

lithium titanate

Midwest Reliability Organization

lithium nickel manganese cobalt oxide

National Renewable Energy Laboratory

original equipment manufacturer

Regional Transportation Agency

Society of Automotive Engineers

state of charge

Transit Investments for Greenhouse Gas and Energy Reduction

Washington State Department of Enterprise Services 


\section{Table of Contents}

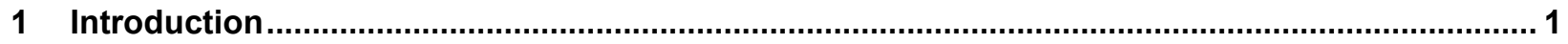

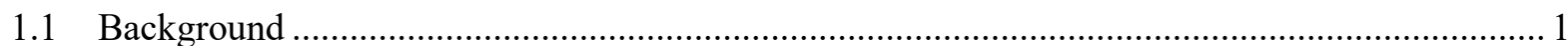

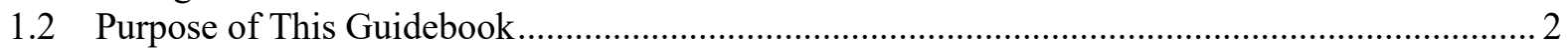

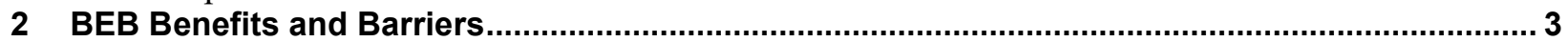

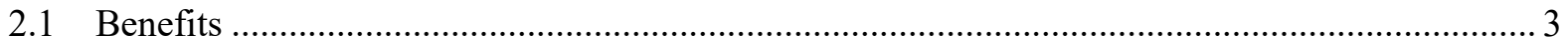

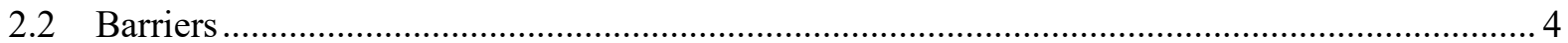

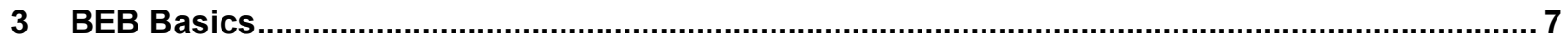

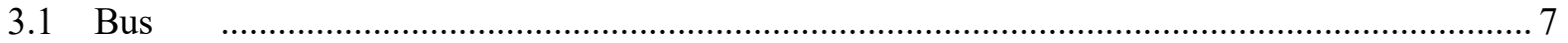

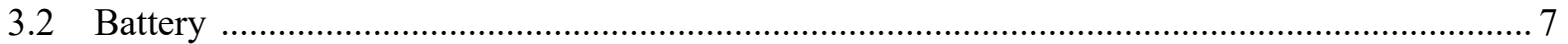

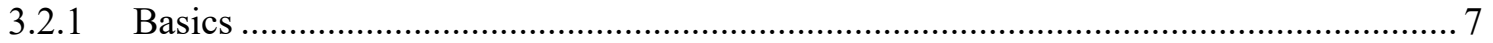

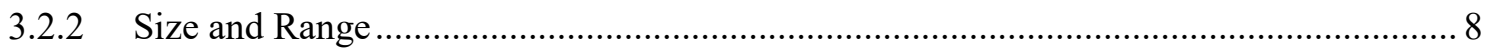

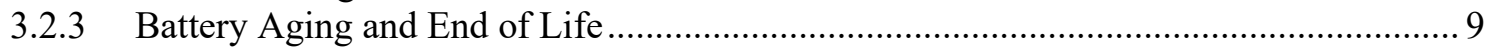

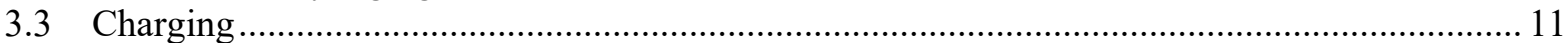

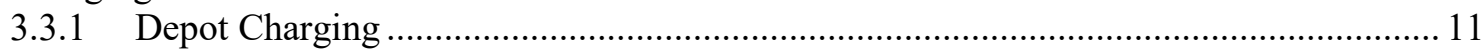

3.3.2 On-Route Charging .................................................................................... 12

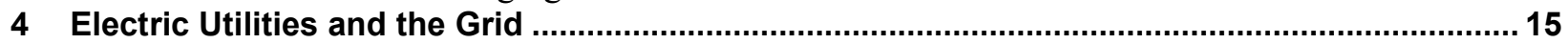

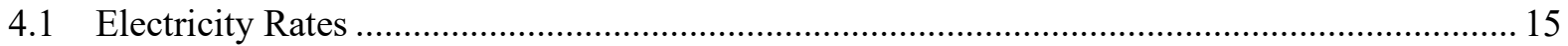

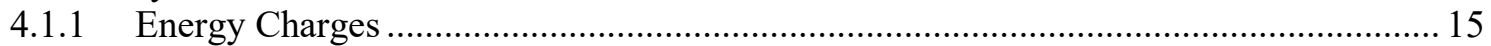

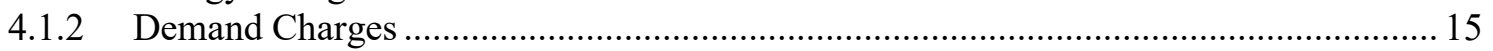

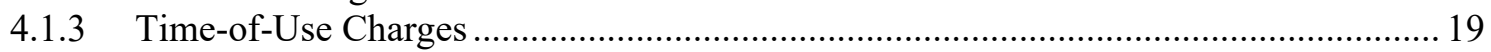

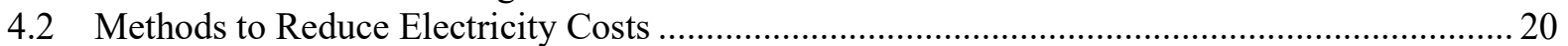

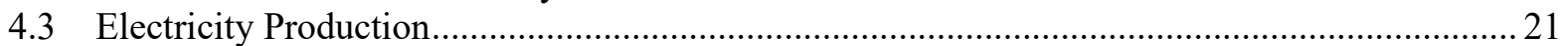

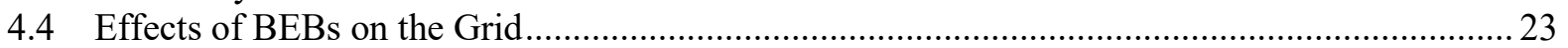

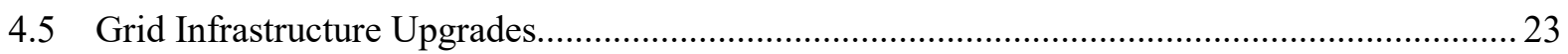

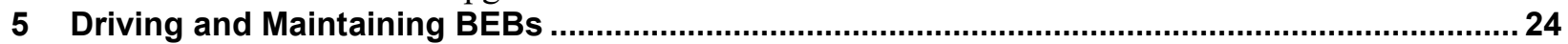

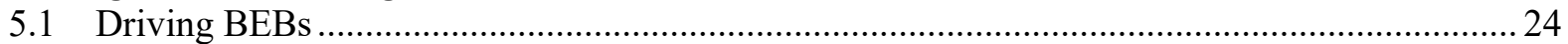

5.1.1 On-Route Charging Procedures ............................................................... 24

5.1 .2 Regenerative Braking ................................................................................. 24

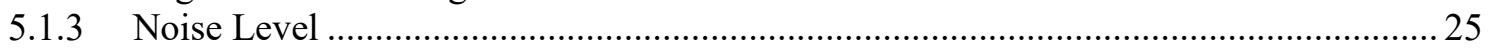

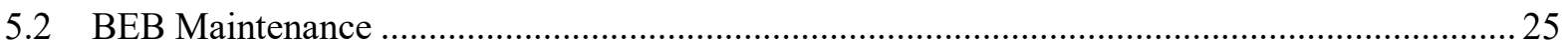

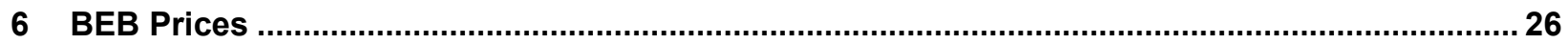

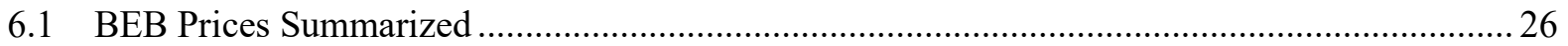

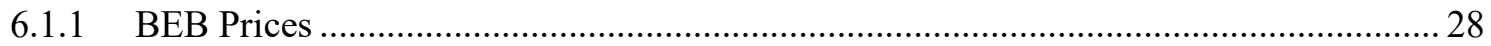

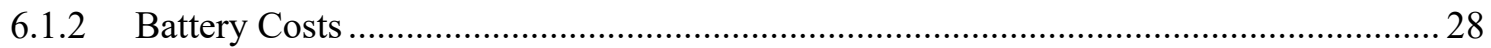

6.1.3 Fuel (Electricity) Costs.............................................................................. 29

6.2 Funding and Financing Options ............................................................................ 30

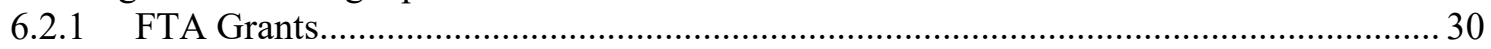

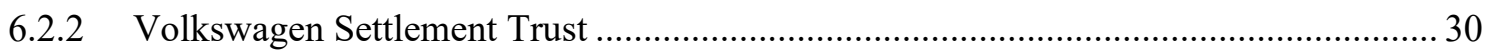

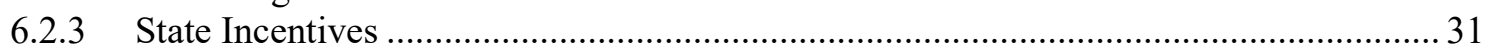

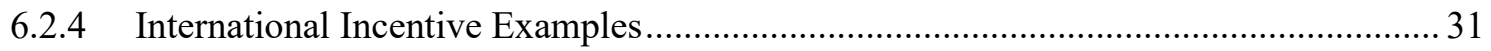

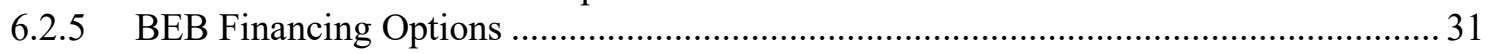

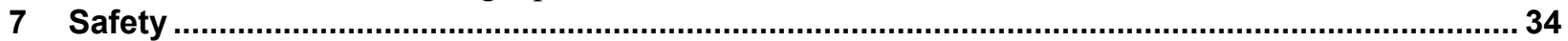

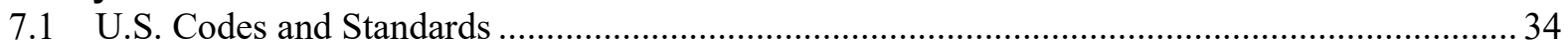

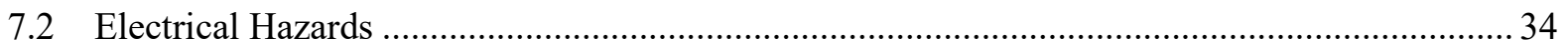

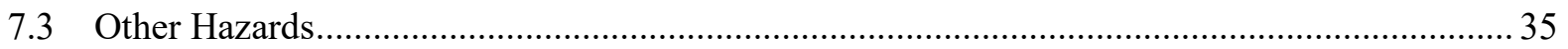

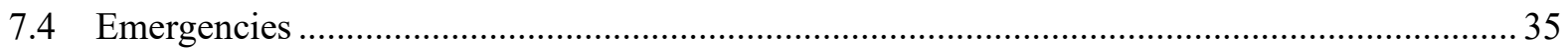

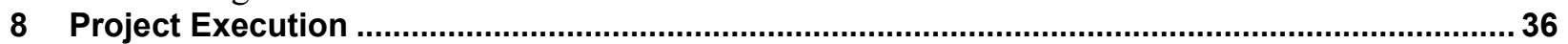

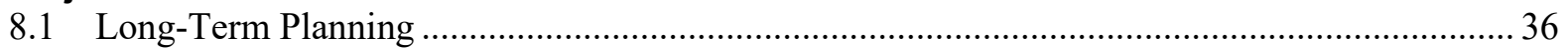

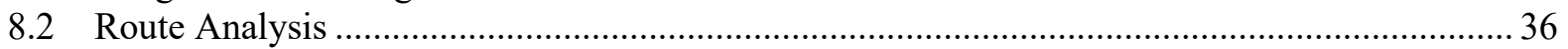

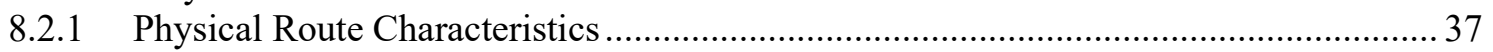




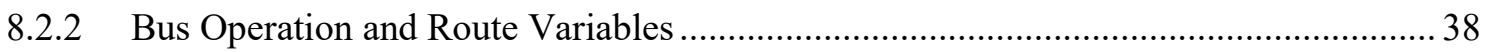

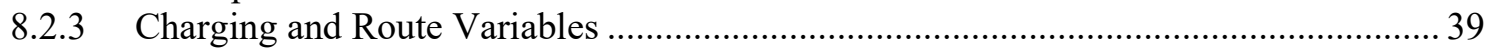

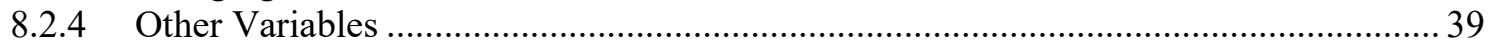

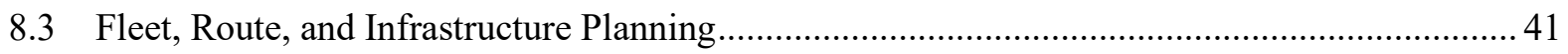

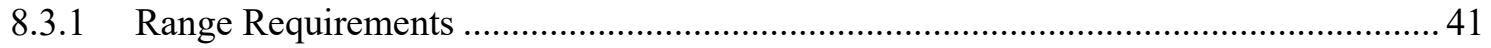

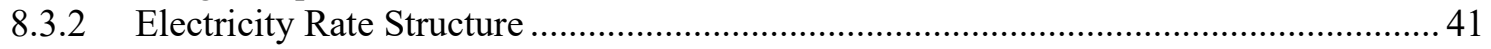

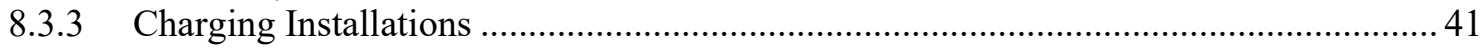

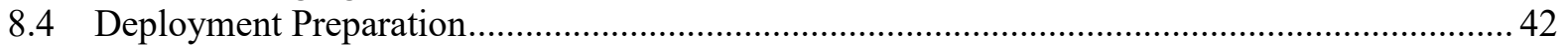

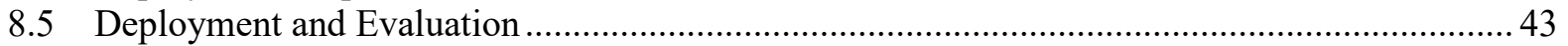

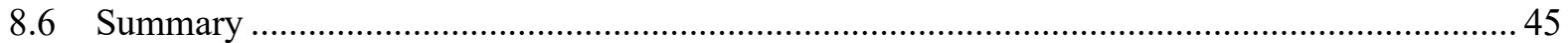

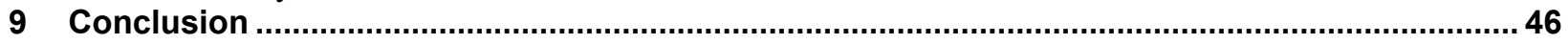

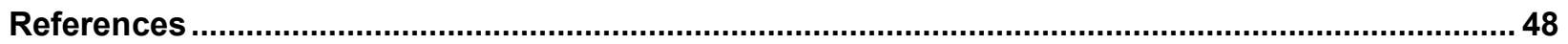

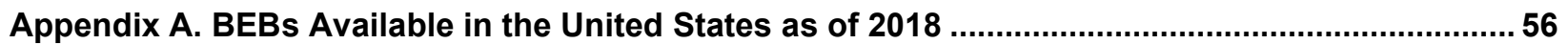

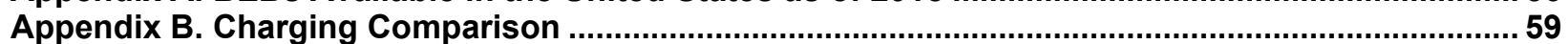

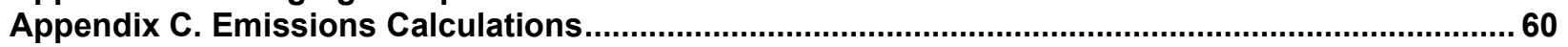




\section{List of Figures}

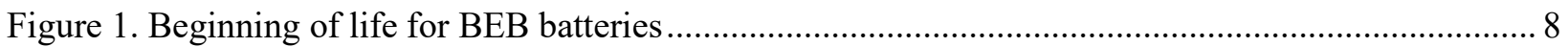

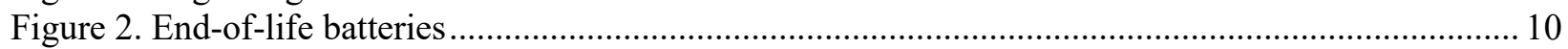

Figure 3. Battery capacity vs. time for locations of varying ambient temperatures (Electric car, not BEB)

Figure 4. Depot chargers at Antelope Valley Transit Authority Depot

Figure 5. Foothill Transit overhead 500-kW fast charger..................................................................... 13

Figure 6. Wireless advanced vehicle electrification brand charging station for AVTA, embedded in the

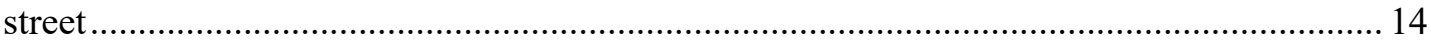

Figure 7. Maximum commercial demand charge rates by utility service territory ................................. 16

Figure 8. Demand charges for three hypothetical BEB charging scenarios............................................ 18

Figure 9. Fuel cost per mile for various demand charges ..................................................................... 19

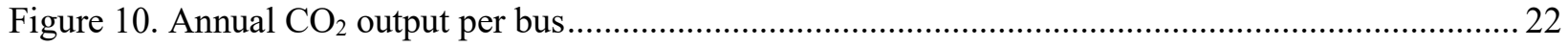

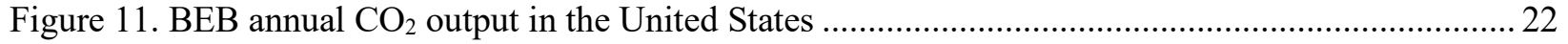

Figure 12. Lithium-ion battery pack price and demand outlook............................................................ 29

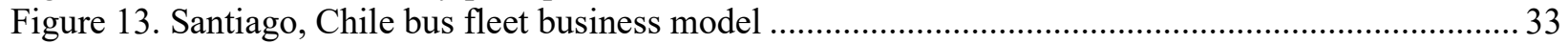

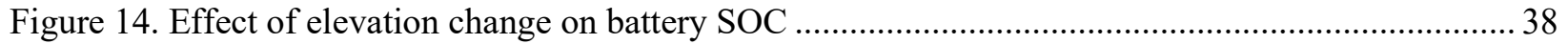

Figure 15. Effects of ambient temperature on LFP battery capacity .................................................... 40

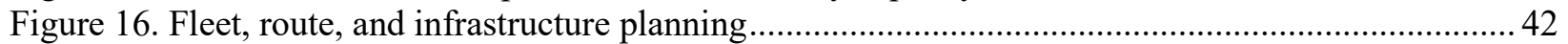

Figure 17. Cost difference by technology resulting from the financial feasibility evaluation for the Base

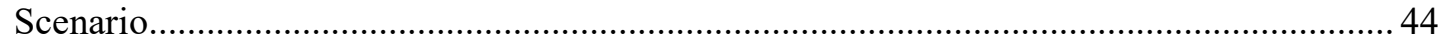

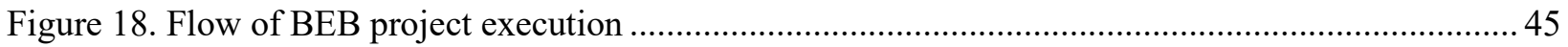

\section{List of Tables}

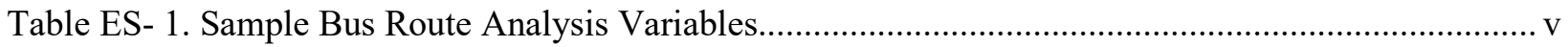

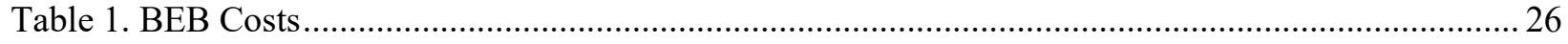

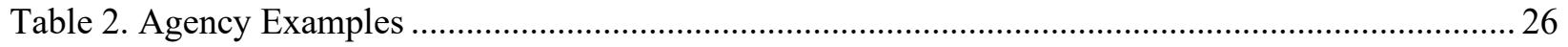

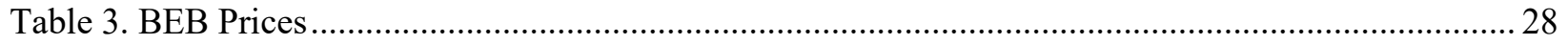

Table 4. Costs of Battery Electric vs. Diesel Hybrid vs. Diesel vs. CNG Buses ...................................... 28

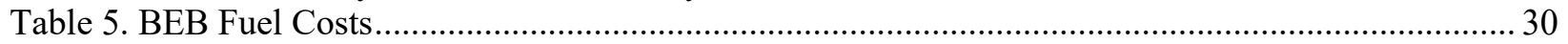

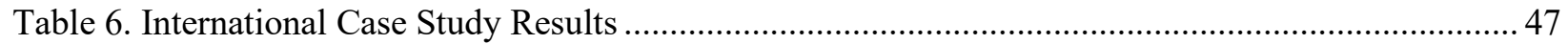

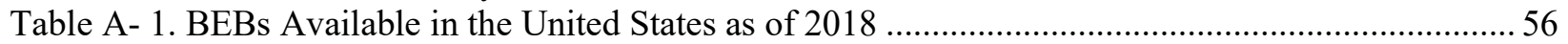

Table B- 1. Comparison of On-Route and Depot Charging....................................................................... 59

Table C- 1. Calculation for the Amount of $\mathrm{CO}_{2}$ Produced by a Single BEB Annually .............................. 60

Table C- 2. Calculation for the Amount of $\mathrm{CO}_{2}$ Produced by a Single Diesel Bus Annually.................... 60 


\section{Introduction}

Electric vehicle (EV) adoption is rapidly increasing across the world (H. Engel et al. 2018); annual sales have increased from fewer than 100,000 units in 2010 to over 2,000,000 in 2019 (McKerracher et al. 2020; IEA 2020). While these recent sales totals comprise only $2 \%-3 \%$ of the overall vehicle market, EVs are expected to continue growing for decades, with projections of 500 million passenger EVs being sold by $2040 .{ }^{3} \mathrm{EVs}$ offer a variety of potential benefits, including (but not limited to) reduction of emissions, noise, and lower maintenance costs. As such, many local, state, and national governments have declared goals for increased EV deployment. Public transit offers a practical entry point for transportation electrification. As of 2020, there were over 500,000 battery electric buses deployed worldwide (McKerracher et al. 2020). As agency-owned fleets with dedicated service patterns, battery electric buses (BEBs) can have fewer barriers to deployment than passenger light-duty vehicles (LDVs). BEBs offer predictable routes, long operating hours that take advantage of fuel and emissions savings, generous federal government incentives in the United States, and large-scale (thus more cost-effective) charging infrastructure.

\subsection{Background}

Electric buses have existed for decades and encompass trolley buses, hybrid buses, fuel cell buses, and BEBs. Trolleys, the oldest type of electric bus, draw their power from permanently connected overhead wires. Fuel cell buses use hydrogen fuel cells to power an electric motor, while hybrid electric buses utilize an internal combustion engine as well as an electric propulsion system, relying on both diesel fuel and electric charging. BEBs, which are the focus of this guidebook, rely on rechargeable battery packs to store electricity for power, similar to the typical plug-in electric car on the market today.

Electric buses experienced a modern resurgence beginning around 2010, propelled by advancements in BEB technology such as improved battery performance, lower battery cost, and rapid on-route charging (NASEM 2018). Battery prices continue to decrease worldwide, falling $79 \%$ from 2010 to 2018, including a single-year decline of 24\% between 2016 and 2017 (BloombergNEF 2018). In addition to falling battery prices, calls to decrease urban air pollution have spurred an enabling policy environment that has driven BEB uptake. For example, in September 2019, more than 30 cities worldwide, including Los Angeles, London, and Tokyo, signed the C40 Fossil-Fuel-Free Streets declaration, pledging to purchase only zero-emission buses from 2025 onward (C40 2019). ${ }^{4}$

Several countries and cities in Europe and Asia are leading in BEB deployment, most notably China, which has deployed over 170,000 BEBs, including full electrification of bus fleets in certain cities such as Shenzhen (NASEM 2018; European Commission 2016). As another example, in 2018, the European Commission approved $€ 70$ million for BEB deployment in Germany, covering the upfront cost difference of electric buses as compared to diesel, as well as the required charging infrastructure (European Commission 2018). According to the 2018 Battery Electric Buses-State of the Practice, there are currently 78 planned or in-service BEB programs in the United States, totaling 568 BEBs. These U.S. numbers are growing with the help of grants from the Federal Transit Administration (FTA), as well as

\footnotetext{
3 The COVID-19 pandemic significantly impacted EV and other vehicle sales during 2020, though some countries such as China have seen relatively rapid rebounds in EV sales during the same year (McKerracher 2020).

${ }^{4}$ Cities include Amsterdam, Auckland, Austin, Barcelona, Berlin, Birmingham, Cape Town, Copenhagen, Heidelberg, Honolulu, Jakarta, Liverpool, London, Los Angeles, Madrid, Greater Manchester, Medellin, Mexico City, Milan, Moscow, Oslo, Oxford, Paris, Quito, Rio de Janeiro, Rome, Rotterdam, Santa Monica, Santiago, Seattle, Seoul, Tokyo, Vancouver, Warsaw, and West Hollywood.
} 
settlement funds from the recent Volkswagen lawsuit. ${ }^{5}$ Bus electrification is rapidly accelerating across the world and is expected to outpace the electrification of other forms of transportation.

\subsection{Purpose of This Guidebook}

This guidebook provides an overview of BEB project planning for stakeholders interested in BEB fleet deployment. Compared to diesel buses, BEB deployment requires unique planning considerations to and minimize costs. Drawing from NREL's experience supporting BEB deployment as well as a thorough literature review of BEB case studies and published papers, this guidebook explains the technology, costs, and stakeholder involvement necessary for successful BEB deployment. Utilities, planning agencies, transit agencies, policymakers, and others seeking to understand the best methods of supporting BEB implementation may find this guidebook useful. With a deeper understanding of BEB deployment fostered by this guidebook, decision makers can engage in in-depth planning to design and deploy BEB systems that meet their highest-priority goals.

This guidebook assumes that prior decisions have been made to deploy BEBs and does not focus on comparisons between BEBs and other forms of transportation. For such comparisons, see Johnson et al. 2020. BEBs, depending on location and situation, may not be the best option for a transit agency. A jurisdiction's routes, duty cycles, and other transit needs may require customized analysis to determine whether or not to invest in BEB deployment. Once BEB deployment has been committed to, this guidebook can be used as a starting point to outline the decisions and actions necessary for creating a BEB fleet. Successful BEB deployment requires an understanding of many interrelated factors; the guidebook is intended to articulate this larger scope of BEB decisions and enable decision makers to effectively progress with their plans for deployment.

5 The EPA approved three partial settlements as part of the civil enforcement case against Volkswagen for false advertisement of their "clean diesel" vehicles, totaling more than 9.5 billion USD. These funds are being used to purchase electric buses in cities across the US, including New York, Colorado, and Washington (US EPA 2019). 


\section{BEB Benefits and Barriers}

Even with the limited deployment experience to date, it is clear that BEBs present multiple potential benefits when compared to traditional diesel buses. This new technology also presents challenges. Overcoming these barriers to BEB adoption will require creative approaches to transit planning and bus implementation. This section explores both the main advantages and main challenges for BEB planning and deployment.

\subsection{Benefits}

There are a number of benefits potentially realized by BEB deployment. This section highlights five major motivations for bus fleet electrification:

1. Lower fuel costs: ${ }^{6}$ BEBs have a much greater fuel efficiency than diesel buses—around 2.17 $\mathrm{kWh}$ per mile, or 17.35 miles per diesel gallon equivalent (DGE) (Eudy et al. 2016). For comparison, a typical diesel transit bus achieves a fuel efficiency of about 4.2 miles per DGE (OEERE 2016), which is four times less efficient per DGE than an average BEB. With a combination of utility rate structure, charging method, and number of buses, BEB fleets can capture the benefits of this efficiency and reduce fuel costs.

2. Lower maintenance costs: Electric-drive buses contain fewer moving parts than buses with traditional internal combustion engines. Average maintenance costs for a diesel bus total $\$ 0.88 /$ mile, whereas maintenance costs for BEBs average to $\$ 0.64 /$ mile (Johnson et al. 2020).

\section{Improved performance:}

A. The electric propulsion system within BEBs relies on magnetic induction rather than combustion, resulting in less vibration and a smoother, quieter ride (Learn Engineering 2017).

B. Electric drive vehicles deliver instant maximum torque capabilities (low-end torque), making them better than internal combustion vehicles for hauling heavy loads and accelerating up hills (DOE Clean Cities 2012).

\section{Lower emissions:}

A. BEBs produce zero tailpipe emissions, reducing local air pollution $\left(\mathrm{CO}_{2}, \mathrm{NO}_{\mathrm{x}}, \mathrm{HC}, \mathrm{PM}\right)$ in dense urban areas.

B. The majority $\mathrm{CO}_{2}$ emissions from $\mathrm{BEB}$ operation arise from electricity generation, and so vary based upon a given region's power sector fuel mix:

i. Even in the most carbon-intensive electricity production area in the United States (the Midwest Reliability Organization [MRO] East region, around Wisconsin), refueling a $\mathrm{BEB}$ will only generate about $2 / 3$ the $\mathrm{CO}_{2}$ emissions of a diesel bus (see Appendix C for calculation).

ii. The aggregated effects of fleet conversion can result in significant emissions reductions. For example, China's electric bus deployment is intended to displace a cumulative 270,000 barrels per day of diesel demand by the end of 2019 (Nightingale 2019). That is equivalent to over 250 million pounds of $\mathrm{CO}_{2}$ emissions per day.

\footnotetext{
${ }^{6}$ This is a common, but not guaranteed, benefit that depends upon the prices of petroleum and electricity applicable to the transit agency.
} 
C. In order to decarbonize their power sectors and more fully capture the emissions reduction benefits of BEBs and EVs generally, many jurisdictions are increasing the share of renewable energy in electricity generation. Examples of countries and states with commitments to integrating clean energy into their power sectors include (REN21, 2019):

i. Denmark established a target of $100 \%$ renewable primary or final energy, including electricity generation, renewable transport, and renewable heating and cooling by 2030 .

ii. Costa Rica declared in 2018 that it plans to be the first decarbonized country in the world and that it plans to ban all fossil fuels with $100 \%$ zero-emission vehicles by 2050 (McKerracher et al. 2020).

iii. Lithuania committed to $80 \%$ total energy demand (electric, transport, heating, and cooling) from renewable energy by 2030 (Vilnius 2020).

iv. The EU has a goal of meeting at least $32 \%$ of its final power consumption from renewable sources by 2030 and $14 \%$ of transportation energy from renewables by 2030 .

v. California (USA) has a mandate to reach $100 \%$ carbon-free electricity by 2045 .

vi. Hawaii (USA) will achieve 100\% renewable electrical energy to meet all net electricity sales by the end of 2045 .

vii. China set a goal to achieve 35\% renewable electricity consumption by 2030 .

5. Energy Security: There are potential economic and security advantages to using and supporting locally produced energy rather than fossil fuels. By electrifying transportation, a portion of energy demand shifts from petroleum products traded in a global market to local electricity generation, which is much less likely to depend on the same petroleum fuels. This shift reduces domestic dependence on the oil market and lowers exposure to the risks of oil price volatility. Most countries import more petroleum than they export and thus stand to increase their share of domestic energy production in addition to gaining security, but even net exporter countries may benefit by being more insulated from price shocks (Bordoff 2019). The displacement of petroleum consumption by BEBs can therefore provide both economic and security benefits.

6. Environmental Justice: Many studies have shown that disadvantaged individuals are more likely to be exposed to traffic emissions and suffer the negative health effects from conventional vehicles (Citizens Utility Board, 2020; Pinto De Moura and Reichmuth, 2019; NASEM 2018). The reduction in local air pollution associated with BEB fleet deployment can help lessen this injustice.

\subsection{Barriers}

There are a number of barriers to BEB deployment. This section highlights the four major challenges that can prevent deployment of BEBs for municipal and regional bus fleets.

1. Economic Challenges (Kunith et al. 2016):

A. Upfront cost: while BEB prices continue to decline, in 2015 "a typical 40-foot diesel bus cost about $\$ 445,000$ while BEB of similar length went for $\$ 770,000$ ” (Nunno 2018). Thus, there is a significant cost premium for BEB purchases when compared to incumbent technologies. 
B. Charging infrastructure: beyond the bus itself, additional funding is needed to install $\mathrm{BEB}$ charging stations. These additional expenses for charging infrastructure include the cost of the charging equipment, installation, and coordination with the utility and other project partners. BEBs may be charged at a depot or on the bus routes. For installation, prices can range from $\$ 2,000$ to $\$ 64,000$ for depot charging and $\$ 50,000$ to $\$ 400,000$ for on-route charging (Johnson et. al 2020).

C. Grant dependence: BEB investments in the United States and Germany, among other countries, are at least partially funded by grants to overcome the high upfront costs. This reliance on grant funding could negatively affect deployment scalability.

2. Planning Burden: Planning for a BEB fleet and charging infrastructure is complex and fundamentally different than for diesel bus deployment. Unfamiliar bus and charging technologies require capacity building for transit agency staff at all levels, technology options take time and effort to identify and select, and routes may need to be altered in order to simultaneously optimize transportation service, BEB performance, and recharging efficiency. More information is provided in Section 8.3, but general examples include:

A. Characteristics of the bus (e.g., dimensions, heater, passenger load), the charging infrastructure (e.g., location, power level), and the battery (e.g., battery size, state of charge leaving and returning from the depot) impact each other. Selecting appropriate and compatible equipment while considering and optimizing these interrelated factors will require time and iteration. Characteristics of the route itself (e.g., length, incline) will impact technology choices as well.

B. Electricity rate structure must also be considered. The tariff(s) that will apply to the BEB's charging regime, the charging arrangement that results in the least cost for the operator, and the compatibility of those rates with the chosen charging method are all crucial factors.

\section{BEB Range:}

A. The distance a BEB can travel before refueling, or BEB range, is constrained by the placement of EVSE, limiting BEBs to certain routes and areas. Meeting the charging infrastructure requirements of BEB routes throughout a city or region can take significant amounts of time and may impact the BEB deployment schedule.

B. In connection with Section 2.2.2.A above, BEB range is heavily impacted by factors such as ambient temperature, road grade, and operator driving style, all of which impose variability on BEB range projections. Local conditions and training for drivers are critical considerations for planning EVSE networks and BEB routes.

C. Additional battery capacity can increase range but adds weight, resulting in more rapid deterioration of a BEB's suspension and axles. In addition, this added weight may make the bus too heavy for certain roads, so road weight ratings should be consulted in tandem with BEB deployment efforts.

\section{Novelty of BEB Technology:}

A. As a less established and more rapidly evolving technology sector than internal combustion engine vehicles, there is higher risk of BEB component manufacturing and model-specific maintenance services being unavailable or discontinued.

B. BEBs have less established records of performance than internal combustion engine buses, so prospective funders of BEB deployment may be hesitant to invest, or demand higher rates of return, since there is some degree of trial and error associated with 
planning, and the full scope of technology lifespan and lifetime costs are still relatively uncertain.

\section{Case Study 1. Bogotá, Colombia}

\section{Provision and Operation of 483 Zonal Electric Buses in Bogotá, Colombia}

According to recent reports on air quality in Bogotá, mobile emission sources appear to cause main roads and neighboring regions to have high levels of particulate matter concentration. The country of Colombia is also concerned about its exposure to climate change impacts. As such, the Bogotá Integrated Public Transport System (SITP, TRANSMILENIO S.A) decided to incorporate electric buses to reduce pollution.

The SITP manages the bus system, selects the vendors, and contracts for the acquisition and operation of 483 electric zonal buses. These zonal buses provide service to the Fontibón, Perdomo, Suba, and Usme areas of the larger Bogotá region.

These 483 electric zonal buses are expected to improve the users' travel experiences and Bogotá's environmental impact as follows:

1. Increase the supply of public transport and access to city jobs, particularly access to the massive mainline of the Integrated Public Transportation System

2. Contribute to the reduction of the total travel cost for low-income populations, because transfers are at zero cost

3. Reduce noise pollution

4. Improve safety

5. Provide access to real-time travel information

6. Offer a sustainable transportation alternative in terms of city air quality and reducing greenhouse gas emissions compared to a Euro II bus by:

A. Reducing 8.2 tons of particulate matter per year

B. Reducing 43,800 tons of carbon dioxide equivalent annually

7. Reduce the costs associated with mortality and morbidity due to air quality issues on the order of 5,000,000,000 Colombian Pesos per year.

Source: Asociación Sustentar and Universidad Nacional of Rosario (Carolina Chantril, Andres Pisani, and Agustina Krap 2020) 


\section{BEB Basics}

BEBs are composed of three main components: (1) the bus itself, which includes the electric motor, braking system, heating and cooling, and other typical components for bus operation; (2) the battery system onboard the bus, which is used to power the bus; and (3) the charging infrastructure, which is a stationary system separate from the bus designed to connect the BEB to external electricity sources, thus supplying power to charge the bus battery. Each is discussed below.

\subsection{Bus}

BEBs are powered by electric motors rather than internal combustion engines. Internal combustion engines rely on burning fuel to create translational mechanical energy through the action of pistons, which is then converted to rotational energy through the crankshaft. Electric motors are simpler and rely on electrically powered onboard magnets to directly create mechanical rotational energy. EVs have a high energy conversion efficiency, transferring $72 \%$ to $94 \%$ of the input electrical energy into motion (DOE Electric Cars n.d.), dramatically more than the $12 \%$ to $30 \%$ of gasoline energy converted into movement for internal combustion engine vehicles (DOE Gasoline Vehicles n.d.). Appendix A shows a list of all the BEB options offered in the United States by vehicle manufacturer and option in 2018.

Electric drive vehicles also utilize regenerative braking, which can make a large, positive impact on fuel efficiency. Friction braking is used to slow traditional ICE vehicles, dissipating kinetic energy in the form of unused heat. Regenerative braking allows electric motors to recover some of this kinetic energy by switching to "generator mode" during gradual braking. In generator mode, the spinning wheels power the drivetrain in reverse, storing energy in the battery. When this generative braking torque slows the vehicle enough, traditional friction brakes are engaged to bring it to a full stop (Bosch Mobility Solutions 2014). Slow, gradual braking takes advantage of this aspect of EV technology, maximizing fuel efficiency for BEBs. See Section 5.1 for details on how drivers can take full advantage of regenerative braking and increase BEB range.

Typical diesel buses have an FTA-required expected life of 12 years, but they often last longer: on average, 15 years (Laver et al. 2007). BEBs have a current predicted lifespan of 12 years (Eudy and Jeffers 2017), but the technology is in an early enough stage of deployment that there is not yet a proven understanding of BEB useful lifetime. For instance, Foothill Transit in Southern California has one of the longest-running BEB demonstrations in the United States, starting in 2010 and expanding in 2014. Most of their buses will not hit the 12-year main bus structure warranty until 2026 (Eudy and Jeffers 2017).

Auxiliary BEB accessories to consider include diesel heaters for the cabin to avoid battery drain (discussed in Section 8.2.4), data loggers to track BEB performance, and computer-based charge management systems. These are all generally available through the bus original equipment manufacturer (OEM).

\subsection{Battery}

\subsubsection{Basics}

Lithium-ion batteries are used by modern BEBs because of their high energy densities and satisfactory power densities compared to earlier battery technologies, described further below (Perner and Vetter 2015). The most common types of lithium-ion batteries used in BEB applications are lithium iron phosphate (LFP), lithium titanate (LTO), and lithium nickel manganese cobalt oxide (NMC) ${ }^{7}$. Batteries store electrical energy as chemical energy, then convert that chemical energy to electricity when needed

\footnotetext{
${ }^{7}$ May be limited by the resource availability of cobalt.
} 
to power the vehicle. BEB batteries are embedded into the bus structure on the top, bottom, or back of the bus, depending on the BEB OEM (RTA Transit 2018).

Batteries are typically described by their energy capacity $(\mathrm{kWh})$ and power $(\mathrm{kW})$. Power $(\mathrm{kW})$ describes the instantaneous work able to be performed by the battery and can be compared to horsepower in ICE vehicles. Energy $(\mathrm{kWh})$ describes the exercise of that power over a period of time, and the energy capacity of a BEB (in $\mathrm{kWh}$ ) can be compared to the fuel tank size of diesel buses. For example, a BEB may have a power rating of $220 \mathrm{~kW}$ (equivalent to 295 horsepower) and battery storage of $105 \mathrm{kWh}$ (equivalent to 2.8 gallons of diesel) (RTA Transit 2018; California Energy Commission 2008).

Energy density $(\mathrm{kWh} / \mathrm{kg})$ is a metric used to determine how many battery cells are needed to achieve the desired energy capacity for a BEB. Fuel economy is measured in $\mathrm{kWh} / \mathrm{mile}$ - a BEB with a fuel efficiency of $2.17 \mathrm{kWh} /$ mile would be equivalent to 17.35 miles per DGE (Eudy and Jeffers 2017). BEBs are much more fuel-efficient than diesel buses because the electric engine incorporates regenerative braking and wastes less energy (see Section 3.1).

The amount of energy left in a battery pack is referred to as the state of charge (SOC). It can be thought of like the fuel gauge on a traditional vehicle, telling the driver how much energy remains. While in theory SOC may vary from $0 \%$ to $100 \%$ full, in practice the SOC has minimum and maximum limits in place to protect the long-term useful life of the battery, as shown in Figure 1. The lower limit of SOC is set above $0 \%$ to minimize battery performance degradation (Kunith et al. 2016). An additional lower level of the SOC is reserved for backup during emergencies and unforeseen delays (yellow in Figure 1). This total lower security margin varies from $15 \%$ to $35 \%$. When fast charging, there is an additional upper limit (typically the upper $10 \%-25 \%$ ), which ensures fast chargers do not try to exceed the maximum storage capacity (Kunith et al. 2016). After the minimum and maximum limits are applied, the usable energy is around $70 \%$ of the theoretical battery capacity at its beginning of life (Rogge, Wollny, and Sauer 2015).

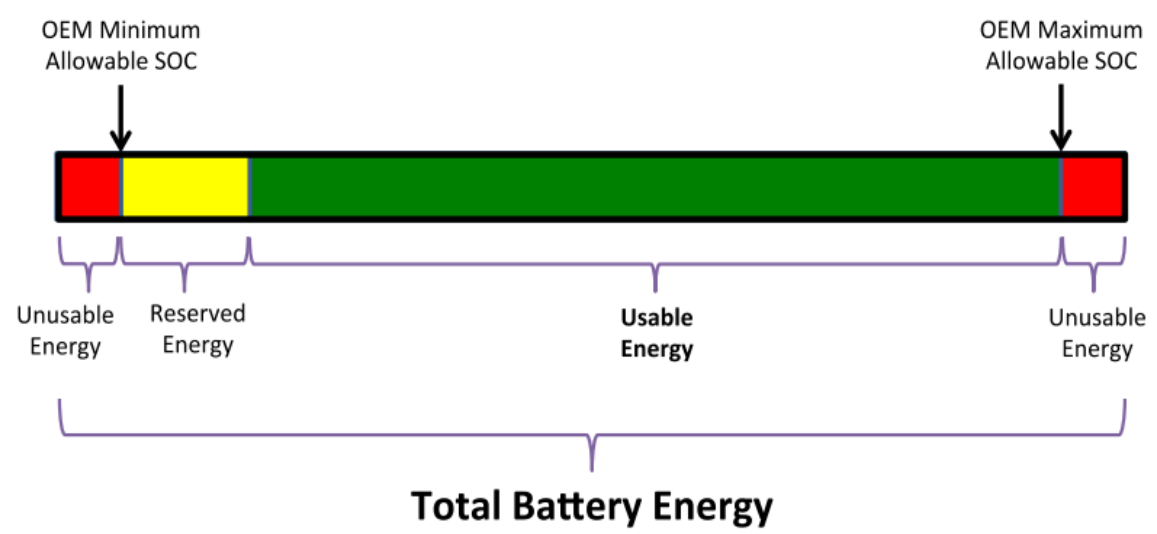

Figure 1. Beginning of life for BEB batteries

Source: (Bigelow 2017)

\subsubsection{Size and Range}

The optimal battery capacity for a given BEB application heavily relies on the charging technology paired with it (see Section 3.3 for additional detail). Generally, BEB batteries can range from $76 \mathrm{kWh}$ (e.g., Nova bus LFSe) to $660 \mathrm{kWh}$ of capacity (e.g., Proterra Catalyst E2). 
BEB range depends on a multitude of variables, most significantly battery capacity, battery age, and environmental factors. Standard methods of range measurement have not yet been established in the industry, and with so many route variables, advertised ranges can be misleading or confusing. One method by which U.S. bus OEMs estimate range is the Altoona energy efficiencies, measured by the FTA's required bus testing method known as Altoona testing (FTA 2017). The Altoona energy efficiencies are calculated based on bus performance on a standard flat test track, without passengers or heating, ventilation, and air conditioning (HVAC) loads, and is therefore not reflective of real-world bus service. Combining these efficiencies with the total $\mathrm{kWh}$ of energy on board can give a general best-case scenario for range, often called the nominal range. Accurate range predictions that incorporate route variables require in-depth analysis for each and every route. See Section 8.2 for more information on route analysis.

\section{Case Study 2. Mexico City and León, Mexico}

\section{Technical Feasibility of BEBs in Mexico City and León}

In 2013, Mexico's transport sector produced $26.2 \%$ of national greenhouse gas emissions, motivating Mexico's Ministry of Environment to incorporate clean energy use in the transport sector. Advanced vehicle technologies such as BEBs are being investigated and implemented in Mexico.

NREL, in partnership with USAID Mexico's Low Emissions Development II program and Mexican transportation stakeholders, conducted a study evaluating the technical feasibility of transit bus electrification in Mexico City and León, Mexico. NREL collected diesel bus data such as speed, distance traveled, and frequency of stops along one bus route in Mexico City and two routes in León over a 2-4-week period. The Future Automotive Systems Technology Simulator (FASTSim) model along with the collected data was used to analyze the energy consumption and fuel economy or efficiency of conventional diesel buses and BEB alternatives. Energy consumption informed the battery size needed to complete these specific routes if BEBs were used instead of diesel buses. For air quality and emissions, NREL compared fuel and electricity production emissions of battery electric and diesel buses.

NREL's analysis indicates that BEB vehicle and battery technologies are commercially available for both Mexico City and León's selected bus routes with a likely production of fewer $\mathrm{CO}_{2}$ emissions than conventional diesel buses. The slower speeds and numerous stops that characterize these three bus routeswhich are quite common in other cities worldwide - make them a potential candidate for bus electrification. While the two urban areas are different-Mexico City is denser than Leon-BEBs can provide localized environmental benefits.

See Technical Evaluation of Battery Electric Bus Potential in Mexico City and Leon, Mexico for more information.

\subsubsection{Battery Aging and End of Life}

Battery capacity fades depend on time and usage: as batteries charge and discharge, their internal physical and chemical structures degrade (Trippe et al. 2014). Batteries age naturally over time, regardless of use, but high usage increases the rate of degradation. As a new and rapidly evolving technology, batteries for BEBs are subject to lifetime uncertainty, though some major bus OEMs offer 12-year warranties on their batteries (Proterra 2018; New Flyer 2018; ICCT 2018). The end of battery life typically occurs when a battery has less than $80 \%$ of its initial capacity, although this threshold can be pushed as low as $60 \%$ (BloombergNEF 2018). Figure 2 shows the SOC limits for a battery near the end of its life. While the 
minimum allowable SOC is highly similar to a new battery, the upper reserve has diminished significantly compared to Figure 1 .

\section{End-of-Life Batteries}

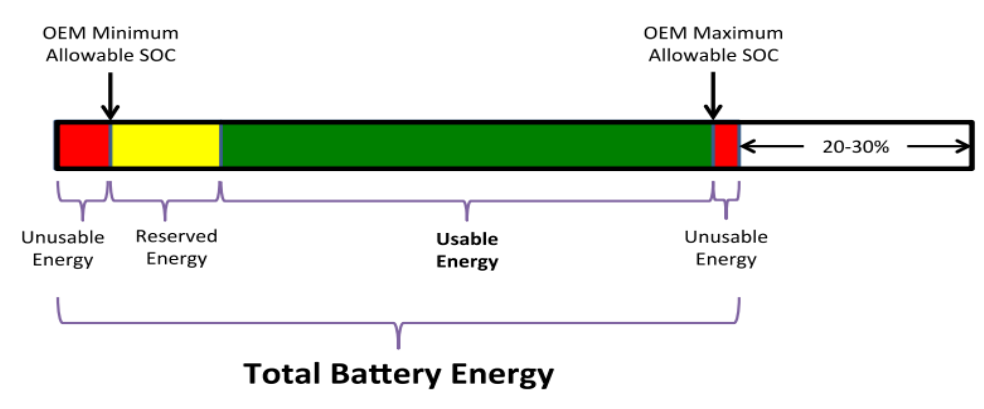

Figure 2. End-of-life batteries

Source: (Bigelow 2017)

High temperatures can also accelerate the natural battery aging process (Trippe et al. 2014) (Pesaran et al. 2013), shortening battery life as shown in Figure 3 for electric cars.

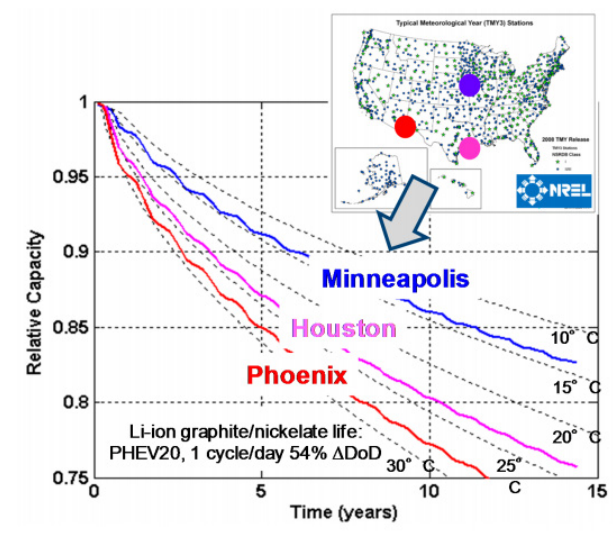

Figure 3. Battery capacity vs. time for locations of varying ambient temperatures (Electric car, not BEB)

Source: (Pesaran, Santhanagopalan, and Kim 2013)

Keeping batteries at a high SOC accelerates battery degradation as well. BEB battery life can be extended by: cycling the battery at lower SOCs when possible, avoiding high SOC when the BEB is not in use, and/or decreasing the upper SOC limit (Lunz et al. 2012). For example, it is more advantageous for battery longevity to cycle a BEB battery from a SOC of $40 \%$ up to $70 \%$ instead of frequently recharging from $60 \%$ to $90 \%$. The rate of battery charging matters, too. In a study done on light-duty electric cars in Phoenix, Arizona, fast-charged (see Section 3.3) vehicles had a capacity as much as $8.7 \%$ lower than their slow-charged counterparts. The hot climate and high charge frequency led the authors to conclude this to be representative of the upper bound of capacity loss difference (Shirk and Wishart 2015).

Once a battery reaches the end of its useful life for BEB applications, it will still retain $60 \%-80 \%$ of its initial capacity, leading to opportunities for second-life applications before eventually being recycled. Potential second-life use cases include on-site storage at transit depots or charging stations (BloombergNEF 2018). Storage provides value to transit agencies by reducing their peak electricity 
demand and enables increased renewable energy integration (see Section 4.2). When a Li-ion battery has degraded so much that it is no longer useful for any application, it can be recycled, although the recycling process can incur costs and potentially create hazardous waste (Elkind et al. 2014). NMC batteries, although less common than LFP, possess higher recycle value due to their cobalt composition (BloombergNEF 2018).

\subsection{Charging}

BEBs may be charged while on their routes or at a bus depot. With more available time, depot charging typically uses slower, lower-powered $(<200 \mathrm{~kW})$ EVSE while on-route charging often requires highpowered $(>300 \mathrm{~kW})$ fast chargers. On-route charging includes inductive and conductive charging methods, while depot charging refers to conductive charging only. Each method of charging has advantages and disadvantages, and the optimal charging choice for a BEB fleet depends on route variables, electricity rate structure, and transportation objectives. Table 2 in Chapter 6 notes the cost differences between charging types.

\subsubsection{Depot Charging}

Depot charging refers to BEB charging infrastructure co-located with the facility at which off-duty buses are stored (see Figure 4). In this context, BEBs are charged via a plug-in connection in a similar manner to how most light-duty electric cars are charged. The buses are charged overnight, when ridership demands are at their lowest. The process can take anywhere from 1 to 8 hours, but the majority of BEBs can fully charge in 5 hours or less (NASEM 2018). Correspondingly, depot chargers can range from supplying $40 \mathrm{~kW}$ of power (NASEM 2018) to over $200 \mathrm{~kW}$ (Hanlin 2016), with most requiring $100 \mathrm{~kW}$ or less (Gallo, Bloch-Rubin, and Tomic 2014). Buses that use depot charging are fitted with batteries large enough to ensure operation for a full day's service, though this requires proper scheduling to allow all required BEBs to charge within the given time window. Depot charging is often preferred for smaller-scale deployments, because the infrastructure is less expensive than for on-route charging; however, large agencies that operate in spaceconstrained urban locations may run into obstacles when siting all required EVSE in the depot or planning for future fleet growth.

Depot charging is currently the most popular option in the world, a statistic heavily influenced by the reliance of China's BEB fleets on the charging method (China possesses $99 \%$ of the world's BEBs)

\section{Text Box 1. Depot Charging in Illinois}

An example of a U.S. BEB fleet using depot charging is the Chicago Transit Authority (CTA). CTA has successfully operated two New Flyer BEBs since 2014, using them to service the morning and afternoon rush periods of Chicago. The two buses charge at the depot overnight (3-5 hours of charging), using a 100$\mathrm{kW}$ charger to charge each of their $300-\mathrm{kWh}$ battery packs, providing 100 miles of range (Tomford 2018).

Their morning service covers 50-60 miles over 6 hours, after which they return to the depot to charge midday for 3-5 hours. They then return to service in the afternoon, covering 70-80 miles over 8 hours before returning to the depot once again to charge overnight (Tomford 2018). Plans are now in the works for CTA to expand their fleet with orders for at least 20 additional BEBs and the addition of on-route fast chargers (CTA 2018).

Source: Chicago Transit Authority 2018

(BloombergNEF 2018). 


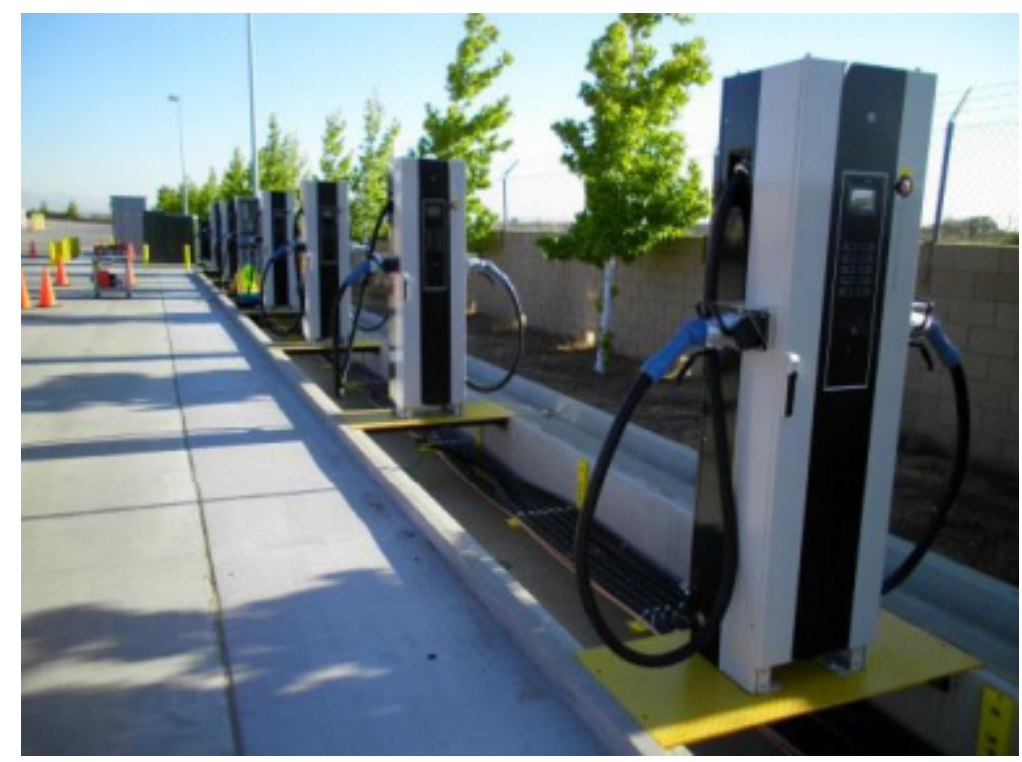

Figure 4. Depot chargers at Antelope Valley Transit Authority Depot

Source: (L. Engel 2017)

\subsubsection{On-Route Charging}

On-route charging, sometimes referred to as "opportunity charging," is done through high-powered fast chargers that can charge buses in a matter of minutes. Maximum charging power varies from $200 \mathrm{~kW}$ to $500 \mathrm{~kW}$ (Kunith et al. 2016), and buses charged on-route often take advantage of this frequent charging by being fitted with smaller-sized batteries for their lighter weight and concomitant efficiency. On-route EVSE allows for partial battery refills rather than full charges, although full charges are possible. It is common practice for agencies using on-route fast charging to also have plug-in EVSE at the bus depot for overnight charging. The Battery Electric Buses-State of the Practice noted that of the 10 U.S transit agencies interviewed that use on-route charging, all of them also used plug-in depot charging. On-route charging can be performed through conductive charging, inductive charging, or battery swapping (NASEM 2018).

\subsubsection{Conductive On-Route Charging}

Conductive charging employs a movable pantograph mounted on the roof of the vehicle or, in the case of the inverted pantograph, mounted as part of an overhead mast at the charging station (BloombergNEF 2018). Pantographs are the constant connection between overhead catenary lines and light rails or trolleys, but in the case of BEBs they serve as temporary connections at specific charging locations. As a BEB approaches an overhead conductive charger, the bus communicates with the charging station to engage automatic docking. This ensures the bus is guided to the correct spot underneath the charger (NASEM 2018). Once in place, the pantograph either rises from the bus (roof-mounted) or reaches down from the station (inverted) to make the connection. During this time, passengers can board and exit the bus normally. Charge power can vary from $175-500 \mathrm{~kW}$ and take 5-20 minutes (NASEM 2018). Five to seven minutes would be typical for a bus that needs to recuperate only part of its battery power.

Drawbacks of overhead conductive charging include the space required on-route to install a charger, the potential unsightliness of charging stations, exposure of charging system to inclement weather, and the potential for collisions with other vehicles (especially because of height/clearance requirements). The Battery Electric Buses-State of the Practice noted that out of 11 transit agencies who responded to a question about collisions with on-route EVSE, four reported non-BEB vehicles colliding with charging structures (NASEM 2018). 
An example of conductive on-route charging is Foothill Transit in California's San Gabriel and Pomona Valleys. Foothill Transit has used BEBs in conjunction with Proterra fast-charging equipment since 2010, expanding their three-bus fleet to 15 BEBs in 2014. Foothill Transit uses two 500-kW on-route EVSE with Proterra EcoRide BE35 buses equipped with 88-kWh battery packs (Eudy et al. 2016). The buses can be fully charged in 10 minutes, but typical charge times are around 7 minutes. The buses run on average 13.2 hours a day and charge on average 13 times a day, with each recharge averaging $20 \mathrm{kWh}$ (Eudy et al. 2016).

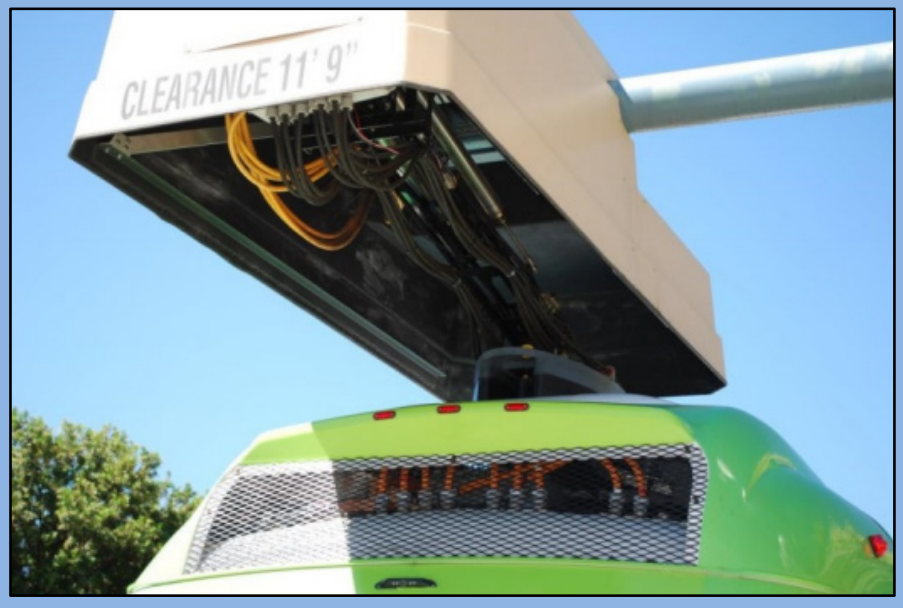

Figure 5. Foothill Transit overhead 500-kW fast charger

Source: Eudy et al. 2014

\subsubsection{Inductive Charging}

Inductive charging of BEBs occurs wirelessly, without any physical connection. This is made possible through inductive charging coils buried beneath street level at bus stops. When a BEB drives over the charging pad, the bus wirelessly communicates with the inductive EVSE to begin the charging process, sending current through the buried coil. This current induces a magnetic field, which then induces an electrical current in a matching coil within the bus. The electricity is then stored in the onboard battery. Typically, inductively charged buses are paired with medium-sized battery packs and possess a medium range (NASEM 2018).

Buses must be parked while inductive charging happens, although there is active research on the possibilities of inductive charging while driving. Inductive charging technology is newer and more expensive than conductive charging, making it less common today in the United States. Additionally, inductive charging is slightly less efficient than conductive charging, with a $90 \%$ energy transfer compared to conductive charging's 95\% efficiency (NASEM 2018). Currently, U.S. inductive EVSE is capable of $50 \mathrm{~kW}$ to $250 \mathrm{~kW}$ (Engel 2017). 


\section{Text Box 3. Inductive Charging in Maryland and California}

An example of inductive charging application comes from the Regional Transportation Agency (RTA) and Howard County in Maryland. RTA has three BEBs, which are charged overnight with two 40-kW chargers per bus for a total power transfer of $80 \mathrm{~kW}$ with both connected, taking up to 4 hours to fully charge (RTA Transit 2018). The on-route portion of charging takes place inductively via a charging pad. A management module to control charge and communication within the bus communicates to the buried coil to activate charging. When properly aligned, energy is transferred wirelessly at $50 \mathrm{~kW}$ to the bus (RTA Transit 2018).

Antelope Valley Transit Authority (AVTA) in Los Angeles is another transit agency using $50-\mathrm{kW}$ inductive chargers. AVTA is in the process of fully converting their fleet, with the goal of $87 \mathrm{BEBs,} 87$ depot chargers, and up to 15 inductive fast chargers rated at $200 \mathrm{~kW}$ (AVTA 2018).

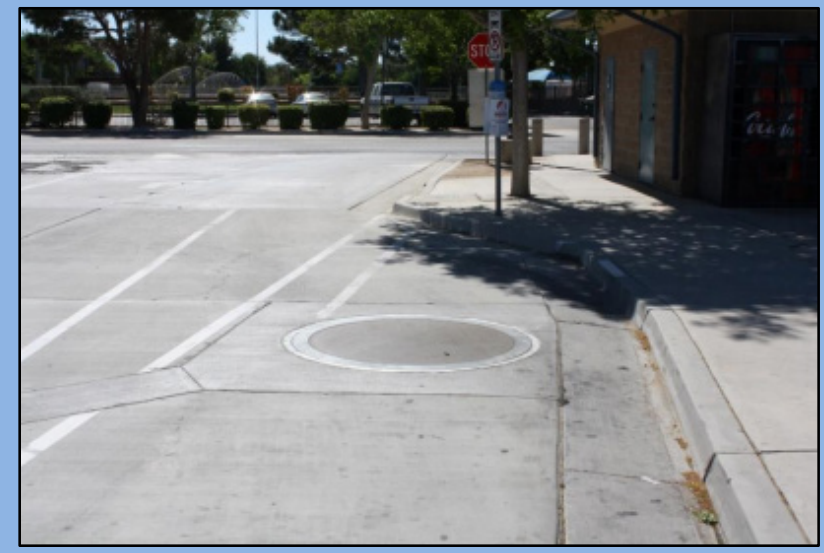

Figure 6. Wireless advanced vehicle electrification charging station for AVTA, embedded in the street

Source: L. Engel 2017

\subsubsection{Battery Swapping}

Battery swapping is the least common on-route charging method, with current examples found only in Asia. A battery swapping operation entails the physical removal of empty or low-SOC batteries via an automated system and their replacement with fully charged batteries. Recharging batteries at these stations can be managed to minimize electricity costs. Drawbacks include the potential costs of additional batteries and ensuring that batteries are swapped without causing damage.

\section{Text Box 4. Battery Swapping in South Korea}

BEBs in Pohang, Korea were equipped with a roof-mounted battery exchanging mechanism that could swap a battery in less than 1 minute. The exchange occurs at designated storage systems along the route where robots perform the swap and passengers can board and exit normally. The depleted batteries are then charged at that storage location. Relatively small battery packs of $48.62 \mathrm{kWh}$ are used, with one serving as the main battery pack and an optional second pack serving as backup or range extension. The BEBs can also be plugged in à la depot charging. The looping route demo included three buses and two exchange stations.

Source: Kim et al. 2015 


\section{Electric Utilities and the Grid}

BEBs are refueled with electricity rather than petroleum products, necessitating new relationships between transit agencies and the electrical grid. Charging timing, installation placement, and prices are all intertwined with services provided by electric utilities, making it crucial for organizations deploying BEBs to coordinate with the local utility from the earliest project stages. The 2018 Battery Electric Buses-State of the Practice survey found that $78 \%$ of transit agencies involved their local utility early when making procurement decisions and $83 \%$ when making installation decisions (18 agencies deploying BEBs responded).

\subsection{Electricity Rates}

Electricity rate structures vary drastically by utility, leading to similarly variable costs of electricity for BEB charging methods. Energy charges $(\$ / \mathrm{kWh})$, demand charges $(\$ / \mathrm{kW})$, usage charges (generally $\$ /$ month), and time-of-use (TOU) charges are all common components within utility rates.

\subsubsection{Energy Charges}

Most utilities charge for total energy $(\mathrm{kWh})$ usage at a constant dollar per $\mathrm{kWh}$ rate. For commercial electricity rates in the U.S., this varies (in May 2019) from $\$ 0.08 / \mathrm{kWh}$ to $\$ 0.30 / \mathrm{kWh}$, with the average being $\$ 0.11 / \mathrm{kWh}$ (Choose Energy 2018).

\subsubsection{Demand Charges}

Many utilities apply demand charges, which are based on the maximum power used by the customer within a specific time span. This can be 5 minutes, 15 minutes, or 1 hour. The demand charge can also be subject to a ratchet effect, such that a customer's demand charge over 1 month, or even up to 1 year, is based on that customer's peak demand in the last X months. In other words, if there is a 12-month rolling average and peak demand occurred in July, the electricity bills for the following 12 months are partially based on that 15-minute span in July. For this reason, ratchets are especially important to keep in mind when undertaking a short-term pilot project for BEBs. Demand charges range widely and can be anywhere from $\$ 0.00 / \mathrm{kW}$ to $\$ 23.65 / \mathrm{kW}$ in the United States (Gallo, Bloch-Rubin, and Tomic 2014).

Demand charges can have dramatic effects on electricity pricing. To explore this further, NREL created a few hypothetical scenarios to illuminate how certain variables, including charging location, number of $\mathrm{BEBs}$, and charging parameters, ultimately impact demand charges. 


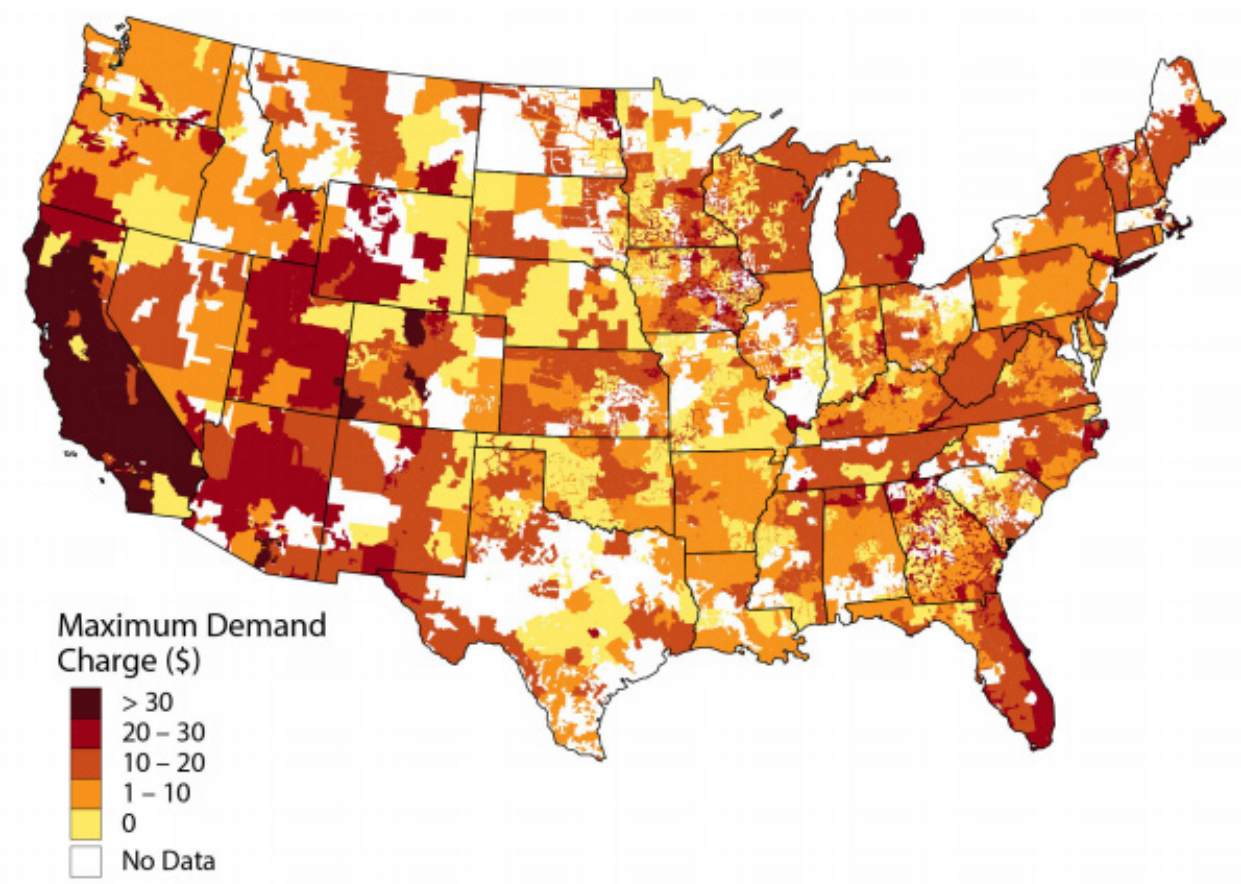

Figure 7. Maximum commercial demand charge rates by utility service territory

Source: (McLaren, 2019). This map was produced by NREL for the U.S. Department of Energy. Billy J. Roberts. February 26, 2016.

Scenario 1: A transit agency has three BEBs that charge overnight in the depot, each using 80-kW plug in chargers, and can also "opportunity charge" during the day via one on-route conductive fast charger capable of $450 \mathrm{~kW}$. Assume a medium demand charge of \$10/kW (Gallo, Bloch-Rubin, and Tomic 2014). Three BEBs all charging simultaneously at night at their max $80 \mathrm{~kW}$ for multiple hours adds to $80 \mathrm{~kW}+$ $80 \mathrm{~kW}+80 \mathrm{~kW}=240 \mathrm{~kW}$. The peak demand from this would be $240 \mathrm{~kW} \mathrm{x} 15$ minutes $/ 15$ minutes $=240$ $\mathrm{kW}$, or $240 \mathrm{~kW}$ demanded for 15 minutes, over the peak period of 15 minutes.

A few hours later, the three buses are servicing their routes and using the fast charger. If it takes a bus 7 minutes to charge via the on-route charger, and only one bus charges in a 15-minute interval, then the peak demand would come out to be $450 \mathrm{~kW} \mathrm{x} 7$ minutes $/ 15$ minutes $=210 \mathrm{~kW}$. If the buses retain this charging schedule for the length of the billing period, usually 1 month, the peak demand charge for the transit authority will be the highest demand incurred, or $240 \mathrm{~kW}$. The corresponding demand charge for the month will equal $240 \mathrm{~kW} \mathrm{x} \$ 10 / \mathrm{kW}$ to equal $\$ 2,400$. This $\$ 2,400$ is in addition to the total energy and usage charges on the bill.

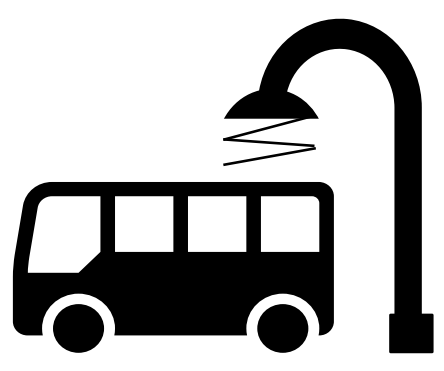


Scenario 2: If, however, two buses use the on-route charger back-to-back, the demand charges would increase. If one bus charged for 7 minutes at the $450-\mathrm{kW}$ fast charger, followed by a 3-minute transition period where that bus pulled out and was immediately replaced by another bus, the charging during that 15 -minute period would be: 7 minutes of $450 \mathrm{~kW}, 3$ minutes of $0 \mathrm{~kW}$, and 5 minutes of $450 \mathrm{~kW}$ throughout the 15 -minute period. The peak demand would then be $(450 \mathrm{~kW} \mathrm{x} 7 \mathrm{~min} / 15 \mathrm{~min})+(0 \mathrm{~kW} \times 3$ $\mathrm{min} / 15 \mathrm{~min})+(450 \mathrm{~kW} \times 5 \mathrm{~min} / 15 \mathrm{~min})=210 \mathrm{~kW}+0 \mathrm{~kW}+150 \mathrm{~kW}=360 \mathrm{~kW}$. This new peak demand would result in a demand charge of $360 \mathrm{~kW}$ x $\$ 10 / \mathrm{kW}$ equaling $\$ 3,600$, which is $\$ 1,200$ more than the first scenario.
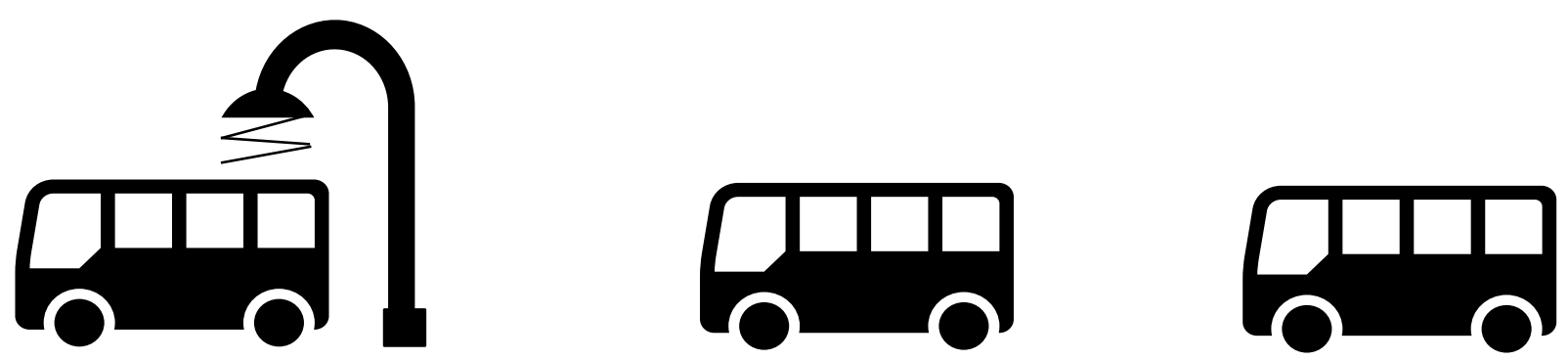

Scenario 3: An agency with the same demand charges as Scenario 2, but twice as many BEBs, demonstrates the importance of considering demand charges from the perspective of per-bus refueling costs. The \$3,600 demand charge in Scenario 2 was spread over the agency's three total buses. If the agency charged each bus once an hour, with 10 minutes required per charge occurrence ( 7 minutes of charging and 3 minutes of transition time), the agency could feasibly refuel six buses without incurring additional demand charges. While this would increase the total energy usage, dividing the $\$ 3,600$ demand charge by the six BEBs served instead of three would reduce the per-bus demand charge to $\$ 600$ instead of $\$ 1,200$ per month.
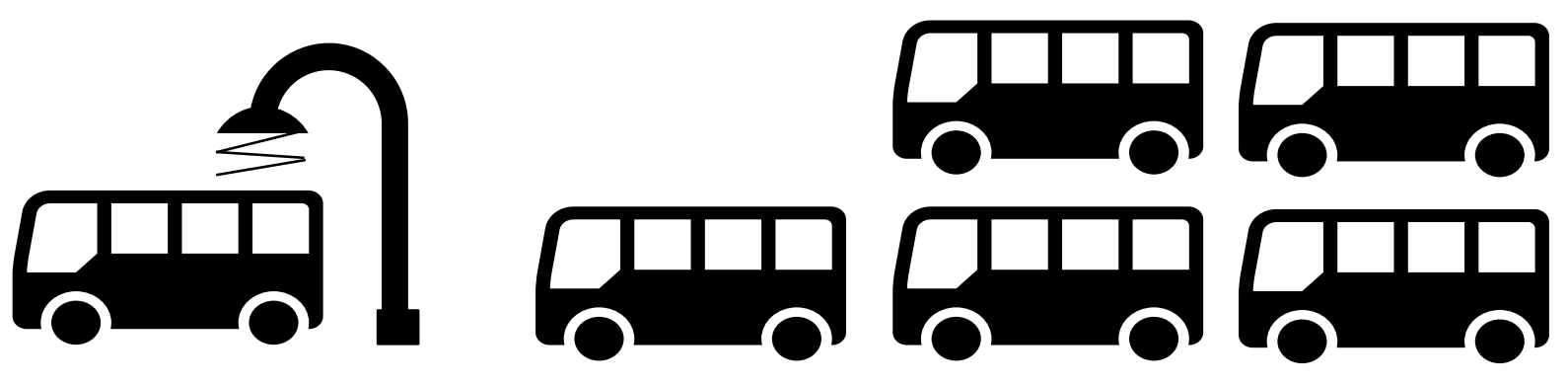

Figure 8 shows the total and per-bus demand charges incurred in each scenario. The results demonstrate two main takeaways. First, it is important to understand how and when each BEB is charged. Scenario 2 and Scenario 1 both involve three buses, but because the on-route charging of multiple buses happens within the same hour in Scenario 2, the on-route charging sets the demand charge instead of the lower cost for simultaneous depot charging of all three buses. If on-route charging were more temporally spread out, the demand charges per bus would decrease significantly. Second, the figure shows that efficient use of infrastructure is critical. Scenario 3 has a higher overall monetary charge, but the total charge per bus is the same (depot charging) or lower (on-route charging). For transit agencies that require more frequent 
charging than Scenario 1 describes, Scenario 3 illustrates the potential value of planning around scheduling and logistical constraints.

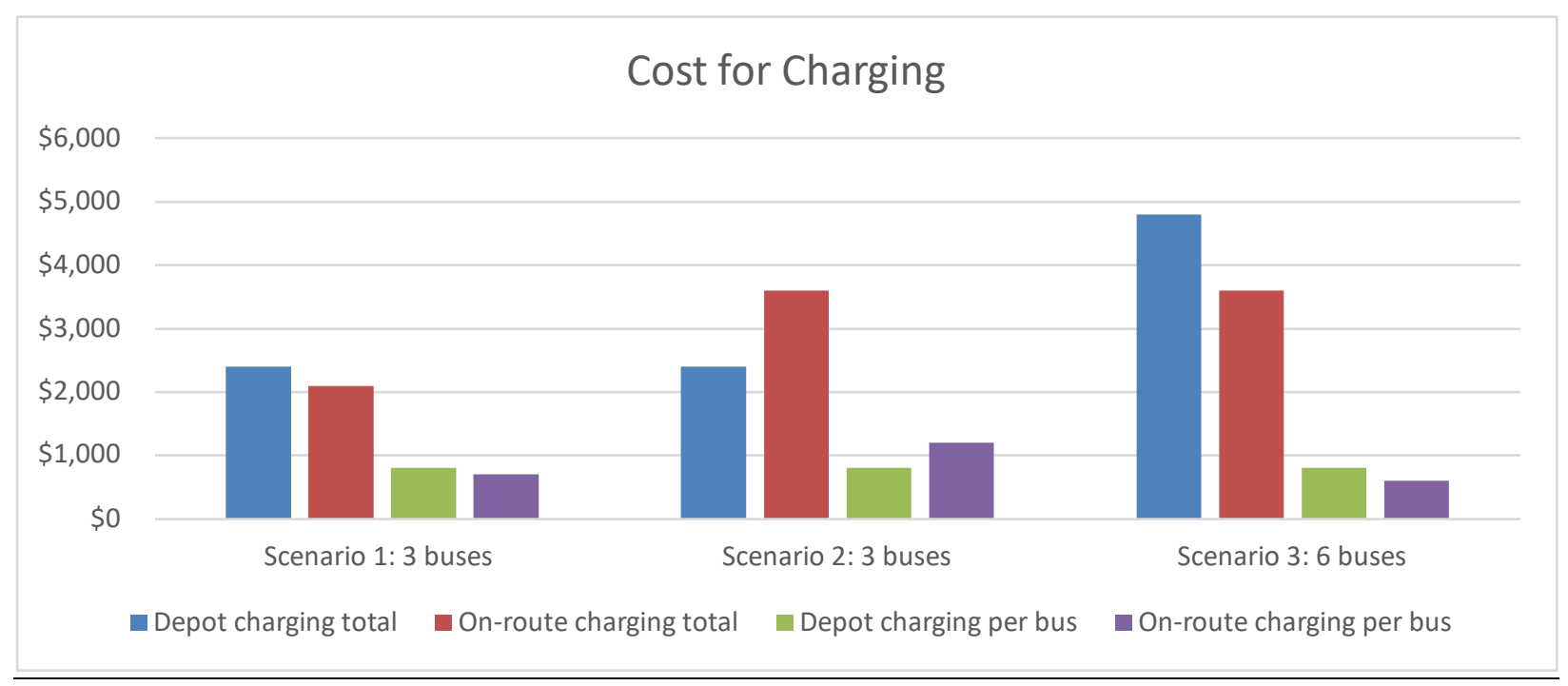

Figure 8. Demand charges for three hypothetical BEB charging scenarios

In CALSTART's Peak Demand Charges and Electric Transit Buses white paper for the FTA, hypothetical fuel costs are analyzed to show the impact of various demand charges in conjunction with bus-to-charger ratio. Figure 9 shows various fuel cost projections for zero, low, medium, and high demand charges, visualizing the cost advantage of having more buses share a single charger. It also shows how higher demand charges can lead to increased costs; however, it is only in the case of high demand charges and a single bus per on-route charger that the costs exceed diesel bus costs. 

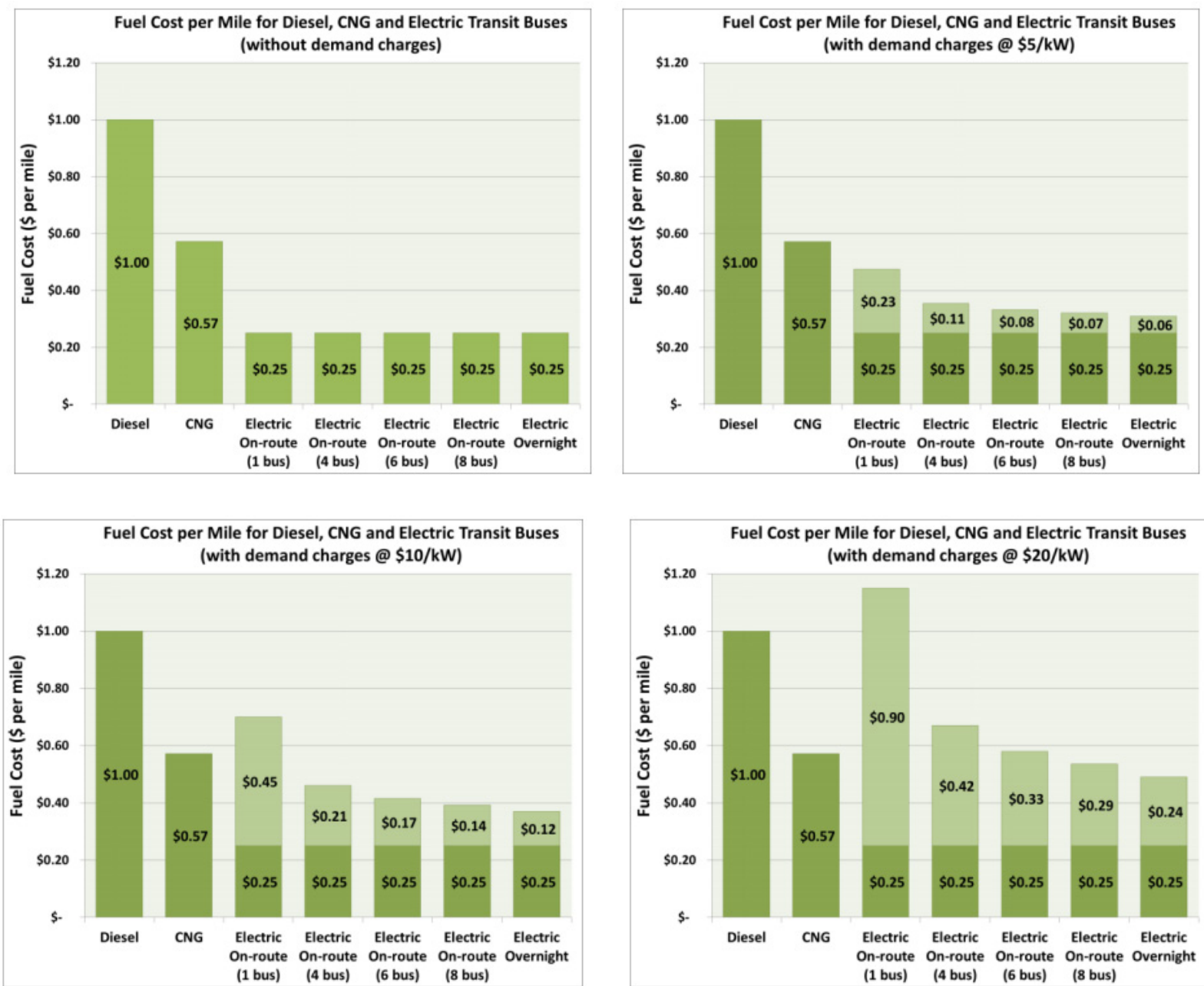

Assumptions: "each bus drives 40,000 miles per year. The diesel bus has a fuel economy of 4 miles per gallon and diesel is priced at $\$ 4.00$ per gallon. The compressed natural gas (CNG) bus has a fuel economy of 3.5 miles per DGE and CNG is priced at $\$ 2.00$ per DGE. The electric transit buses have an efficiency of $2.5 \mathrm{AC} \mathrm{kWh} / \mathrm{mile}$ and electricity is priced at $\$ 0.10 / \mathrm{kWh}$. One electric bus charging on-route draws $150 \mathrm{~kW}$ from the grid, 4 draw $280 \mathrm{~kW}, 6$ draw 330 $\mathrm{kW}$ and 8 draw $380 \mathrm{~kW}$. The electric bus charging overnight draws $40 \mathrm{~kW}$ from the grid."

\section{Figure 9. Fuel cost per mile for various demand charges}

Source: (Gallo, Bloch-Rubin, and Tomic 2014)

\subsubsection{Time-of-Use Charges}

Time-of-use charges make energy charges and/or demand charges more expensive during peak periods; in the United States, these periods typically occur between 12 p.m. and 6 p.m. (EIA Operating Data 2018) to discourage excessive grid stress. Grid stress from high peak demand is especially prevalent in summer months because of high air conditioning use, causing some utilities to implement seasonal time-of-use charges that increase in summer months. In a 2014 review of 26 major electric rate schedules, five utilities varied their demand charges seasonally, four utilities included time-of-use demand charges, and 19 utilities included time-of-use energy pricing; time-of-use demand charges can be as high as $\$ 59.24 / \mathrm{kW}$ (Gallo, Bloch-Rubin, and Tomic 2014), depending on season and time. Energy charges can also increase during peak periods if they coincide with peak demand. Some utilities have opt-in time-of-use rate structures, which could be a good choice for fleets that mainly rely on overnight depot charging, when both energy and demand charges are low. 
While all utilities employ energy charges, the inclusion of demand charges and time-of-use charges varies. Some utilities may not have any form of demand charge, increasing the appeal of on-route charging (see Figure 9, upper left). Many utilities offer a variety of rate structures combining energy usage and demand charge options. Any time-of-use or demand charges can impact BEB charging economics. Cost modeling for various charging strategies in conjunction with utility rate structure options can help decision makers optimize their BEB and charging infrastructure selections.

\subsection{Methods to Reduce Electricity Costs}

In the United States, the price of electricity varies so well-planned BEB charging can save transit agencies money. The following methods provide useful insights for how to manage and reduce electricity costs (adapted from Gallo et al. (2014)):

- Increase BEB efficiency. A more efficient BEB requires less energy to go the same distance, which means transit agencies pay less for electricity. Aside from bus manufacturers' technological advancement, measures to increase BEB efficiency include adding a diesel heater to reduce electricity needs during the winter (see Section 8.2.4) or training drivers to operate the BEB more efficiently (see Section 5.1).

- Optimize BEB fast charging. Scheduling fast-charging usage to maximize the number of BEBs served while avoiding demand charge increases can decrease the cost of charging per bus (see Section 4.1.2).

- Charge management. Electricity costs may also be decreased by strategically planning the timing and duration of BEB charging. If a transit agency can accommodate slightly longer layovers or stops in their schedule, the BEBs may charge at a lower power level, thus decreasing demand charges. Transit agencies may also choose to have buses stop for smaller, more frequent top-offs to reduce demand charges. If time-of-use charges are in place, creating a charging schedule that minimizes peak hour charging and maximizes off-peak charging will reduce electricity costs as well. Software and data platforms can help avoid high peak demand by monitoring charging status and preventing charging during peak times. This type of demand management may also be of value to utilities.

- Energy storage. Storing cheaper, off-peak electricity to offset demand at later, peak-hour times can reduce demand charges caused by fast charging stations. Lithium-ion batteries are effective forms of storage but are subject to significant upfront costs and physical space requirements. Nonetheless, even small reductions in peak demand can result in substantial cost savings based on how demand charges are assessed (see Section 4.1.2), and energy storage can enable this peak shaving.

Instead of performing time arbitrage using grid electricity, energy storage could also be paired with solar photovoltaic (PV) power: peak solar production often overlaps with peak time-of-use rates, leading to multiple types of potential value from a combined PV + storage system. Solar power could directly assist BEB charging and reduce the need for grid electricity at these peak times, the solar energy could be stored in batteries for later use as described above, the transit agency could choose some blend of these strategies that maximizes electricity cost savings. Finally, the upfront costs of battery acquisition may be defrayed through the use of end-of-life BEB batteries, which are typically taken out of service at about $70 \%-80 \%$ of their design capacity (see Section 3.2.3).

- Collaboration and support from utility companies. BEB charging is an unfamiliar technology for many utilities. The demand charges and time-of-use charges in traditional rate structures were not designed with BEB charging infrastructure in mind. For these reasons, it can be highly beneficial for transit agencies and fleet managers to establish channels of communication with their utility early in the BEB deployment process (see Sections 4.4 and 4.5). Setting expectations and working with the utility to establish a favorable rate structure can provide numerous project benefits, including electricity cost savings. For transit agencies relying on fast-charging infrastructure, desirable rates 
will include higher energy usage rates, lower demand charges, and low time-of-use charges. Demand charges are especially detrimental for agencies just beginning to deploy BEBs, with only one or two buses, and may discourage the transition from diesel to electric buses.

As of 2014, some utilities in the United States were beginning to offer rate structures specific to commercial EVs: Southern California Edison, Los Angeles Department of Water \& Power, Georgia Power Company, and Portland General Electric (Gallo, Bloch-Rubin, and Tomic 2014). Southern California Edison offers a Charge Ready transit bus program that will provide rebates and guidance on installation of BEB charging infrastructure. To participate, transit agencies must choose a route that impacts a disadvantaged community and agree to an eligible time-of-use rate structure for EV charging (SCE n.d.). These initial examples indicate that there is a large opportunity space for future utility: BEB collaboration.

\subsection{Electricity Production}

Understanding how electricity is produced in the local area can increase public and political support for a BEB project by providing clarity on the environmental impact. Because the electricity used to refuel BEBs can still produce harmful emissions when generated, the exact emissions reduction benefits of switching from diesel to electric buses may be challenging to assess (see Section 2.1.4). Many countries are striving to increase their understanding of the linkages between electricity production, BEB deployment, and environmental benefits.

Multiple resources and analytical tools have been developed in pursuit of this increased understanding. Figure 10 uses the fuel mix of several electrical grid subdivisions in the United States to estimate the annual $\mathrm{CO}_{2}$ output from a BEB compared to a traditional diesel bus in those subregions. The MRO East region, which primarily encompasses Wisconsin, has the most $\mathrm{CO}_{2}$-intensive electricity production process of any subregion, producing $1,668 \mathrm{lb}$. of $\mathrm{CO}_{2}$ per $\mathrm{MWh}$ of electricity generated. Even in the most $\mathrm{CO}_{2}$-intensive area, a BEB produces substantially fewer emissions per year than a diesel bus, as shown in Figure 11.

The World Resources Institute (WRI) created the "The Costs and Emissions Appraisal Tool for Transit Buses" that determines emissions reductions and costs for fleets of alternative-fueled vehicles (UN Environment Programme 2018). According to the WRI website:

"The Excel-based Tool allows users to compare the cost and emissions reductions of two bus fleets, each composed of up to three bus types. Bus types can differ in terms of fuel type, the technology used to achieve different emissions standards, and length. Users can input fuel and vehicle unit cost data for a city or country. If they lack these data, they can use the default data for Brazil and the United States included in the Tool. Based on either the inputted or default data, the Tool calculates the costs and emissions of each bus type and the total costs and emissions of each fleet." (Cooper et al. 2019)

The United Nations Environment Programme created three calculators that assess the costs and benefits of electrified transportation. One of them is for electric buses; the other two are for motorcycles and lightduty vehicles (including light commercial vehicles such as pick-ups and delivery vans). They can be found at https://www.unenvironment.org/resources/toolkits-manuals-and-guides/emob-calculator (UN Environment Programme 2018). 


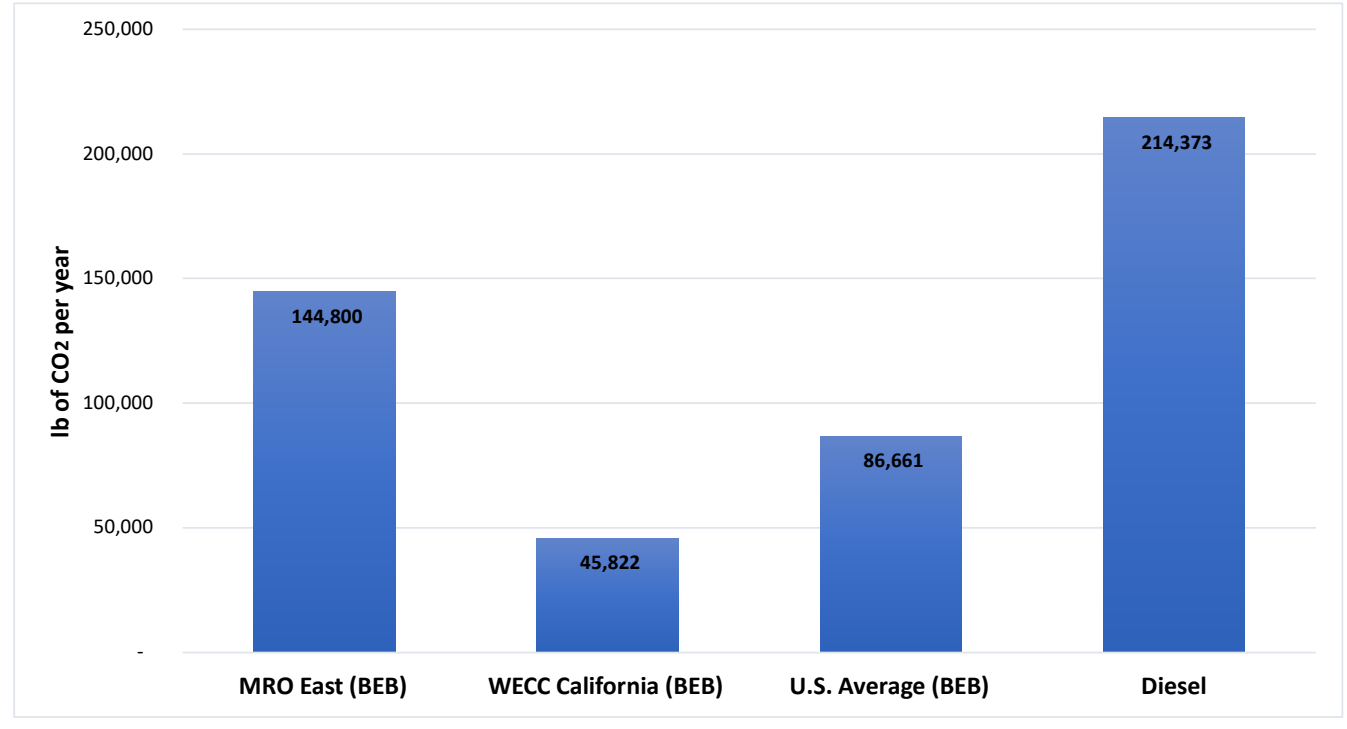

Notes: Assumed each bus travels 40,000 miles per year, BEB fuel efficiency of $2.17 \mathrm{kWh} / \mathrm{mile}$ (Eudy et al. 2016), diesel bus efficiency of 4.2 miles per gallon. Emission factors from March 2018 EPA Inventory (EPA 2018a).

Calculations shown in Appendix C.

Figure 10. Annual $\mathrm{CO}_{2}$ output per bus

\section{Battery electric buses have lower global warming emissions than diesel (and natural gas) buses everywhere in the country.}

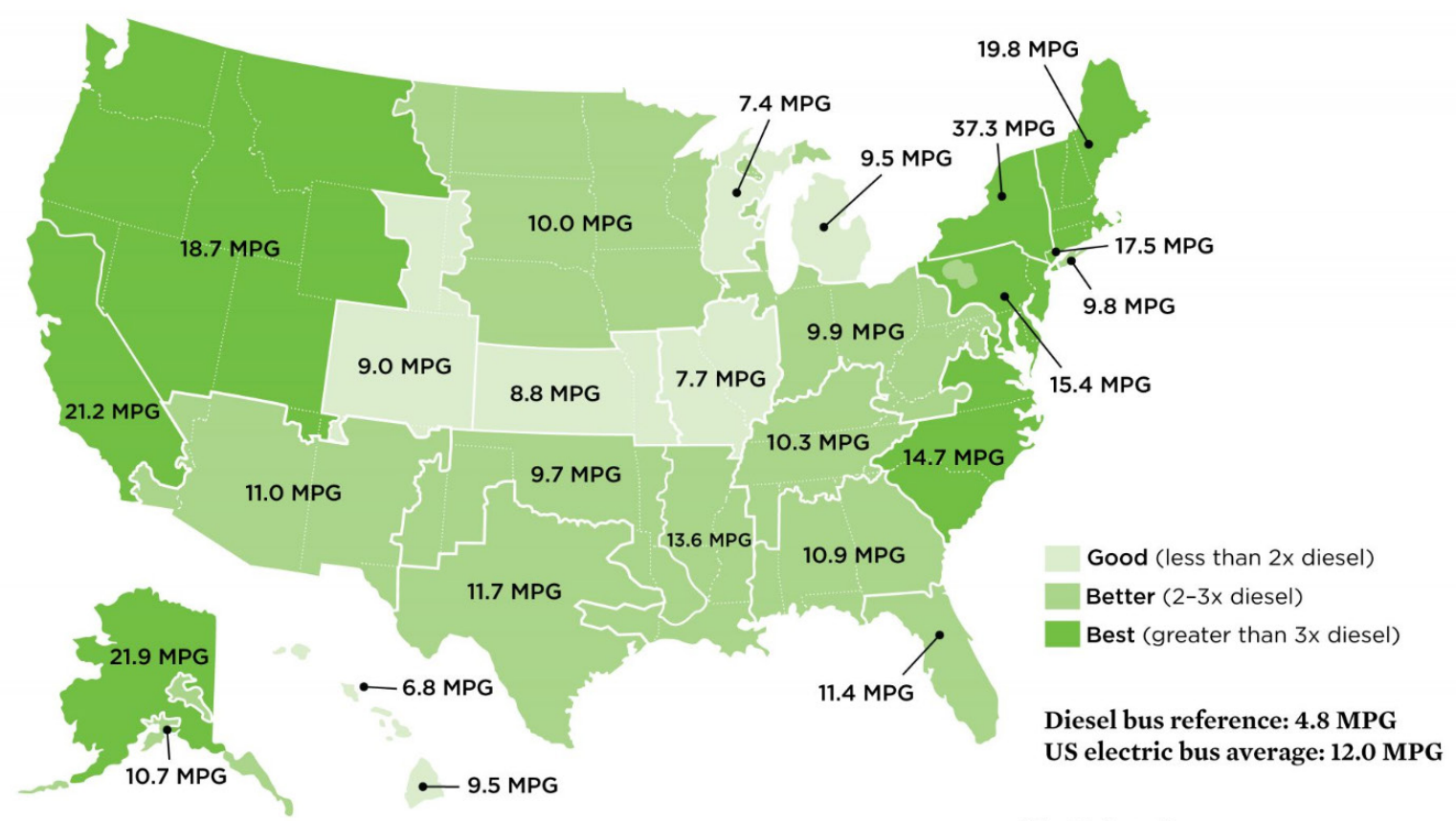

[Concerned Scientists

Note: The MPG (miles per gallon, diesel) value listed is the fuel efficiency a diesel bus would need to have the same life cycle global warming emissions as a battery electric bus in each region. Regional global warming emissions ratings are based on 2016 power plant data in the EPA's eGRID database (the most recent version). Argonne National Laboratory's GREET 2017 model was used to estimate emissions from diesel and electricity fuel production.

Figure 11. BEB annual $\mathrm{CO}_{2}$ output in the United States

Source: (O'Dea 2018) 


\subsection{Effects of BEBs on the Grid}

High-power fast charging infrastructure may be advantageous for BEB refueling, but when widely deployed it also presents potential challenges for electric grid operators who are responsible for balancing this sudden demand. In the report Battery-Electric Transit Bus Developments and Operations: A Review, the author notes that if the Los Angeles Metro bus fleet were fully electrified and every bus were to charge at the same time using $500-\mathrm{kW}$ fast chargers, the total demand from those BEBs would be 189 MW (Li 2016). This would immediately require $2.4 \%$ of the Los Angeles Department of Water and Power's total capacity of 7,880 MW (LADWP 2018) and is a highly unlikely worst-case scenario situation. On the other hand, best-case scenarios for BEB deployment involve charging the vehicles during times of surplus grid generation and with charging infrastructure that does not require grid upgrades to safely accommodate the BEB loads. These circumstances would actually benefit grid management for no additional cost (beyond the buses and EVSE). Each of these extreme scenarios is unlikely, but together they emphasize the importance of planning BEB deployment in terms of local grid conditions and trends.

\subsection{Grid Infrastructure Upgrades}

The same power demands that may affect overall grid balance (see Section 4.4) also have potential impacts at a highly local level. The electrical wires and equipment that transfer power from the grid to a BEB must be able to safely accommodate the power requirements of all connected loads. As a result, the installation of EVSE may necessitate grid infrastructure upgrades to the distribution and/or transmission systems. In the case of fast chargers or multiple depot chargers, these upgrades may come in the form of additional transformers, distribution and service panels, trenches, conduit, and conductors (Hodge and Anandhan 2018). Placing charging infrastructure near existing transformers may allow transit agencies to avoid such upgrades, which could impact route requirements of the BEBs. Additionally, right-sizing these grid infrastructure upgrades through long-term planning is key to ensuring that the grid will be able to serve future BEB fleet expansion. Repeated construction and upgrades will cost more money than building appropriately sized infrastructure upgrades the first time. As in the case of rate structure determination (see Section 4.1), the utility should be engaged on BEB projects to assess the needs for grid infrastructure upgrades and plan accordingly, as these projects can take several months, or even years, to finish.

\section{Text Box 5. Grid Infrastructure Upgrades in California}

The AVTA in Los Angeles experienced the need for grid upgrades when installing their depot chargers. Originally, two separate distribution lines fed into the depot for redundancy at $12.5 \mathrm{kV}$ each. Their planned implementation of 87 depot chargers would require high enough current that the resulting heat loss would be too great to be considered efficient . AVTA and their local utility, Southern California Edison, solved this issue by running wiring through open trenches covered in plates. The results were a more efficient system that dissipated heat safely while being easily serviceable. AVTA's experience demonstrates the importance of engaging and partnering with utilities to help identify and solve grid integration issues in the planning and design stages before implementation.

Source: National Academies of Sciences, Engineering, and Medicine 2018 


\section{Driving and Maintaining BEBs}

Consistent driver and mechanic training can smooth the transition to BEBs and help minimize the inevitable learning curve for BEB maintenance and operation. The Battery Electric Buses-State of the Practice survey reported that operations and maintenance training for the bus and charging infrastructure was predominantly provided by the bus OEM. Transit agencies, equipment providers, and third-party organizations were also reported as sometimes providing additional training for bus operators and bus maintenance staff (NASEM 2018).

\subsection{Driving BEBs}

Training drivers on the differences between diesel bus and BEB operation is important for safety and efficiency. Training for BEB operators is important to address the concerns of proper docking, braking, and shut down, but is also important for general understanding of BEB operation. Drivers need to know how battery state of charge (SOC) relates to range and how environmental factors can affect range, so that sufficient charge can be maintained according to the planned route. Additionally, operators must be familiar with emergency safety protocols (see Section 7).

\subsubsection{On-Route Charging Procedures}

Fast-charging systems are usually accompanied with some sort of semi-autonomous docking system to ensure that the bus and the charger are properly aligned. An example of the docking process for an overhead conductive charger, as detailed in the Foothill Transit Electric Bus Demo report, is as follows:

1. The charger's wireless communication is automatically established as a bus approaches;

2. Sensors on the bus and charger detect the presence and location of a bus;

3. At approximately 10 feet from the charger, the bus speed is automatically limited. The driver only has to steer the bus just as they would approaching any normal bus stop;

4. As the bus passes under the charger, it automatically comes to a stop, and the charge head lowers to the roof of the bus;

5. The bus moves forward automatically to seat the charge head with the charging connection on the roof of the bus;

6. The driver sets the parking brake to start the charging process. At this time, there are numerous automatic safety checks performed by the system before any current begins to flow;

7. Passengers can get on and off the bus as they normally would; and

8. After the batteries are fully charged, the connecting arms automatically retract.

After introducing drivers to the above docking method, the Foothill Transit team reported:

"During the docking procedure, the operator needs to apply the accelerator instead of the brake, which is the opposite of the process for pulling up to a stop with a CNG or other conventional bus. The project team recommends providing thorough and ongoing driver training for new technology buses (Eudy et al. 2016)."

\subsubsection{Regenerative Braking}

Regenerative braking, which was introduced in Section 3.1, is a key energy-saving aspect of EVs. Vehicle efficiency increases with slow, gradual braking, and therefore depends largely on the BEB driver. AVTA estimated the impact of the driver by comparing two drivers on the same route, with the same driving conditions; they saw an accumulated $4 \mathrm{kWh} /$ mile difference in efficiency due to their driving techniquea difference in range between 220 miles and 80 miles (NASEM 2018). In a BEB demonstration study 
done in England, a less shocking but still significant $1 \mathrm{kWh} /$ mile maximum difference in efficiency was measured between drivers (Kontou and Miles 2015). To successfully shift to a more regenerative brakingfriendly driving style, initial and follow-up driver trainings are necessary.

\subsubsection{Noise Level}

BEBs are so quiet that drivers may not even know they are on - the Foothill Transit project reported battery drainage due to drivers leaving the bus running at the end of their shift because they could not hear it running (Eudy et al. 2016). This problem can also be alleviated with training and with proper lights or sensors.

\subsection{BEB Maintenance}

Overall, regular BEB maintenance is distinct from diesel bus maintenance; the largest difference is the emphasis for BEBs on electric systems within the buses and charging stations as well as in the charging monitoring system and communication system. These maintenance services may require additional hiring of an on-staff electrician, and may also be supported by bus OEMs, especially on advanced systems relating to the electric propulsion system or charging system (NASEM 2018). Regenerative braking's reliance on regenerative torque rather than wholly on friction to slow a BEB results in less wear on the brake pads. Buses with regenerative braking therefore require fewer brake replacements, decreasing brake repair costs by about 55\% compared to traditional buses (CARB 2016).

BEBs possess simpler propulsion systems with fewer moving parts, meaning they generally require less regular mechanical maintenance than a traditional diesel or CNG bus. The Foothill Transit demonstration notes that the studied Proterra BEBs are recommended for preventive maintenance inspections only twice over the course of 48,000 miles, whereas the CNG buses are recommended for six preventive maintenance inspections over 36,000 miles (Eudy and Jeffers 2017). A BEB does not require oil changes or filter changes; there is no air filter due to the lack of tailpipe emissions and no fuel/oil filter because neither fuel nor oil are used. However, BEBs do require motor coolant and transmission fluid refills. 


\section{BEB Prices}

The cost of acquiring a BEB for deployment includes far more than the price of the bus itself - the battery size, bus size, charging type, charging location, route impacts, electricity cost, and maintenance all must be considered holistically, as the alteration of one variable could require reevaluation of any other.

\subsection{BEB Prices Summarized}

The Battery Electric Buses - State of the Practice report provides the following information on costs-the $\mathrm{BEB}$ and EVSE values are for upfront costs. The values include a wide range, and the average values are slightly higher than current costs (Table 1). Table 2 includes details of specific BEB deployments by U.S. transit agencies.

Table 1. BEB Costs

\begin{tabular}{|c|c|c|c|}
\hline Price & Minimum & Maximum & Average \\
\hline BEB (average per bus) & $\$ 579,000$ & $\$ 1,200,000$ & $\$ 887,308$ \\
\hline $\begin{array}{l}\text { Depot charging equipment } \\
\text { (per charger) }\end{array}$ & $\$ 2,000$ & $\$ 100,000$ & $\$ 50,000$ \\
\hline $\begin{array}{l}\text { Depot charger installation } \\
\text { (per charger) }\end{array}$ & $\$ 2,000$ & $\$ 64,000$ & $\$ 17,050$ \\
\hline $\begin{array}{l}\text { On-route charging } \\
\text { equipment (per charger) }\end{array}$ & $\$ 330,000$ & $\$ 600,000$ & $\$ 495,636$ \\
\hline $\begin{array}{l}\text { On-route charging } \\
\text { installation (per charger) }\end{array}$ & $\$ 50,000$ & $\$ 400,000$ & $\$ 202,811$ \\
\hline Fuel (electricity) & $\$ 0.15 /$ mile & $\$ 0.89 /$ mile & $\$ 0.36 /$ mile \\
\hline $\begin{array}{l}\text { Scheduled maintenance cost } \\
\text { (per mile) }\end{array}$ & $\$ 0.09 /$ mile & $\$ 0.92 /$ mile & \$0.36/mile \\
\hline $\begin{array}{l}\text { Unscheduled maintenance } \\
\text { cost (per mile) }\end{array}$ & $\$ 0.09 /$ mile & $\$ 0.55 / \mathrm{mile}$ & $\$ 0.28 /$ mile \\
\hline
\end{tabular}

Source: Battery Electric Buses-State of the Practice via Center for Transportation and the Environment, 2018 (Tables 9 and 11)

Table 2. Agency Examples

\begin{tabular}{|c|c|c|c|c|c|}
\hline & AVTA & King County Metro & City of Seneca & Foothill Transit & IndyGo ${ }^{8}$ \\
\hline ВEВ ОЕМ & BYD & Proterra & Proterra & Proterra & $\begin{array}{c}\text { Complete } \\
\text { Coach } \\
\text { Works }\end{array}$ \\
\hline Year deployed & 2014 & 2016 & 2014 & 2014 & 2015 \\
\hline BEBs & $40^{\prime}(2)$ & $40^{\prime}(3)$ & $35^{\prime}(5), 40^{\prime}(1)$ & $35^{\prime}(15), 40^{\prime}(2)$ & $40^{\prime}(21)$ \\
\hline $\begin{array}{l}\text { Number of depot } \\
\text { chargers }\end{array}$ & 1 & 1 & 1 & 0 & 22 \\
\hline $\begin{array}{l}\text { Number of on- } \\
\text { route chargers }\end{array}$ & $\begin{array}{l}2(50 \mathrm{~kW} \\
\text { inductive })\end{array}$ & $\begin{array}{l}1 \text { (overhead } \\
\text { conductive) }\end{array}$ & $\begin{array}{l}2 \text { (overhead } \\
\text { conductive) }\end{array}$ & $\begin{array}{l}2 \text { (overhead } \\
\text { conductive) }\end{array}$ & 0 \\
\hline
\end{tabular}

${ }^{8}$ https://www.indygo.net/inside-indygo/indygo-begins-building-largest-electric-bus-fleet-in-the-country/ (IndyGo 2015) 


\begin{tabular}{|c|c|c|c|c|c|}
\hline & AVTA & King County Metro & City of Seneca & Foothill Transit & IndyGo ${ }^{8}$ \\
\hline $\begin{array}{r}\text { BEB cost } \\
\text { (per bus) }\end{array}$ & $\$ 770,000$ & $\$ 797,882$ & $\$ 950,000$ & $\begin{array}{l}\$ 789,000 \text { base, } \\
\$ 823,000 \text { with } \\
\text { add-ons }\end{array}$ & $\$ 579,000$ \\
\hline $\begin{array}{l}\text { Depot charge } \\
\text { equipment cost } \\
\text { (per charger) }\end{array}$ & $\$ 19,000$ & $\$ 60,000$ & $\$ 60,000$ & $\mathrm{n} / \mathrm{a}$ & $\$ 10,000$ \\
\hline $\begin{array}{l}\text { Depot charge } \\
\text { installation cost } \\
\text { (per charger) }\end{array}$ & $\$ 55,000$ & Included & $\$ 8,000$ & $\mathrm{n} / \mathrm{a}$ & $\$ 5,000$ \\
\hline $\begin{array}{l}\text { On-route charger } \\
\text { equipment cost } \\
\text { (per charger) }\end{array}$ & $\$ 350,000$ & $\$ 600,000$ & $\$ 600,000$ & $\$ 5,000,000$ & $\mathrm{n} / \mathrm{a}$ \\
\hline $\begin{array}{l}\text { On-route charger } \\
\text { installation cost } \\
\text { (per charger) }\end{array}$ & $\$ 250,000$ & $\$ 241,510$ & $\$ 225,000$ & $\$ 200,000$ & $\mathrm{n} / \mathrm{a}$ \\
\hline Funding Sources & $\begin{array}{l}\text { LA County grant, } \\
\text { Antelope valley } \\
\text { Air Management } \\
\text { District, LA } \\
\text { Metro Call for } \\
\text { Projects } 9\end{array}$ & $\begin{array}{l}\text { TIGGER }^{10} \text { (expired } \\
\text { FTA grant) and local } \\
\text { funds }\end{array}$ & $\begin{array}{c}\text { TIGGER III } \\
\text { (expired), State } \\
\text { Vehicle } \\
\text { Replacement } \\
\text { Funds, local } \\
\text { general funds }\end{array}$ & $\begin{array}{l}2009 \text { American } \\
\text { Recovery \& } \\
\text { Reinvestment } \\
\text { Act, TIGGER, } \\
\text { TIGER }{ }^{11}, \text { Low- } \\
\text { no }^{12}, \text { Hybrid and } \\
\text { Zero-Emission } \\
\text { Truck and Bus } \\
\text { Voucher } \\
\text { Incentive Project }\end{array}$ & TIGER \\
\hline
\end{tabular}

\section{Source: Unless otherwise noted, date from 'Battery Electric Buses-State of the Practice' via Center for Transportation and the Environment, 2018}

${ }^{9}$ AVTA is part of the Five-year Capital Improvement Program in 2018 with plans to replace diesel buses with electric buses (AVTA 2018).

${ }^{10}$ In 2011, the Federal Transit Administration's Transit Investments for Greenhouse Gas and Energy Reduction (TIGGER) grant was originally initiated through the 2009 American Recovery \& Reinvestment Act. The purpose of the grant was to work with public transportation agencies to develop and implement strategies to reduce emissions within the transportation sector (FTA 2016).

${ }^{11}$ The Transportation Investment Generating Economic Recovery, or TIGER I and TIGER II Discretionary Grant programs, provide a unique opportunity for the U.S. Department of Transportation to invest in road, rail, transit and port projects that promise to achieve critical national objectives (DOT 2012).

${ }^{12}$ Under the FTA, the Low or No Emission program announced specific project selection in 2020. This is a competitive program as the FTA provides funding to the selected projects to support the purchase of zero-emission and low-emission transit buses (FTA 2020). 


\subsubsection{BEB Prices}

Table 3 comprises bus prices from various sources. It is important to note that battery prices are included within the bus price. Generally, the larger the bus, the larger the battery needed to propel the bus and thus the higher the price.

Table 3. BEB Prices

\begin{tabular}{|c|c|c|c|c|c|}
\hline Source & OEM & Year & Charging type & Length & Price \\
\hline $\begin{array}{l}\text { California Air } \\
\text { Resources Board }\end{array}$ & BYD & 2016 & Depot & $40 \mathrm{ft}$ & $\$ 770,000$ \\
\hline $\begin{array}{l}\text { California Air } \\
\text { Resources Board }\end{array}$ & Proterra & 2016 & On-route & $40 \mathrm{ft}$ & $\$ 749,000$ \\
\hline $\begin{array}{l}\text { Washington State } \\
\text { Department of } \\
\text { Enterprise Services } \\
\text { (WSDES) }\end{array}$ & Proterra & 2017 & On-route & $35 \mathrm{ft}$ & $\$ 692,720$ \\
\hline WSDES & BYD & 2017 & On-route & $35 \mathrm{ft}$ & $\$ 616,100$ \\
\hline WSDES & New Flyer & 2017 & On-route & $40 \mathrm{ft}$ & $\$ 812,830$ \\
\hline WSDES & Proterra & 2017 & On-route & $40 \mathrm{ft}$ & $\$ 806,620$ \\
\hline WSDES & BYD & 2017 & On-route & $40 \mathrm{ft}$ & $\$ 806,620$ \\
\hline WSDES & BYD & 2017 & On-route & $60 \mathrm{ft}$ & $\$ 1,241,510$ \\
\hline WSDES & Green Power & 2017 & Depot & $35 \mathrm{ft}$ & $\$ 568,340$ \\
\hline WSDES & BYD & 2017 & Depot & $35 \mathrm{ft}$ & $\$ 616,100$ \\
\hline WSDES & Green Power & 2017 & Depot & $40 \mathrm{ft}$ & $\$ 816,650$ \\
\hline WSDES & BYD & 2017 & Depot & $40 \mathrm{ft}$ & $\$ 806,620$ \\
\hline WSDES & Proterra & 2017 & Depot & $40 \mathrm{ft}$ & $\$ 785,910$ \\
\hline WSDES & Green Power & 2017 & Depot & $60 \mathrm{ft}$ & $\$ 1,075,420$ \\
\hline WSDES & BYD & 2017 & Depot & $60 \mathrm{ft}$ & $\$ 1,241,510$ \\
\hline
\end{tabular}

Source: California Air Resources Board data (CARB 2017) and WDES data (WDES 2018).

For comparison, the 2016 price estimates for fossil-fueled bus technology (40-ft. buses) are included in Table 4.

Table 4. Costs of Battery Electric vs. Diesel Hybrid vs. Diesel vs. CNG Buses

\begin{tabular}{|c|c|c|}
\hline Bus Type & Sample Size & Cost \\
\hline BEB & 128 & $\$ 861,669$ \\
\hline Diesel bus & 2773 & $\$ 704,518$ \\
\hline Diesel hybrid bus & 525 & $\$ 624,814$ \\
\hline CNG bus & 784 & $\$ 417,277$ \\
\hline
\end{tabular}

Source: American Publication of Transportation Association 2020

\subsubsection{Battery Costs}

Battery costs, although included in the BEB costs, are the most expensive component of the BEBs; they are also currently challenging to estimate. According to the California Air Resources Board, the difficulty in estimating battery costs for heavy-duty EVs stems from the following: 
“(1) Battery costs vary widely with chemistry, yet most estimates are for all types of lithium-ion batteries lumped into one group; (2) most published estimates are applicable for light-duty BEVs and not for heavy duty vehicle applications; and (3) there is lack of information about explicit relationships between production volume and battery cost for heavy duty vehicle applications.” (CARB 2016a)

BloombergNEF (McKerracher 2020) was able to use the observed battery costs for lithium-ion battery packs to forecast costs, as seen in Figure 12. Battery storage costs are changing quickly, and agencies planning for BEB deployment will benefit from seeking the most recent available reports.

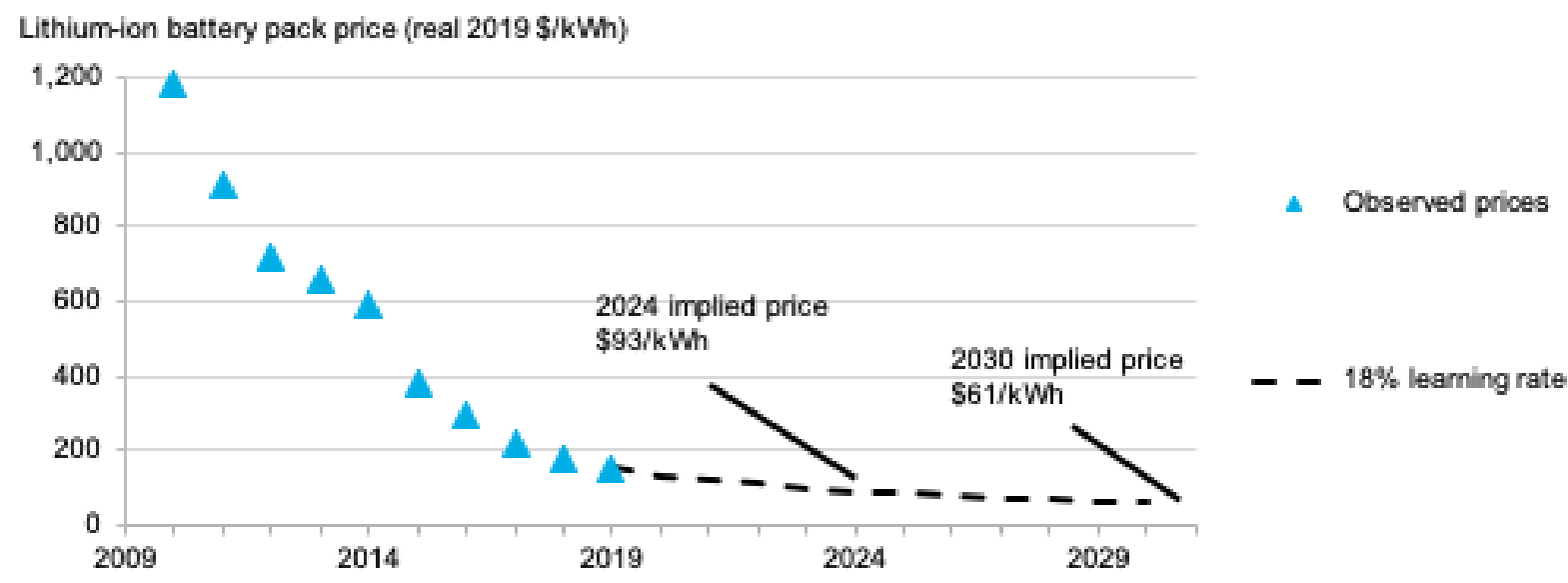

Figure 12. Lithium-ion battery pack price and demand outlook

\subsubsection{Fuel (Electricity) Costs}

BEB fuel costs are dependent on electricity rates, charging method, charging schedule, and number of buses using each EVSE (see Section 4.1). Combinations of these interrelated variables can result in vastly different electricity costs. To better understand how these factors influence electricity cost, the California Air Resources Board developed its Truck and Bus Charging Cost Calculator. This publicly available Excel tool allows various rate structures, charging strategies, charging power, number of vehicles, charging efficiencies, and vehicle energy usages to be input. The tool's outputs include maximum power demand, charging time per vehicle, and electricity cost (by time, season, and annually) (CARB Calculator 2018).

Table 5 summarizes some reported values for BEB fuel costs. For comparison to traditional buses, King County Metro reported spending \$1.60/gal (Agencies can lock in low diesel prices with long-term contracts) for their diesel buses during the evaluation (Eudy and Jeffers 2017), while the national average diesel price for the past 8 years has been \$3.27/gal (EIA Gasoline and Diesel 2018a). Assuming an efficiency of $4.2 \mathrm{miles} / \mathrm{gal}$ of diesel for a typical diesel bus (OEERE 2016), a diesel bus could vary from costing \$0.38/mile (King County Metro) to \$0.76/mile (national average) (CARB 2018) or more. The cost of electricity is unique to each agency's location at any given time: King County Metro found that their electricity costs were 1.9 times as expensive as diesel (Eudy and Jeffers 2017), while AVTA found that their electricity costs were one-third that of diesel fuel (AVTA 2018). 
Table 5. BEB Fuel Costs

\begin{tabular}{|c|c|c|c|c|c|}
\hline \multirow{2}{*}{$\begin{array}{c}\text { Source } \\
\text { Foothill Transit (Eudy and } \\
\text { Jeffers 2017) }\end{array}$} & $\begin{array}{c}\text { RCE TOU-GS-1 } \\
\text { exemption rate }\end{array}$ & $500 \mathrm{~kW}$ on-route (2) & 12 & 0.175 & 0.44 \\
\cline { 2 - 6 } & $\begin{array}{c}\text { SCE TOU-EV-4 with } \\
\text { charge management }\end{array}$ & $500 \mathrm{~kW}$ on-route (2) & 12 & 0.17 & 0.42 \\
\hline $\begin{array}{c}\text { King County Metro (Eudy } \\
\text { and Jeffers 2017) }\end{array}$ & PSE Commercial 25 & on-route (1) & 3 & 0.2 & 0.57 \\
\hline \multirow{2}{*}{$\begin{array}{c}\text { State of the Practice Survey } \\
\text { (NASEM 2018) }\end{array}$} & Min rate & Unavailable & Unavailable & Unavailable & 0.15 \\
\hline & Max rate & Unavailable & Unavailable & Unavailable & 0.36 \\
\hline
\end{tabular}

Note: Table does not include demand charges, visit https://afdc.energy.gov/files/u/publication/financial analysis be transit buses.pdf for more information.

\subsection{Funding and Financing Options}

Although initial BEB costs are dropping, diesel, CNG, and hybrid buses remain less expensive technologies in the short term. To combat the high upfront cost, multiple financing and funding options exist, which are detailed below as examples.

\subsubsection{FTA Grants}

The Bus \& Bus Facilities Investment program (49 U.S.C/5339) exists, according to the FTA website, to:

"make federal resources available to states and direct recipients to replace, rehabilitate and purchase buses and related equipment and to construct bus-related facilities including technological changes or innovations to modify low- or no-emission vehicles or facilities. Funding is provided through formula allocations and competitive grants." (FTA Investment Program 2015)

This is a three-part program, including a formula grant program, a competitive grant program, and a lowor no-emission program. The first two options can fund a range of activities, including funding new buses, depot repairs, and bus lane construction, and can be applied to any type of bus, including BEBs. The competitive program alone supplied over \$250 million from fiscal year (FY)2016 through FY2019 (FTA 2020). However, to receive such funding, bus procurements must satisfy the FTA's "Buy America" requirement, which mandates that a bus must undergo final assembly in the United States and that $65 \%$ of the bus's components (70\% for FY2020 and beyond), by cost, be produced in the United States (FTA 2017s). This virtually eliminates foreign bus manufacturers from U.S. bus procurement consideration.

The Low- or No-Emission Bus Program provides funding to state and local governmental authorities for the purchase or lease of zero-emission and low-emission transit buses, as well as acquisition, construction, and leasing of required supporting facilities. In June 2020, the FTA awarded nearly \$130 million to 41 projects for the FY2020 FTA Low-No Program. With an average award being around \$3 million, these eligible projects will be able to fund efficient technologies such as hydrogen fuel cells, battery electric engines, and related infrastructure investments such as charging stations (FTA 2020).

\subsubsection{Volkswagen Settlement Trust}

As part of a 2016 U.S. Federal Court settlement with Volkswagen AG, \$2.9 billion will be divided among states, Tribes, Puerto Rico, and the District of Columbia via an environmental mitigation trust (Nigro 2018). This settlement comes after software was found in multiple VW diesel vehicle models to deceive emissions testing, leading to approximately 590,000 vehicles sold in the United States that produce anywhere from 9 to 38 times the U.S. limit of $\mathrm{NO}_{\mathrm{x}}$ emissions (Nigro 2018). Beneficiaries will receive 
anywhere from $\$ 8$ million to $\$ 209$ million, with the exception of California receiving $\$ 423$ million because of its role in the case (Nigro 2018). This money is being distributed with the goal of reducing $\mathrm{NO}_{\mathrm{x}}$ emissions in the transportation sector through the replacement and repowering of diesel vehicles; states started submitting their mitigation plans in 2018 and funds can be distributed after 30 days (CDPHE 2017). Included in the list of eligible mitigation actions:

"Eligible Buses include 2009 engine model year or older class 4-8 school buses, shuttle buses, or transit buses. For Beneficiaries that have State regulations that already require upgrades to 1992-2009 engine model year buses at the time of the proposed Eligible Mitigation Action, Eligible Buses shall also include 2010- 2012 engine model year class 4-8 school buses, shuttle buses, or transit buses (EPA 2017)."

For non-government-owned buses, funds can cover up to $75 \%$ the price of a new all-electric bus or allelectric repower (retrofitting with an electric engine). For government-owned eligible buses, this may increase to $100 \%$ of the price (EPA 2017). States and other beneficiaries have mitigation plans in place, many of which already include plans for BEB implementation. These plans do have flexibility to change. See www.vwclearinghouse.org for a beneficiary directory and to be pointed toward specific state mitigation plans.

\subsubsection{State Incentives}

The U.S. Environmental Protection Agency provides funding to states via grants under the Diesel Emission Reduction Act. Through this act, states may receive funding to cover up to $45 \%$ of the price of a new, zero-emission replacement bus and $60 \%$ of the price, including labor and equipment, of replacing a non-bus diesel engine with a zero-emission power source (EPA 2018).

Other opportunities for funding may be provided by state governments. For example, the California Air Resources Board, in partnership with CALSTART, launched the hybrid and zero-emissions truck and bus voucher incentive project and has funding over \$100 million for zero-emission projects (California HVIP 2020). Incentives vary by state and can be referenced at https://afdc.energy.gov/laws.

\subsubsection{International Incentive Examples}

Numerous countries provide specific incentives to support purchase of BEBs and supporting infrastructure; a small number of representative examples are listed here. The country of India is focusing transportation electrification efforts on public and shared transportation, including buses, rickshaws, and taxis, as well as private two-wheeled vehicles. Incentives reduce the purchase price of these vehicles as part of the Faster Adoption and Manufacturing of Electric Vehicles in India scheme (IEA 2019).

South Korea has an extensive set of national subsidies and policies designed to increase low-carbon vehicle purchases, including public procurement, subsidies and rebates on vehicle acquisition taxes, reduced highway tolls, and reduced public parking fees. In 2018, Korea also announced ambitions to increase the export of Korean-manufactured low-emission vehicles, which includes financial support and loan guarantees to major Korean industrial manufactures, with a goal to increase production capacity to more than $10 \%$ of all vehicles by 2022 (IEA 2019).

\subsubsection{BEB Financing Options}

- The first option for funding for BEB charging stations and batteries is to use available agency funds and state or federal grants upfront. Most grants include funding for charging infrastructure, as well as buses themselves.

- Leasing the BEB: The high upfront cost of BEBs, due in part to the high price of batteries, is a major financial barrier to transit agencies. 
- Purchasing the bus and leasing the battery is an option demonstrated by Park City, Utah, in partnership with Proterra. By leasing the batteries using city transit operational funds, the funding awarded through a Low-No grant could be used to purchase more buses (BloombergNEF 2018). Battery leasing offers a way to reduce risks associated with the battery, as manufacturers can better determine longevity and the market for second-life batteries.

- Some bus OEMs may also offer the option to lease the entire bus and battery, often to test route performance. The Metropolitan Transportation Authority in New York City used this method to lease 10 BEBs over 3 years, which included leasing the depot charging stations (MTA 2018). The demonstration began with BEB operation in December 2017 (BloombergNEF 2018).

- Green bonds or climate bonds are bonds in which proceeds go to projects that involve climate mitigation or adaption. Specifically, Translink - a noncorporate transit agency-launched their zeroemission BEB pilots in 2019 in Vancouver, Burnaby, and New Westminster (Translink 2019). Uniquely, the pilot is testing the buses of four separate manufacturers (New Flyer, Nova Bus, ABB, and Siemens) and is also testing compatibility between the buses and the manufacturers' charging station equipment. The goal of this program is to increase sustainability in combination with their plan to reduced their greenhouse gases (Bryan and Pillai 2018).

- The Utility Pay As You Save tariff can be used for clean transit, decreasing the upfront cost of BEBs. The tariff structure involves utility companies investing in charging stations and recovering that investment via charges on the transit agency's electric bill (Climate Policy Initiative 2018). 


\section{Case Study 3. Santiago, Chile}

\section{BEB Financing in Santiago, Chile}

Santiago, Chile's capital city, has a population of nearly 7 million people with a public bus transportation system that accounts for 3 million transactions on the 6,800 buses that connect the city on an average working day. As of 2019, the Ministry of Transportation and Telecommunications has over 400 BEBs operating in Santiago daily, causing major improvements in the residents' quality of life by reducing air pollution and transit noise.

The business model created to replace aging buses in Santiago separates the ownership of buses from their operation and maintenance. In a public-private partnership, the government secured a loan to pay private fleet provider companies for the buses, which were then assigned to specific private bus operators, as shown in Figure 13. Fleet providers and bus operators are required to sign preapproved contracts that regulate their relationship and secure remaining buses in the system until the debt is paid. Doing so reduces payment risks, which lowers credit rates and funding costs and also allows the government to handle shorter operator contracts (that exclude the cost of the bus assets).

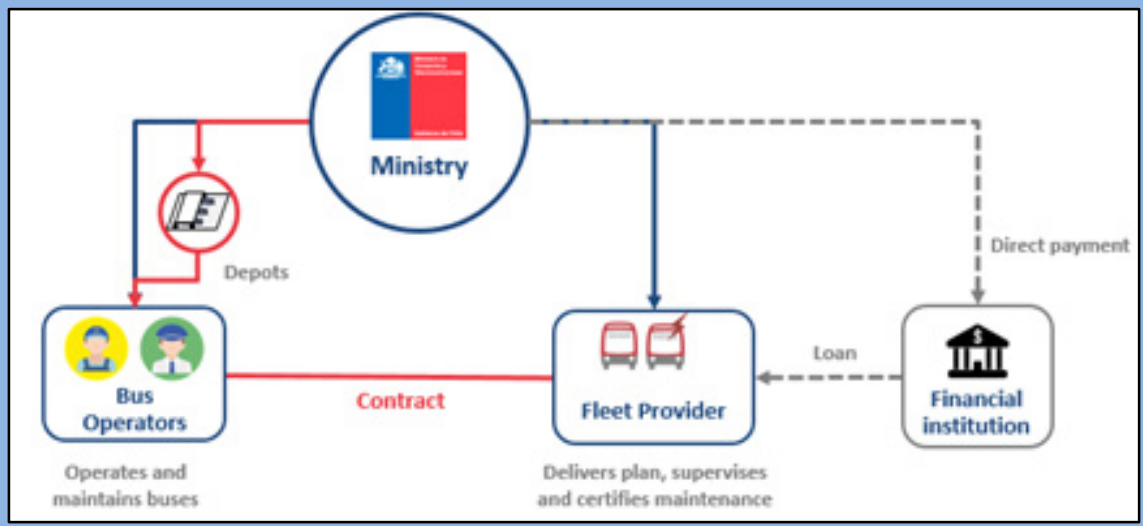

Figure 13. Santiago, Chile bus fleet business model

The transportation authority ran simulations based on electric bus performance data and Santiago's route features to determine operation range. Results showed more than $70 \%$ of the routes tested can be operated daily with a single full charge. In addition, the standardized driving cycle that matches Santiago's landscape showed that electric buses are nearly five times more energy efficient than diesel buses.

Looking ahead to 2030, emissions outcomes of bus electrification were modeled through MODEM simulations of fleet replacement. ${ }^{1}$ Compared to the 2018 baseline fleet which includes approximately 400 BEBs and 400 "soot-free" Euro VI diesel buses (each comprising 6\% of Santiago's bus fleet), a 2030 scenario in which the fleet is $50 \%$ BEBs and 50\% Euro VI buses reduces $\mathrm{NO}_{\mathrm{x}}$ and $\mathrm{HC}$ emissions by approximately $90 \%$ each, $\mathrm{CO}_{2}$ emissions by $15 \%$, and $\mathrm{PM}_{2.5}$ and $\mathrm{PM}_{10}$ emissions by $70 \%$ and $56 \%$, respectively.

By the end of 2022, the Chilean government expects to replace more than 5,000 buses through consecutive tendering processes and is expecting a high percentage of electric buses; by 2030 , the country expects to replace the entire fleet.

Source: Directorio de Transporte Público Metropolitano, del Ministerio de Transportes y Telecomunicaciones

(Santiago Larraín Barahona, Carolina Simonetti de Groote, Fernando Saka Herrán 2020) 


\section{Safety}

Compared to conventional buses, BEBs must comply with universal bus safety standards and additional standards for EVs, batteries and EVSE. BEBs must meet codes and standards, be prepared for crashes and other emergencies, and be able to perform safely in the heat, rain, and snow.

\subsection{U.S. Codes and Standards}

Any bus purchased with FTA funds must pass a suite of federally designed tests. Altoona testing, the FTA's bus testing program, tests new transit models for maintainability, reliability, safety, performance (including braking performance), structural integrity (including structural durability), fuel economy (energy efficiency and range for BEBs), noise, and emissions (LTI Bus Research and Testing Center 2018).

Charging infrastructure must be inspected and approved to meet the National Electric Code, as well as all local electrical and building requirements. Article 625 of the National Electric Code is specifically dedicated to EV charging systems and includes information on equipment construction, installation, and wireless power transfer (NFPA 2016).

- Depot charging: The standard plug-in chargers in the United States are the Society of Automotive Engineers (SAE) J1772 (or J plug), used generally for EVs, and the recently published SAE J3068, specific to charging medium- and heavy-duty vehicles (SAE 2018). The CHAdeMO protocol is a global standard with the largest global coverage for EV users in Europe, North America, Asia, and Japan (CHAdeMO 2019).

- On-route conductive charging: The publication of SAE J3105, the standard for heavy duty automatic conductive chargers, is available at https://www.sae.org/standards/content/j3105_202001/.

- On-route inductive charging: SAE International published the Recommended Practice SAE J2954 standard for wireless charging for EVs up to $11 \mathrm{~kW}$. After conducting multiple tests throughout 2019, the standard is available at https://www.sae.org/standards/content/j2954_201904/.

The American National Standards Institute (ANSI):

"facilitates the development of American National Standards by accrediting the procedures of standards developing organizations. These groups work cooperatively to develop voluntary national consensus standards. Accreditation by ANSI signifies that the procedures used by the standards body in connection with the development of American National Standards meet the Institute's essential requirements for openness, balance, consensus and due process." (ANSI 2018)

ANSI is a source for various EV, battery, charging, and safety standards, including SAE, International Organization of Standardization, and International Electrochemical Commission standards.

\subsection{Electrical Hazards}

BEBs are powered by an electric drive system that contains high voltage batteries up to $630 \mathrm{~V}$. As advised by the National Fire Protection Agency, cutting, breaching, or touching the high voltage components or cabling could result in serious injury or death. It is important to wait at least 10 minutes for complete discharge of the high-voltage capacitor when shutting down the high-voltage system, as the system may remain powered for up to 4 minutes after shutoff/disabling (Long et. al. 2013). 


\subsection{Other Hazards}

BEBs operate extremely quietly because of their electric motor. This reduced noise can be a collision hazard to pedestrians, who are more familiar with louder diesel buses. Ensuring that drivers are aware that pedestrians may not hear their approach in addition to spreading public awareness on BEB lack of noise pollution could help protect pedestrians.

It is important to note that lack of engine noise does not mean the vehicle is off. Silent movement capability exists until the vehicle is fully shut down. In the case of an emergency, it is advised to place a wedge or block against the wheel to prevent the vehicle from moving.

\subsection{Emergencies}

Collisions with vehicles or charging infrastructure, as well as power outages, should be carefully considered in planning for BEB deployment.

Transit agencies can prepare for electrical power outages in a variety of ways, such as having backup power generation or a reserve of diesel buses. AVTA maintains a 1.5-MW backup generator capable of supplying power to all 87 of its depot chargers in the case of an emergency (AVTA 2018). The city of Seneca placed its two fast chargers in locations served by two different electricity grids, so if one loses power the other can serve as a backup (NASEM 2018).

In the event of an on-road emergency such as a crash, the electrical system of a BEB can be shut down manually via a master switch on the exterior of the bus. The National Fire Protection Association maintains a collection of emergency response guides for alternative-fuel vehicle manufacturers and for first responders. Amongst the collection currently available for public download are BEB guides from BYD, GILLIG, Nova Bus, and Proterra (NFPA 2018). Charging stations will also have an emergency shutdown method. In the case of the Foothill Transit demo, emergency shutoff switches for each charge head are located externally on either side of the building enclosing the charging infrastructure. This building is temperature controlled and houses the base of the chargers (Eudy and Jeffers 2017).

There are several precautions emergency responders must take to safely free people trapped in a bus. First and foremost, emergency responders must ensure that they do not cut through the orange high voltage lines running through the bus without first disconnecting the electrical system and waiting several minutes for it to fully discharge (NFPA 2018). In the rare case of a battery fire, emergency crews will need to monitor the bus, as battery fires may spontaneously reignite hours after the initial fire is doused. Coordination between transit agencies and first responders, through emergency response trainings, will ensure any BEB-related emergencies are met with efficient, synchronized responses. 


\section{Project Execution}

Successful BEB deployment requires a deep understanding of local conditions. The novelty of the technology combined with the high number of jurisdictional variables at the government, utility, and transit agency levels require significant planning to overcome these many areas of potential uncertainty. This section describes the flow of project execution from high-level planning to technology selection and route adjustments, synthesizing the information presented in previous sections of this guidebook. It is meant to serve as general decision guidance to help maximize project efficacy for transit agencies that have already decided to deploy BEBs.

\subsection{Long-Term Planning}

Before embarking upon a BEB project, it is important to develop a long-term set of goals and a vision for the fleet. With an explicit target for the number of BEBs in the fleet, charging infrastructure can be selected and sized accordingly. For example, an agency with an aggressive BEB deployment goal may not have sufficient space in its depot for the number of plug-in chargers that would eventually be needed to support the BEB fleet, and so may need to pursue an on-route charging strategy. These long-term goals can also prevent unnecessary expenses for grid infrastructure upgrades - it is less burdensome and costly to expand infrastructure for higher power capabilities all at once instead of needing to install multiple sets of upgrades as the BEB fleet grows.

Long-term planning also includes establishing key performance indicators. Choosing standardized metrics for progress will inform the need for any adjustments as the BEB deployment proceeds. Such indicators could include fuel savings, emissions reductions, cost reductions, bus availability, or others. The key is to collect data associated with these priority indicators throughout the project so that analysis can be done more easily over time; it can be much more difficult to obtain past data once the fleet is operational.

When planning for BEB implementation, it is crucial to engage stakeholders early. Public and city officials can provide resources and support for policy and regulatory considerations throughout the BEB project with consistent engagement. Early involvement with the utility company is important as utility staff can help identify optimal grid access points for high power charging, provide rate structure assistance, and determine the magnitude of any required grid upgrades. Once the utility company is involved, city planners, construction companies, and bus OEMs may be added to these planning conversations. This group of stakeholders can inform route analysis, discuss the trade-offs of different bus/battery/charger combinations, and plan training for operators and maintenance staff. City planners and construction companies can then work with the utility to identify best placements for charging stations and install right-sized charging infrastructure. As the city begins to prepare for deployment, it is then advised to involve first responders in training on appropriately responding to BEB-specific hazards.

Identification of potential funding sources, both federal and state level, will also shape early BEB planning during this time, as initial fleet size and the timeline for fleet expansion are heavily affected by the availability of funding assistance (see Section 6.2).

\subsection{Route Analysis}

To achieve service comparable to diesel buses, BEB range must be optimized and properly matched to route length and characteristics, a process that entails thorough, location-specific route analysis for viable BEB routes. This analysis will produce the range and bus requirements that can be used to outfit the fleet and charging infrastructure. Routes are examined for variables that correspond to shifts in fleet decisions (described below). 
Simulations and models can perform this analysis to see the degree to which each variable influences a $\mathrm{BEB} /$ charging arrangement. Demonstrating BEBs on the actual routes is another way to make sure the BEBs will meet the desired performance standards. Seneca's Clemson Area Transit did these demonstrations for a month to ensure that BEBs met their standards (NASEM 2018). Assistance with route analysis may be provided by bus OEMs, nonprofit consortia (e.g., Center for Transportation and the Environment, or CALSTART), or other local organizations and consultants.

The following location and route variables can affect BEB deployment decisions.

\subsubsection{Physical Route Characteristics}

- Route Length: The physical distance a bus must travel to complete a route varies from short neighborhood routes to longer commuter routes and has implications for the selection of charging strategy. Longer commuter or highway routes benefit from larger batteries with extended range capabilities and depot charging at the destination during midday layovers or overnight. On-route charging, however, requires a bus to pass the same charging point(s) repeatedly throughout the day, which favors shorter routes that frequently pass the charging site. For example, Foothill Transit charges their buses on-route about once an hour on a 16.7-mile route.

- Start/Stop Frequencies: The benefits of regenerative braking, namely increased efficiency and range extension, are best produced by using BEBs on routes that feature frequent stops. Each braking opportunity allows the BEB's electric drive system to recover energy. This feature favors neighborhood or city routes with many stop signs, traffic lights, or bus stops.

- Grade: The incline of the road impacts BEB range. Ascending steeper grades requires more power and drains the bus's battery more quickly than flat road transit. This effect was shown in the Foothill Transit demonstration evaluation via Figure 14. The blue line shows the SOC of the battery over time. The rate at which the battery is drained along the route, shown by the slope of the blue line, has two distinct portions within the North Loop. The steep rate of discharge seen approximately between 4:18 p.m. and 4:38 p.m. is due to the bus climbing $302 \mathrm{ft}$ (or $92 \mathrm{~m}$ ) in elevation over about 7.7 miles (R. Prohaska, Kelly, and Eudy 2016). The second portion of the north loop shows a slow rate of battery discharge, indicated by the small negative slope after 4:38 p.m. and coinciding with the BEB's descent down the $302 \mathrm{ft}$ hill to the charging station. Although $302 \mathrm{ft}$ is a small elevation change, it caused a significant difference in power requirement and energy consumption. Agencies looking to implement BEBs on hilly routes should be aware of these demands and adjust battery size or charging frequency as needed. Additionally, agencies deploying BEBs for the first time may want to avoid large changes in elevation to simplify fleet configurations and reduce risk. 


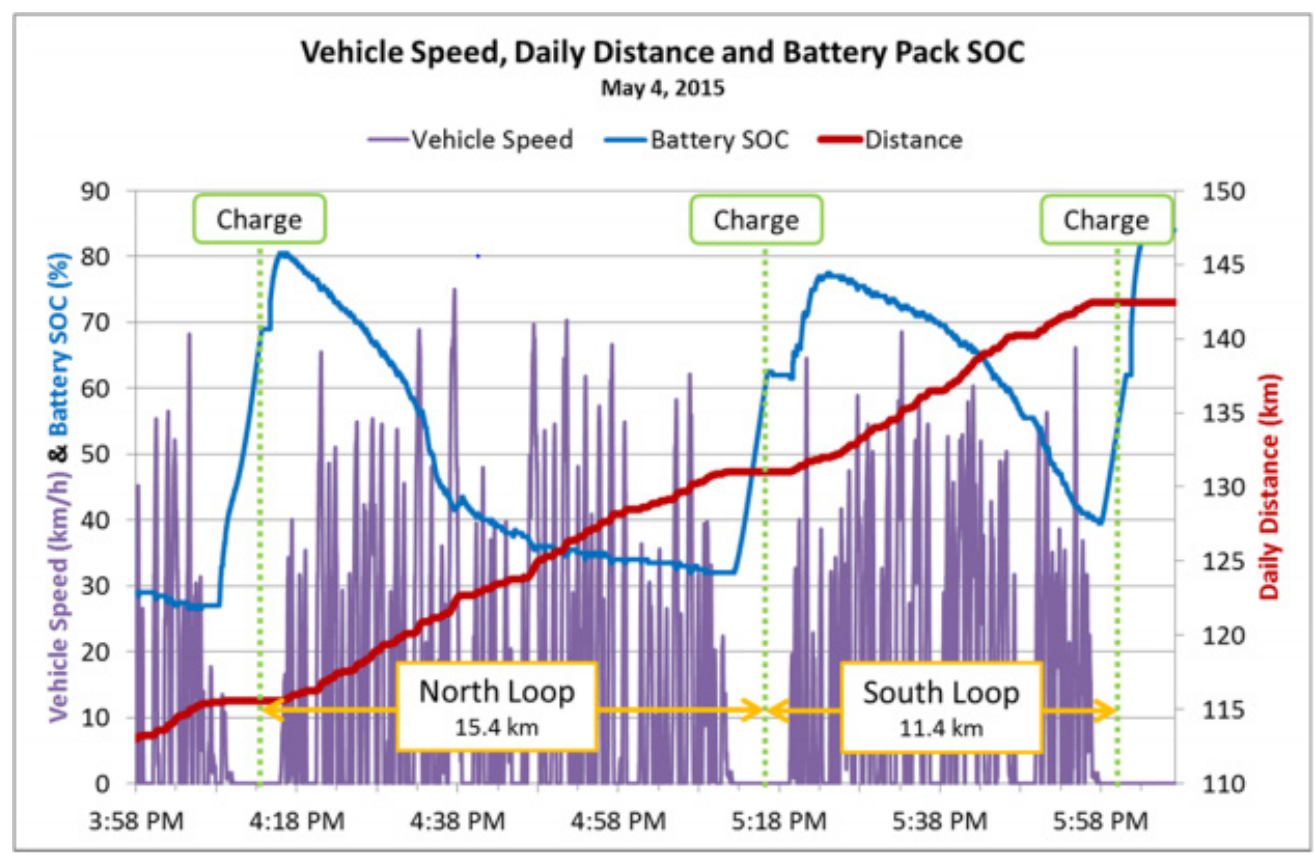

Figure 14. Effect of elevation change on battery SOC

Source: (R. Prohaska, Kelly, and Eudy 2016)

\subsubsection{Bus Operation and Route Variables}

- Road dimensions: When choosing the physical size of the bus, attention must be paid to route widths and clearance height requirements to ensure the bus will fit on selected routes.

- Bus speeds: BEBs demonstrate the largest energy efficiency advantage over diesel vehicles at lower average speeds (CARB 2017a). Shorter neighborhood or inner-city routes maximize this BEB advantage in addition to operator training.

- Passenger capacity/bus ridership: Certain routes require minimum passenger capacity to adequately meet bus ridership needs. Buses filled to capacity are heavier and require more energy from the battery, reducing BEB range. Larger batteries or more frequent charging may be needed for routes with high ridership.

- Operational schedules:

$\circ$ On-route charging theoretically allows BEBs to operate continuously (except for maintenance downtime). For buses that only operate during the day, depot charging is a viable option alongside on-route charging.

- Some transit systems operate on a pulse schedule, where all buses depart and arrive from a central location at the same time, allowing passengers to easily transfer buses. This system typically means that bus layovers also take place simultaneously, which can make on-route charging more difficult as a centrally located on-route charging station would be in high demand. Pulse scheduled buses may prefer depot charging, although on-route charging is not impossible on such a system, as proven by Seneca's transit operation in South Carolina (NASEM 2018).

- Deadhead:

- Deadhead is the distance a bus must travel, while not in service, to return to the bus depot and travel at the beginning of the shift. Routes must be located close enough to the BEB storage depot such that BEBs have enough remaining charge to return to the depot after completing routes. 
- Susceptibility to route interruptions:

- Route changes or interruptions due to events like parades or community festivals can temporarily increase route length and impact on-route charging access.

- Natural disasters can limit access to chargers or require route changes; however, if strategically utilized, fuel diversification can make a bus fleet more resilient to these events (Johnson 2019).

\subsubsection{Charging and Route Variables}

- Layovers: On-route charging requires anywhere from 5 to 20 minutes per charge, depending on how much charge needs to be replenished and the power supplied by the EVSE. To accommodate this charging time, transit agencies often opt to integrate charging with layovers already built into their schedules, which can expose the BEB service to disruptions due to schedule slips. Some agencies reduce their layover time to make up for any slips, but only if the bus does not need to be charged. Routes that allow for these advantageously timed layovers may be favored for BEB implementation.

- Traffic patterns and density:

- Routes with predictable traffic patterns enable more consistent charging.

- On-route charging infrastructure can benefit from low-density traffic areas where the chances of collisions between other vehicles and the charging station are reduced.

- Electrical grid access: BEB charging requires reliable access to the electrical grid. As stated in Section 4.5, charging locations near transformers are favorable and can decrease the need for costly distribution system upgrades. Planning for on-route charging locations should account for this transformer proximity, in addition to potential overlap with existing light rail or trolley infrastructure, which also require high-power grid access. Utility collaboration will be key for this analysis.

- Overlap with other routes: Routes that overlap, especially at centralized locations, make it easier for BEBs to share on-route charging infrastructure, reducing demand charges by spreading them out over more buses and passengers. Overlapping charging locations that serve as stops for not-yet-electrified routes also ease future electrification of the buses on those routes. This logic has led a number of transit agencies to locate on-route chargers at transit centers, where many bus routes overlap.

- Land access: Charging locations, whether on-route or in depot, require some amount of land to accommodate their physical footprint. Depot charging depends on space within the depot and the total number of depot chargers necessary (both for current and future BEB deployment - see Section 8.1). On-route chargers require access to land that the transit agency either owns or can lease for an extended period, which is another reason on-route charging is often located at transit centers owned by the agency. Other potential fast-charging locations, such as government-owned land available for lease, should be evaluated when considering BEB routes. City officials and city planners can help identify these possible sites, and utilities can assess whether these in locations require grid upgrades, as BEB fleets may overwhelm the available capacity (Daniels and O'Donnell 2019).

\subsubsection{Other Variables}

- External Temperature Differential:

- A BEB's interior environment controls are powered by the same battery source as the rest of the bus, and as a result HVAC demand accounts for the single largest impact on usable range (Bigelow 2017). Seasonal HVAC loads affect energy consumption; a model of energy consumption by the Center for Transportation and the Environment showed a bus with average number of passengers uses $2 \%$ more energy in the summer (for cooling) and $28 \%$ more energy in the winter (for heating) compared to autumn operation (Bigelow 2017). A separate simulation showed a $26 \%$ increase in energy consumption when auxiliaries, in this case mostly air 
conditioning in summer, were being used compared to when they were not (Rogge, Wollny, and Sauer 2015). Interior heating demands especially affect range because, unlike internal combustion engine vehicles than can utilize excess heat from the engine, BEBs must generate heat from battery electricity. Diesel heaters are an effective option for cold-climate BEBs, sole reliance on the vehicle battery for heat decreases the battery power by $50 \%$. Using a diesel heater, four liters of fuel can heat a bus for $100 \mathrm{~km}$ of typical operation in the winter (equivalent to 1.1 gallon for 62 miles of heat) (Eliptic 2017). HVAC use may also necessitate larger batteries, more frequent charging, and/or seasonal scheduling or route adjustments.

- High external temperature has a negative effect on battery aging, as explained in Section 3.2.3.

- At cold temperatures, power and energy performance are lower because of poor ion transport within the lithium-ion battery, as illustrated by Figure 16. This can cause reduce acceleration, limit the benefits of regenerative braking, and decrease range compared to BEB operation in warmer temperatures (Brotherton and Gallo 2014). Possible design solutions include larger batteries, more frequent charging, storing BEBs in insulated or temperature-controlled buildings, and/or seasonal scheduling adjustments to allow longer charging times.

\section{Relative Capacity vs. Temperature}

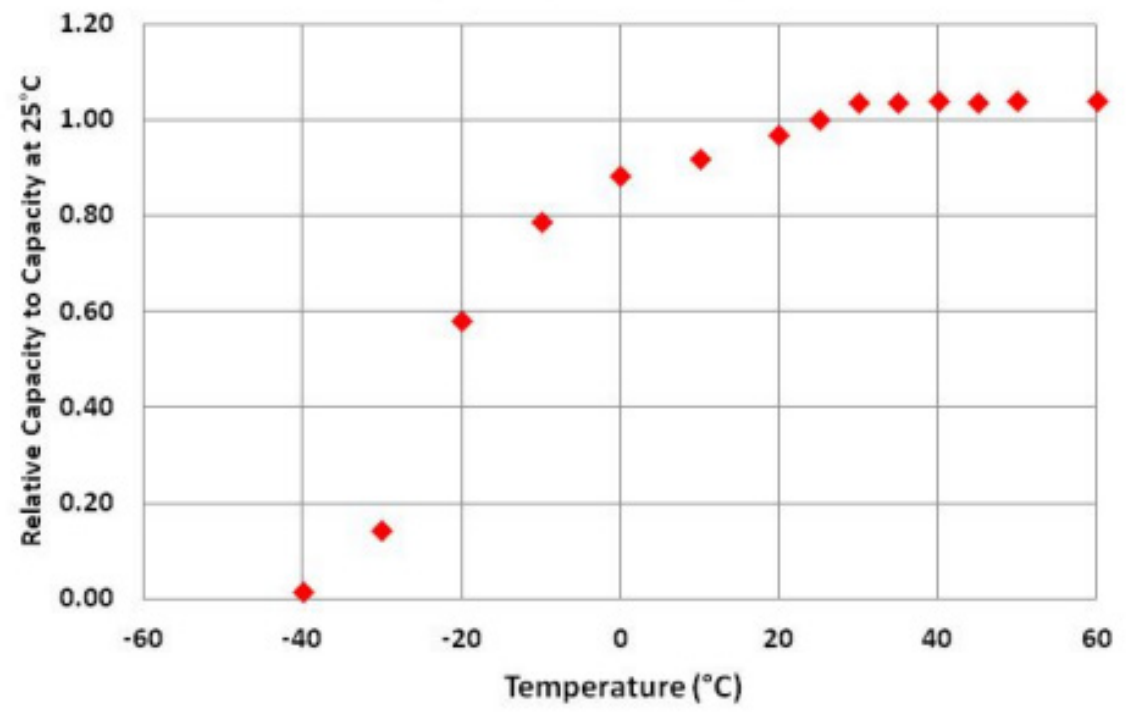

Figure 15. Effects of ambient temperature on LFP battery capacity

Source: (Pesaran, Santhanagopalan, and Kim 2013)

- Weather:

- In flood zones, it is important for safety that the charging equipment is fully floodproofed or located outside the likely flood area.

- Driving on packed snow raises the height of the bus, which can affect charging station clearance. King County Metro in Seattle experienced this issue and installed clearance requirement signs, warning striping, and restriction bars for the charging lane to warn tall vehicles not to enter. In the long term, the agency will add a method of height adjustment for the charging apparatus (NASEM 2018). 


\subsection{Fleet, Route, and Infrastructure Planning}

After analyzing possible routes, agencies will want to identify route options that optimize BEB deployment. The best possible routes take advantage of positive variables (e.g., close proximity to transformers/charging locations, frequent stops that maximize regenerative breaking, adequate route overlap) and avoid negative variables (e.g., long deadhead, common interruptions, dense traffic, steep grades) when possible. Other route and location variables are also considered, and together produce range requirements for the BEBs.

When choosing the bus, charging infrastructure, and battery configuration required to meet the needs of the identified routes, these selections must be considered holistically. These considerations entail identifying the most relevant questions and understanding that a change to one variable impacts the others.

\subsubsection{Range Requirements}

For range requirements in particular, these questions can include:

- What charging method or combination of charging methods would best satisfy the route/range needs?

- What bus size (length) would best suit route/passenger needs?

- How many buses are needed/planned for purchase?

- What SOC range for battery charge/discharge does the agency want to use?

- What bus auxiliaries are necessary to satisfy route needs?

- What battery size would satisfy these bus and charging needs?

- How will the weight of the chosen battery size and anticipated passenger load affect efficiency and range?

\subsubsection{Electricity Rate Structure}

When choosing charging structure, electricity rate structure must also be considered:

- Are there multiple electricity rate structure options? Which rate structure option works best for chosen charging method?

- If there are no rate structure choices, which charging method best fits the existing electricity rate structure?

\subsubsection{Charging Installations}

When choosing the number of charging installations and where to locate them, consider:

- With the range requirements from a given battery/bus/charger configuration and the range impacts via route variables, how much EVSE is needed to support the BEB fleet?

- Approximately where do charging installations need to be located to support these range requirements?

- Where are the best EVSE locations based on transit needs?

- Where are the best EVSE locations based on access to the electrical grid and grid infrastructure capacity? What grid upgrades will be necessary? Can the charging installation be moved to reduce the number and severity of grid upgrades that would be required?

- Who owns the land of possible EVSE locations? How will the real estate be leased or purchased?

- How much EVSE is needed at each location? Will the EVSE at the same location be used simultaneously, and if so, what is the impact on electric utility demand charges? 
- Will selected EVSE placements support BEB expansions (if that is a goal)?

- Is the EVSE placement in safe and reliable locations (e.g., away from floodplains, dense traffic, unstable trees, etc.)?

Stakeholder collaborations between the transit agency, utility company, city planners, construction companies, and city officials will be necessary to adequately answer some of these questions. When decisions are made to collectively satisfy the above questions, the costs may be evaluated for the chosen configuration. Any further adjustments can then be made, costs reevaluated, and configurations compared. This cycle of evaluation and comparison can continue until the most cost-effective decisions are made. Figure 16 graphically shows this process.

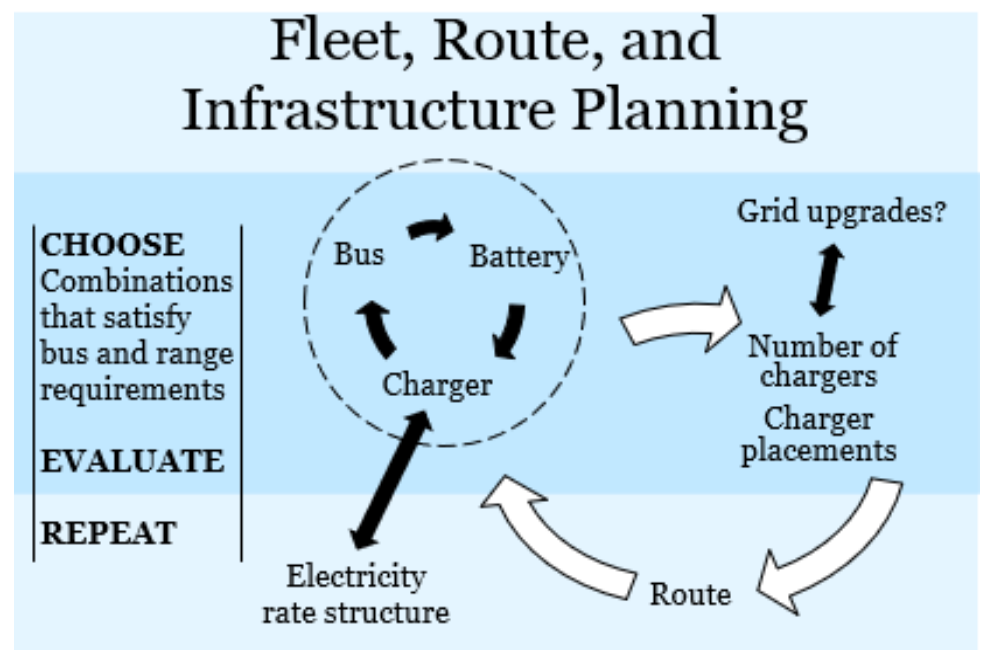

Figure 16. Fleet, route, and infrastructure planning

\subsection{Deployment Preparation}

Once crucial fleet, route, and infrastructure decisions are made, preparation for physical deployment can begin. Bus procurement and EVSE installation can be lengthy processes; as an example, the Center for Transportation and the Environment suggests budgeting about a year for the entire process of installing on-route infrastructure (Bigelow 2017), and bus procurement timelines vary depending on the degree of BEB OEM back orders. For example, the Washington State Department of Enterprise Services contracts allow up to 24 months from order date to bus delivery (Farley 2018). Charging infrastructure installation occurs in close collaboration with utilities, city planners, and permitting bodies, and can take months or even years if large grid upgrades are required.

Introduction of electric charging, especially for on-route charging, will likely require bus scheduling adjustments in the form of increased dwell time (the time a bus stays at a bus stop) or changes in layover times to accommodate charging needs. Schedules may need to be adjusted seasonally as well, depending on HVAC use and the corresponding range reduction.

As discussed in Section 5, training could be conducted in partnership with BEB OEMs and can be implemented during this preparatory period, although some training will require the physical presence of buses. In addition, some trainings will need to be coordinated between first responders and bus operators to ensure streamlined response to BEB-specific emergencies. Formulating backup plans in case of grid outages is another way agencies can prepare for BEB implementation. 
Continued, clear communication with stakeholders will help prepare for BEB deployment. Public education on the benefits and differences of BEBs promotes public understanding, acceptance, and enthusiasm. Specifically, ensuring bus riders understand docking procedures and basic BEB safety can reduce confusion and smooth the BEB transition.

\subsection{Deployment and Evaluation}

Once BEBs are placed in service, gathering data and tracking the key performance indicators established in Section 8.1 will allow for consistent evaluation. Data loggers and charge management systems, available from BEB OEMs, can help track metrics like driving performance, SOC, and emissions. Comparing actual costs and performance to expected cost and performance goals will help guide deployment and identify any necessary adjustments.

It is important to identify and track key indicators that identify the degree of community integration and support for BEBs, and whether the community sees BEB deployment as successful. Elements of this public opinion can include passenger reaction, driver satisfaction, BEB deployment comprehension. Public support can help drive future BEB expansion and increase government support, as well as normalize the concept of widespread vehicle electrification. 
Case Study 4. Bueno Aires, Argentina

\section{Electric Buses Pilot Test in Bueno Aires, Argentina}

From May 17, 2019, to May 16, 2020, two electric buses circulated on Line 59 in Buenos Aires, Argentina. The BEBs were Yutong brand, model ZK6128BEVG (324kWh capacity), and had a manufacturer estimate range of $250 \mathrm{~km}$. A charging station with a nominal power of $150 \mathrm{~kW}$ was also installed (the power contracted from the distribution company is $170 \mathrm{~kW}$ ).

\section{Technical and Operational Evaluation}

- The average energy consumption of both buses throughout the period was $1.01 \mathrm{kWh} / \mathrm{km}$. Considering the inherent losses of the charging process of $13.6 \%$, the real consumption from the charging station was 1.17 $\mathrm{kWh} / \mathrm{km}$.

- Minimum ranges for Buses 1 and 2 were $223 \mathrm{~km}$ and $195 \mathrm{~km}$, respectively. This difference is due, at least in part, to the way the buses were driven, which highlights the need for training drivers. Permanent monitoring will allow for identifying which drives need training.

- After a year of operation, the batteries degraded. Bus 1 and Bus 2 have reduced their capacities by $2.7 \%$ and $4.1 \%$, respectively.

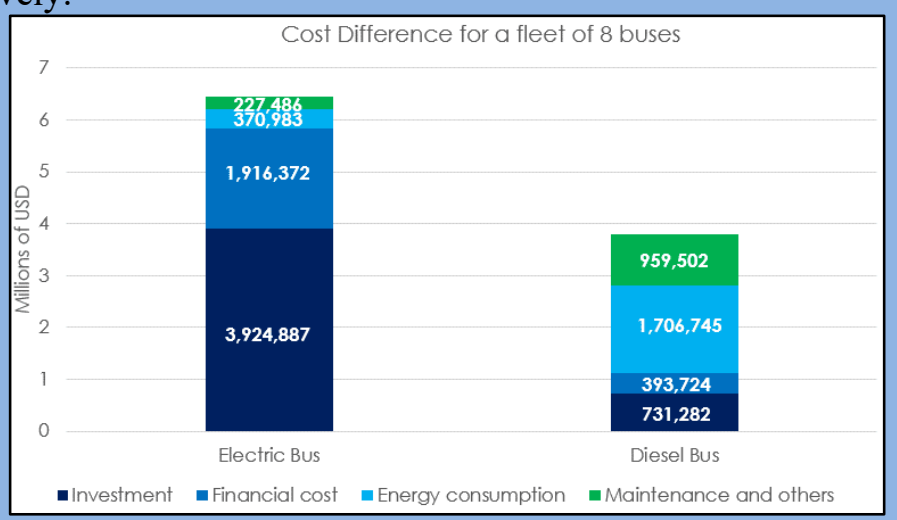

Figure 17. Cost difference by technology resulting from the financial feasibility evaluation for the Base Scenario

\section{Economic and Environmental Evaluation}

In the Base Scenario (current conditions for pilot analysis), the electric buses project is not economically attractive for investors. The capital cost of electric buses compared to diesel buses is $\$ 331,060$ higher per bus over 16 years. This difference is the result of the high capital investment and the associated financial cost (Figure 17). For conventional buses, the greatest costs are fuel and maintenance.

During 10 months of operation, $\mathrm{CO}_{2}$ emissions decreased from approximately 140.2 to 53.6 tons, representing a $62 \%$ reduction.

\section{Conclusions}

In this pilot project, the buses have satisfactorily completed the operation. By using battery recharging during the day, the buses transported passengers and traveled the necessary distance. This technology has been well received by passengers and drivers. A decrease in range is expected due to battery degradation. In Buenos Aires, energy consumption is impacted by the driver's operating style, the ambient temperature, the number of passengers carried, and the average speed of the trip. Although variable operating costs are lower, the upfront cost of BEBs constitutes a significant barrier.

Source: Asociacion Sustentar (Carolina Chantrill 2020) 


\subsection{Summary}

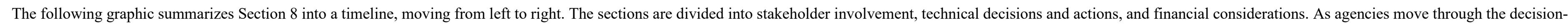
making process, it is important to consult cost prediction models and stakeholder opinions. This graphic shows the general flow of BEB project execution and does not correspond to a specific timeline.

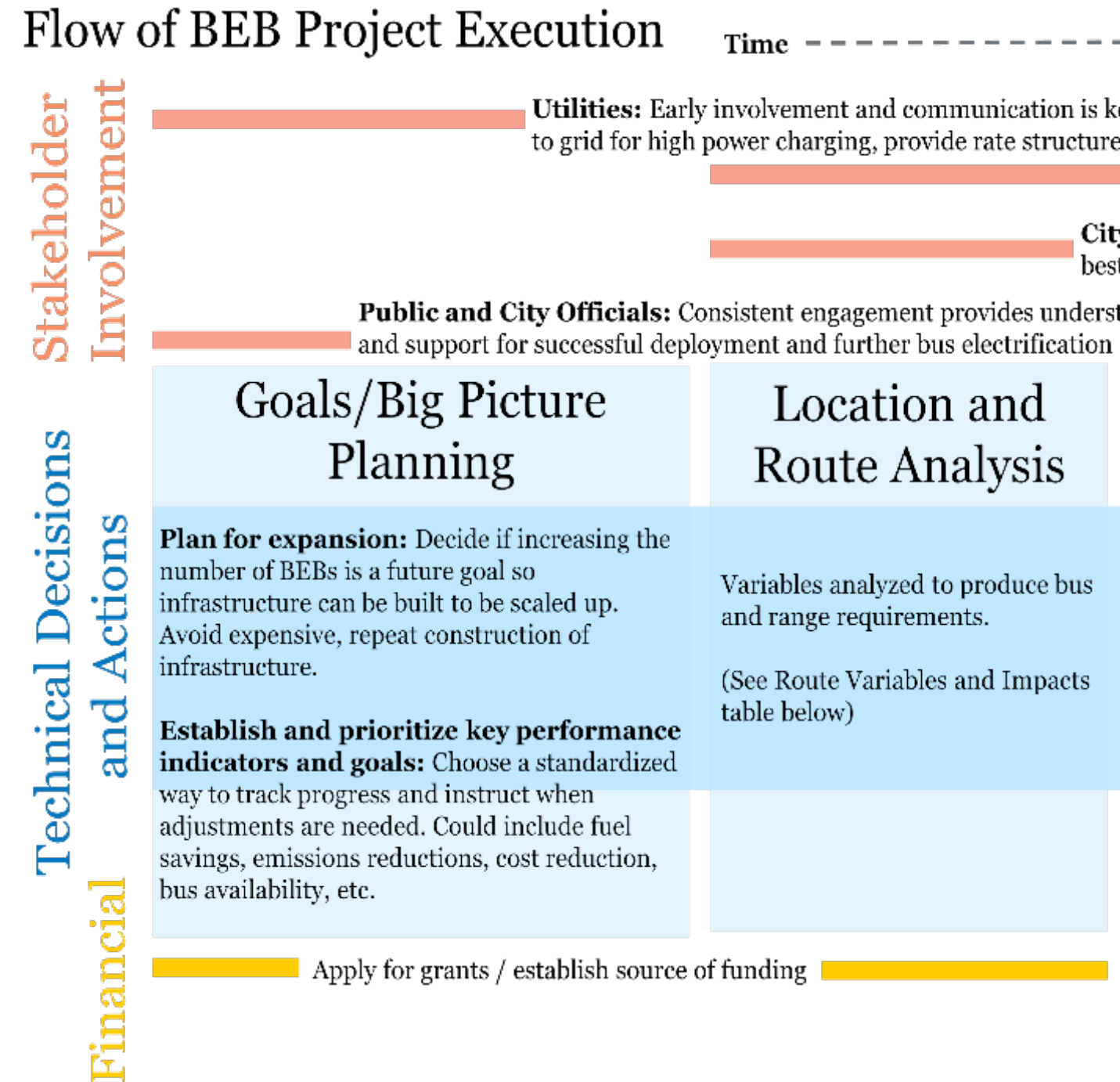

Bus OEMS: Can have a varying range of involvement: route analysis, training drivers and maintenance staff, and advising on bus/battery/charger combinations.

City Planners and Construction Companies: Identification of the

First Responders: Training on how

to respond to BEB specific hazards Infrastructure Planning

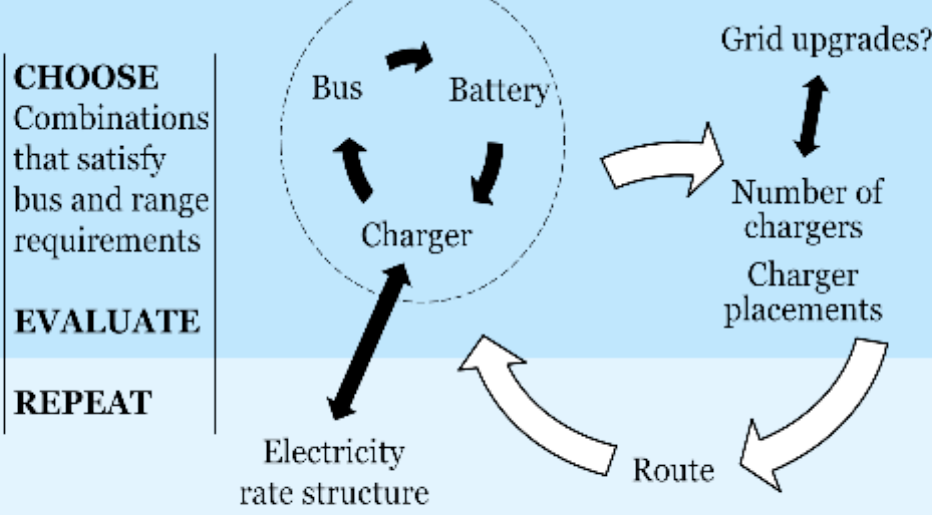

CHOOSE: Financing method, warranty

Model / calculate predicted costs from choices made above. Adjust choices and repeat as necessary. leet, Route, and

\section{Deployment \\ Preparation}

Adjust schedules: Allow for added times at charging stops or bus swap. May vary by season.

Obtain buses and install chargers

Training: Instruct drivers on difference. of BEBs compared to diesel buses, i.e. how to drive efficiently to reserve battery power and how to dock properly. Train maintenance.

\section{Deployment and} Evaluation

\section{Place BEBs in service}

Track previously established key performance indicators Make adjustments as needed

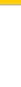




\section{Conclusion}

Modern BEBs are a growing mode of transportation with many benefits, including lower fuel costs, lower maintenance costs, improved performance, lower emissions, and increased energy security compared to incumbent bus technologies. Despite these benefits, overcoming the barriers to BEB adoption will require new approaches to transit planning and bus implementation. Some of the challenges include financial cost, new planning burdens, BEB ranges that are heavily impacted by many external factors, and unfamiliarity with BEB technology.

Well-defined goals for procurement and performance can provide a solid basis for planning BEB operation, but thorough analysis is needed to produce successful BEB deployment that satisfies the needs of the transit agency and the public. This long-term planning may include developing mission goals, outlining key performance indicators, engaging stakeholders, and identifying funding sources. Once the plan has been established, it is key to evaluate the available technology and route options in the context of those overall goals.

There is a high degree of interdependence between various technology combinations and route planning decisions. The main components of a BEB include bus structure, the battery storage system, and charging infrastructure; this guidebook explores the interrelated nature of these components as it relates to BEB deployment decisions. Battery and charging strategy selections are heavily tied to each other, and charging infrastructure also impacts electric utilities and the grid. Engaging utilities early is crucial for successful BEB implementation, as BEB refueling requires many considerations that affect the grid, and utility decisions can likewise have a significant impact on the value proposition of BEB investments. Electricity rate structures and the potential need for grid infrastructure upgrades are major factors for any BEB project. These technical factors also inform (and are informed by) the route requirements of the desired BEBs. Detailed analysis is key to optimizing technology selection and route design for BEBs, including such factors as:

- Physical route characteristics (i.e., route length, start/stop frequencies, and grade)

- Bus operation and route variables (i.e., road dimensions, bus speeds, and operation schedules)

- Charging and route variables (i.e., layovers, traffic patterns and density and access to land)

Transit staff will need training and capacity building in order to safely and effectively maintain and operate BEBs. Safety training topics include codes, standards, regulations, and testing to ensure the wellbeing of the operator and the public. Operational trainings are necessary too, as suboptimal operation of BEBs can affect the bus range and charging efficiency. In addition to training, bus tests, charging infrastructure inspection, and emergency preparedness plans are key practices for ensuring safety.

BEBs have high upfront costs $(\$ 887,308)$ compared to diesel buses $(\$ 445,000)$; however, the lower operations and maintenance costs for BEBs (about $\$ 0.64 / \mathrm{mile}$ vs. $\$ 0.88 / \mathrm{mile}$ ) often lead to net savings over the vehicle's lifetime. There are also many funding and financing options that support BEB purchases, including FTA grants, the U.S. Volkswagen settlement trust, state incentives, leasing options (many of which are from bus OEMs), and green or climate bonds.

Preparing for BEB deployment can be a lengthy and involved process, but it is important that all considerations are addressed. As seen in Table 6's summary of international case studies, various countries have addressed these considerations and made significant strides toward BEB implementation and deployment. While BEBs possess significant potential to reduce urban air pollution, reduce greenhouse gas emissions, reduce fuel and maintenance costs, and improve quality of public transit, issues such as high upfront costs and complex planning stand as barriers to widespread implementation. 
This guidebook aids decision makers by detailing the planning process and basic technologies that define a successful BEB project.

Table 6. International Case Study Results

\begin{tabular}{|c|c|}
\hline City and Country & Case Study Results \\
\hline Bogotá, Colombia & $\begin{array}{l}\text { Bogotá Integrated Public Transport System decided to incorporate electric buses into } \\
\text { fleet of } 483 \text { zonal buses to reduce pollution in their city. This incorporation of e-buses } \\
\text { is expected to increase stewardship, increase payments of tickets, and create a sense } \\
\text { of ownership and co-responsibility in the use of these buses. Although this program is } \\
\text { still in developmental stages, Bogotá officials expect it to be a benchmark for other } \\
\text { cities in Colombia to implement BEBs. }\end{array}$ \\
\hline $\begin{array}{l}\text { Mexico City and } \\
\text { León, Mexico }\end{array}$ & $\begin{array}{l}\text { NREL conducted a technical feasibility study using the FASTSim model on two } \\
\text { routes in León and one route in Mexico City. The results showed that BEBs that can } \\
\text { serve the selected routes are commercially available and are more energy efficient } \\
\text { compared to the conventional diesel buses in dense, urban environments with many } \\
\text { stops. }\end{array}$ \\
\hline $\begin{array}{c}\text { Buenos Aires, } \\
\text { Argentina }\end{array}$ & $\begin{array}{l}\text { Buenos Aires launched a successful BEB pilot project from May } 2019 \text { to May } 2020 \text {. } \\
\text { Results showed that energy consumption was impacted by the driver's operating } \\
\text { style, ambient temperature, the number of passengers on board, and the average speed } \\
\text { of the trip. While operating costs were lower, upfront costs are still a significant } \\
\text { barrier to further implementation. }\end{array}$ \\
\hline Santiago, Chile & $\begin{array}{l}\text { The Santiago, Chile Bus Fleet Business Model was created to replace aging buses } \\
\text { with electric buses. The model showed the relationship between fleet providers and } \\
\text { bus operators and how loans provided by the government can help reduce financial } \\
\text { risks, lowering credit rates and funding costs. After conducting simulations based on } \\
\text { real BEB performance and route features, results showed that more than } 70 \% \text { of the } \\
\text { routes tested can be operated on a single BEB charge. In addition, modeling showed } \\
\text { significant emissions reductions from BEB adoption and the city developed targets to } \\
\text { replace more than } 5,000 \text { buses by } 2022 \text {. }\end{array}$ \\
\hline
\end{tabular}




\section{References}

ANSI. "Introduction to ANSI.” American National Standards Institute. August 23, 2018. https://www.ansi.org/about_ansi/introduction/introduction?menuid=1.

American Public Transportation Association. "2020 Public Transportation Vehicle Database.” American Public Transportation Association. June 10, 2020. https://www.apta.com/research-technicalresources/transit-statistics/vehicle-database/.

Austin, Ryan. “SAE Updates J2954 Wireless Charging Standards for EVs up to $11 \mathrm{Kw.”} \mathrm{Charged:}$ Electric Vehicle Magazine. May 6, 2019. https://chargedevs.com/newswire/sae-updates-j2954wireless-charging-standards-for-evs-up-to-11-kw/.

AVTA. 2018. "Electric Bus Fleet Conversion.” January 2018. http://www.avta.com/index.aspx?page $=482$.

AVTA. 2018a. “Antelope Valley Transit Authority Business Plan.” Antelope Valley Transit Authority. June 10, 2020. http://www.avta.com/modules/showdocument.aspx?documentid=1618.

Bigelow, Erik. 2017. "Battery Electric Buses 101.” Presented at the APTA Sustainability Workshop, Minneapolis, MN. https:/www.apta.com/wp-content/uploads/Resources/mc/ sustainability/previous/2017sustainability/presentations/Presentations/Battery-Electric\% 20Buses\%20101\%20-\%20Erik\%20Bigelow.pdf

BloombergNEF. 2018. "Electric Buses in Cities: Driving Towards Cleaner Air and Lower $\mathrm{CO}_{2}$." Media. BloombergNEF (blog). April 10, 2018. https://about.bnef.com/blog/electric-buses-cities-drivingtowards-cleaner-air-lower-co2/.

Bordoff, Jason. 2019. "Congressional Testimony Before the Committee on Energy and Natural Resources.” October 17, 2019. https://www.energypolicy.columbia.edu/sites/default/files/fileuploads/Bordoff-SPR-Testimony_CGEP_Final.pdf

Bosch Mobility Solutions. "EN | Bosch Regenerative Braking.” October 10, 2014. https://www.youtube.com/watch?v=pqRlkAYLDZs.

Brotherton, Tom, and Jean-Baptiste Gallo. 2014. E-Truck Performance in Cold Weather. Pasadena, CA: CALSTART. https://calstart.org/wp-content/uploads/2018/10/E-Truck-Performance-in-ColdWeather.pdf.

Bryan, Chris, and Tanushree Pillai. 2018. "Translink Gives Green Light to Green Bonds.” The Buzzer Blog (blog). October 9, 2018. https://buzzer.translink.ca/2018/10/translink-gives-green-light-togreen-bonds/.

C40. 2019. "Fossil Fuel Free Streets Declaration.” C40 Cities. 2019. https://www.c40.org/other/fossilfuel-free-streets-declaration.

DOE. n.d. "Fuel Conversion Factors to Gasoline Gallon Equivalents (GGE)." U.S. Department of Energy. September 9, 2020. https://epact.energy.gov/fuel-conversion-factors

California HVIP. "Hybrid and Zero-Emission Truck and Bus Voucher Incentive Project (HVIP).” California HVIP. September 3, 2020. https://www.californiahvip.org/. 
CARB. 2018. Appendix D: Total Fuel Costs. Sacramento, CA: California Air Resources Board. https://www.arb.ca.gov/regact/2018/ict2018/appd.pdf.

CARB. 2017. Appendix F-2: Bus Price Projections. California Air Resources Board. https://ww3.arb.ca.gov/regact/2018/ict2018/appf-2.pdf.

CARB Calculator. 2018. Battery Electric Truck and Bus Charging Cost Calculator. California Air Resources Board. https://www.arb.ca.gov/msprog/actruck/tools/chargecalc.xlsm.

CARB. 2016a. Advanced Clean Transit Battery Cost for Heavy-Duty Electric Vehicles. Discussion Draft. Sacramento, CA: California Air Resources Board.

https://www.arb.ca.gov/msprog/bus/battery_cost.pdf.

CARB. 2016. "Literature Review on Transit Bus Maintenance Cost." California Environmental Protection Agency. https://ww2.arb.ca.gov/sites/default/files/2020-

06/Appendix \%20G\%20Literature \%20Review\%20on\%20Transit\%20Bus\%20Maintenance $\% 20 \mathrm{C}$ ost.pdf.

CARB. 2017a. "5th Innovative Clean Transit Workgroup Meeting." Presented at the California Air Resources Board, Sacramento, California, June 26, 2017. https://ww2.arb.ca.gov/sites/default/files/2020-06/170626Meeting\%20Summary.pdf.

CDPHE. 2017. Proposed Beneficiary Mitigation Plan Volkswagen, Audi, and Porsche Clean Air Act Settlements. Denver, CO: Colorado Department of Public Health and Environment. https://docs.google.com/viewer?url=https $\% 3 \mathrm{~A} \% 2 \mathrm{~F} \% 2 \mathrm{Fwww}$. colorado.gov $\% 2 \mathrm{Fpacific} \% 2 \mathrm{Fsites} \%$ 2Fdefault\%2Ffiles\%2FAP_VW_Beneficiary_Mitigation_Plan.pdf.

CHAdeMO. 2019. “CHAdeMO Protocol.” https://www.chademo.com/.

Choose Energy. 2018. "Electricity Rates by State in 2018." Choose Energy. August 1, 2018. https://www.chooseenergy.com/electricity-rates-by-state/.

Citizens Utility Board (CUB). 2020. "EV for All: Electrifying Transportation in Low-Income Communities." https://www.citizensutilityboard.org/wp-content/uploads/2020/06/EV-for-All.pdf.

Climate Policy Initiative. 2018. “The Global Innovation Lab for Climate Finance.” Background. 2018. https://climatepolicyinitiative.org/climatefinancelab/background/.

Coney, Kamyria, Karlynn Cory, and Alexandra Aznar. 2020. Technical Evaluation of Battery Electric Bus Potential in Mexico City and León, Mexico. NREL/TP-7A40-76815. Golden, CO: NREL. https://doi.org/10.2172/1677435.

Cooper, Erin, Erin Kenney, Juan Miguel Velasquez, Xiangyi Li, and Thet Hein Tun. 2019. Costs and Emissions Appraisal Tool for Transit Buses. Washington, D.C.: World Resources Institute. https://www.wri.org/publication/transit-buses-tool.

CTA. “CTA Expands Electric Bus Fleet.” Mass Transit. June 18, 2018. http://www.masstransitmag.com/press release/12417340/cta-expands-electric-bus-fleet.

Daniels, Lynn, and Brendan O’Donnell. 2019. Seattle City Light: Transportation Electrification Strategy Report. Boulder, CO: Rocky Mountain Institute. https://rmi.org/insight/seattle-city-light/. 
DOE Clean Cities. 2012. Plug-In Electric Vehicle Handbook for Fleet Managers. DOE/GO-1020123273. Washington, D.C.: U.S. Department of Energy. https://www.afdc.energy.gov/pdfs/pev handbook.pdf.

DOE Electric Cars. "Where the Energy Goes: Electric Cars.” www.fueleconomy.gov. June 10, 2020. https://www.fueleconomy.gov/feg/atv-ev.shtml.

DOE Gasoline Vehicles. "Where the Energy Goes: Gasoline Vehicles.” www.fueleconomy.gov. June 10, 2020. https://www.fueleconomy.gov/feg/atv.shtml.

DOT. 2012. TIGER Discretionary Grant Program. U.S. Department of Transportation. https://www.transportation.gov/sites/dot.gov/files/docs/TIGER_DISCRETIONARY_GRANT_P ROGRAM.pdf.

EIA. 2018. “U.S. Petroleum Flow, 2018.” U.S. Energy Information Administration. https://www.eia.gov/todayinenergy/detail.php?id=40752

EIA Gasoline and Diesel. "Gasoline and Diesel Fuel Update.” Energy Information Administration. August 22, 2018. https://www.eia.gov/petroleum/gasdiesel/.

EIA Operating Data. “U.S. Electric System Operating Data." U.S. Energy Information Administration. August 2, 2016. https://www.eia.gov/realtime_grid/\#/summary/demand?end=20160802\&start=20160702.

Eliptic. "Are Buses with a Diesel-Powered Heater True Zero-Emission Buses?| Civitas Eliptic Project." Eliptic - Electrification of Public Transport in Cities. December 13, 2017. http://www.elipticproject.eu/news/are-buses-diesel-powered-heater-true-zero-emission-buses.

Elkind, Ethan N., Sean Hecht, Cara Horowitz, and Steven Weissman. 2014. Reuse and Repower: How to Save Money and Clean the Grid with Second-Life Electric Vehicle Batteries. UCLA Law $\backslash$ Berkeley Law. https://www.law.berkeley.edu/files/ccelp/Reuse and Repower_-Web_Copy.pdf.

Engel, Hauke, Russell Hensley, Stefan Knupfer, and Shivika Sahdev. 2018. "The Basics of ElectricVehicle Charging Infrastructure | McKinsey \& Company.” August 16, 2018. https:/www.mckinsey.com/industries/automotive-and-assembly/our-insights/charging-aheadunderstanding-the-electric-vehicle-infrastructure-challenge.

Engel, Len. “AVTA's Journey to Fleet Electrification.” Presented at the BusCon, Indianapolis, September 11, 2017. https://eventsimages.bobitstudios.com/upload/pdfs/bcs/2017/speaker-presentations/alook-at-conductive-inductive-charging-of-electric-buses-len-engel-91217-945am.pdf.

EPA. 2017. Attachment A: Environmental Mitigation Trust Agreement for State Beneficiaries. Washington, D.C.: United States Environmental Protection Agency. https://www.epa.gov/sites/production/files/2017-10/documents/statebeneficiaries.pdf.

EPA. 2018. Clean Diesel Funding Assistance Program FY 2018. Washington, D.C.: Environmental Protection Agency. https://www.epa.gov/sites/production/files/2018-04/documents/clean-dieselfunding-assistance-program-fy-2018 0.pdf. 
EPA. 2018a. Emission Factors for Greenhouse Gas Inventories. Washington, D.C.: Environmental Protection Agency. https://www.epa.gov/sites/production/files/2018-03/documents/emissionfactors mar 2018 0.pdf.

Estrategia Nacional de Calidad del Aire (ENCA). "National Air Quality Strategy." Secrettaria de Medio Ambiente y Recursos Naturales (SEMARNAT), May 2017. https://www.cccjac.org/uploads/9/1/9/2/91924192/semarnat_national_aq_strategy.pdf.

Eudy, Leslie, and Matthew Jeffers. 2017. Foothill Transit Battery Electric Bus Demonstration Results: Second Report. NREL/TP-5400-67698. Golden, CO: NREL. https://doi.org/10.2172/1369137.

Eudy, Leslie, Robert Prohaska, Kenneth Kelly, and Matthew Post. 2016. Foothill Transit Battery Electric Bus Demonstration Results. NREL/TP-5400-65274. Golden, CO: NREL. https://doi.org/10.2172/1237304.

European Commission. 2016. ZeEUS EBus Report: An Overview of Electric Buses in Europe. UITP, the International Association of Public Transport. https://zeeus.eu/uploads/publications/documents/zeeus-ebus-report-internet.pdf.

—. 2018. "State Aid: Commission Approves $€ 70$ Million Public Support Scheme for Electric Buses and Charging Infrastructure in Germany." European Commission. February 25, 2018. https://ec.europa.eu/commission/presscorner/detail/en/IP 18 1222.

Farley, Keith. 2018. "Personal Correspondence with Keith Farley, Contracts Specialist at Washington Department of Enterprise Services.” August 22, 2018.

FTA. 2020. "U.S. Department of Transportation Announces $\$ 130$ Million in Grants for Nationwide Projects to Expand Advanced, Efficient Bus Technologies | FTA.” June 2020. https://www.transit.dot.gov/about/news/us-department-transportation-announces-130-milliongrants-nationwide-projects-expand.

FTA. 2017. "Bus Testing.” Federal Transit Administration. February 22, 2017. https://www.transit.dot.gov/research-innovation/bus-testing.

FTA. 2017a. Conducting Pre-Award and Post-Delivery Audits for Rolling Stock Procurements. Text Report 0106. https://www.transit.dot.gov/regulations-and-guidance/buy-america/conducting-preaward-and-post-delivery-audits-rolling-stock.

FTA. 2015. "Bus \& Bus Facilities Infrastructure Investment Program.” FTA. December 21, 2015. https://www.transit.dot.gov/bus-program.

FTA. 2016. “TIGGER Program.” Federal Transit Administration. 2016. https://www.transit.dot.gov/funding/grants/tigger-program.

Gallo, Jean-Baptiste, Ted Bloch-Rubin, and Jasna Tomic. 2014. Peak Demand Charges and Electric Transit Buses. Washington, D.C.: U.S. Department of Transportation Federal Transit Administration.

GreenPower Motor Company. 2015. "Product Line.” GreenPower Bus. December 24, 2015. http://www.greenpowerbus.com/product-line/. 
Hanlin, Jason. "Battery Electric Buses Smart Deployment." Presented at the Zero Emission Bus Conference, November 30, 2016. http://www.cte.tv/wp-content/uploads/2016/12/5_Hanlin.pdf.

Harper, Charles, Gregory McAndrews, and Danielle Sass Byrnett. 2019. Electric Vehicles: Key Trends, Issues, and Considerations for State Regulators. Washington, D.C.: NARUC. https://pubs.naruc.org/pub/32857459-0005-B8C5-95C6-1920829CABFE.

Hodge, Cabell, and Anandhan. 2018. "Enabling a Transition to Electric Mobility in Public Transport Fleets: Policies and Enabling Environment." LEDS Global Partnership/Asia LEDS Partnership. Presented June 22, 2018. http://www.asialeds.org/wp-content/uploads/Clean-MobilityCommunity-of-Practice_Webinar-1_Presentation.pdf.

ICCT. 2018. "BYD Electric Vehicles.” International Council on Clean Transportation. September 9, 2020. https://theicct.org/sites/default/files/BYD\%20EV\%20SEDEMA.pdf.

IEA. "Global EV Outlook 2019: Scaling Up the Transition to Electric Mobility.” Informational. May 27, 2019. https://www.iea.org/reports/global-ev-outlook-2019.

IndyGo. "IndyGo Begins Building Largest Electric Bus Fleet in the Country!” IndyGo. April 22, 2015. https://www.indygo.net/inside-indygo/indygo-begins-building-largest-electric-bus-fleet-in-thecountry/.

Johnson, Caley. "Fuel Diversification to Improve Transportation Resilience: A Backgrounder." Senior Transportation Market Analyst Transportation Fuel Resilience in Tampa Bay Workshop. March 25, 2019. https://afdc.energy.gov/files/u/publication/fuel_diversification_for_resiliency.pdf.

Johnson, Caley, Erin Nobler, Leslie Eudy, and Matthew Jeffers. 2020. Financial Analysis of Battery Electric Transit Buses. NREL/TP-5400-74832. Golden, CO: NREL. https://afdc.energy.gov/files/u/publication/financial_analysis be transit buses.pdf.

Kim, Jeongyong, Inho Song, Woongchul Choi, Jeongyong Kim, Inho Song, and Woongchul Choi. 2015. "An Electric Bus with a Battery Exchange System." Energies 8 (7): 6806-19. https://doi.org/10.3390/en8076806.

Kontou, Andriana, and John Miles. 2015. "Electric Buses: Lessons to Be Learnt from the Milton Keynes Demonstration Project." Procedia Engineering 118 (January): 1137-44. https://doi.org/10.1016/j.proeng.2015.08.455.

Kunith, Alexander, Roman Mendelevitch, Anne Kuschmierz, and Dietmar Goehlich. 2016. Optimization of Fast Charging Infrastructure for Electric Bus Transportation - Electrification of a City Bus Network.

LADWP. "Facts \& Figures." Los Angeles Department of Water and Power. August 20, 2018. https://www.ladwp.com/ladwp/faces/ladwp/aboutus/a-power/a-p-factandfigures? adf.ctrlstate=t69uim9nr_21\&_afrLoop=27416359070490.

Laver, Richard, Donald Schneck, Douglas Skorupski, Stephen Brady, Laura Cham, and Booz Allen Hamilton. 2007. "Useful Life of Transit Buses and Vans." FTA-VA-26-7229-07.1. Washington, D.C.: U.S. Department of Transportation Federal Transit Administration. https://www.transitwiki.org/TransitWiki/images/6/64/Useful_Life_of_Buses.pdf. 
Learn Engineering. How Does an Electric Car Work? | Tesla Model S. May 30, 2017. https://www.youtube.com/watch?v=3SAxXUIre28.

Eudy, Leslie, and Matthew Jeffers. 2017. Foothill Transit Battery Electric Bus Demonstration Results: Second Report. NREL/TP-5400-67698. Golden, CO: NREL. https://doi.org/10.2172/1369137.

Leslie Eudy, and Matthew Jeffers. 2018. Zero-Emission Bus Evaluation Results: King County Metro Battery Electric Buses. FTA Report No. 0118. Golden, CO: National Renewable Energy Laboratory. https://www.transit.dot.gov/sites/fta.dot.gov/files/docs/researchinnovation/115086/zero-emission-bus-evaluation-results-king-county-metro-battery-electricbuses-fta-report-no-0118.pdf.

Li, Jing-Quan. 2016. "Battery-Electric Transit Bus Developments and Operations: A Review.” International Journal of Sustainable Transportation 10 (3): 157-69. https://doi.org/10.1080/15568318.2013.872737.

Long Jr, R. Thomas, Andrew F. Blum, Thomas J. Bress, and Benjamin R.T Cotts. 2013. Emergency Response to Incident Involving Electric Vehicle Battery Hazards. https://www.nfpa.org/Newsand-Research/Data-research-and-tools/Electrical/Emergency-Response-to-Incident-InvolvingElectric-Vehicle-Battery-Hazards.

LTI Bus Research and Testing Center. 2018. "Federal Transit Bus Test, Manufacturer: Nova Bus- a Division of Volvo Group Canada, Inc. Model: L920 LFSe Battery-Electric Bus.” Penn State. http://apps.altoonabustest.psu.edu/buses/493.

Lunz, Benedikt, Zexiong Yan, Jochen Bernhard Gerschler, and Dirk Uwe Sauer. 2012. "Influence of Plug-in Hybrid Electric Vehicle Charging Strategies on Charging and Battery Degradation Costs." Energy Policy 46 (July): 511-19. https://doi.org/10.1016/j.enpol.2012.04.017.

McKerracher, Colin, Dr. Ali Izadi-Najafabadi, Dr. Nikolas Soulopoulos, David Doherty, Dr. James Frith, Nick Albanese, Andrew Grant, et al. 2020. "Electric Vehicle Outlook 2020.” Financial, software, data and media. BloombergNEF. 2020. https://about.bnef.com/electric-vehicle-outlook/.

McLaren, J. “A Survey of U.S. Demand Charges: Clean Energy Group Webinar.” Golden, CO: National Renewable Energy Laboratory. September 19, 2017. https://www.nrel.gov/solar/assets/pdfs/2017us-demand-charges-webinar.pdf.

MTA. 2018. "MTA Testing 10 New, All-Electric Buses to Reduce Emissions \& Modernize Public Transit Fleet.” MTA. January 8, 2018. http://www.mta.info/news/2018/01/08/mta-testing-10-new-allelectric-buses-reduce-emissions-modernize-public-transit.

NASEM. 2018. Battery Electric Buses—State of the Practice. Washington, D.C.: The National Academies Press. https://www.nap.edu/download/25061.

New Flyer. 2018. “Xcelsior CHARGE.” New Flyer. https://www.newflyer.com/sitecontent/uploads/2018/03/Xcelsior-CHARGE-compressed.pdf.

NFPA. 2016. National Electrical Code ${ }^{\circledR} 2017$ Edition. NFPA 70. https://www.nfpa.org/codes-andstandards/all-codes-and-standards/list-of-codes-and-standards/detail?code $=70$. 
2018. "NFPA - Emergency Response Guides for Alternative Fuel Vehicles.” August 21, 2018. https://www.nfpa.org/Training-and-Events/By-topic/Alternative-Fuel-Vehicle-SafetyTraining/Emergency-Response-Guides.

Nightingale, Alaric. "Forget Tesla, It's China's E-Buses That Are Denting Oil Demand.” March 19, 2019. https://www.bloomberg.com/news/articles/2019-03-19/forget-tesla-it-s-china-s-e-buses-that-aredenting-oil-demand.

Nigro, Nick. "About the Settlement.” VW Settlement Clearinghouse (blog). August 13, 2018. https://vwclearinghouse.org/about-the-settlement/.

NREL. 2018. Future Automotive Systems Technology Simulator (FASTSim). NREL/FS-5400-71126. Golden, CO: National Renewable Energy Laboratory. https://www.nrel.gov/docs/fy18osti/71126.pdf.

Nunno, Richard. "Fact Sheet: Battery Electric Buses: Benefits Outweigh Costs." Environmental and Energy Study Institute. October 26, 2018. https://www.eesi.org/papers/view/fact-sheet-electricbuses-benefits-outweigh-costs.

O’Dea, Jimmy. "Electric vs. Diesel vs. Natural Gas: Which Bus Is Best for Climate?" Union of Concerned Scientists. July 19, 2018. https://blog.ucsusa.org/jimmy-odea/electric-vs-diesel-vsnatural-gas-which-bus-is-best-for-the-climate? ga=2.226102682.1843563386.1532023761$\underline{1843342382.1531829971 .}$.

OEERE. "DOE Fuel Cell Bus Analysis Finds Fuel Economy to Be 1.4 Times Higher than Diesel." Office of Energy Efficiency and Renewable Energy. November 30, 2016. https://www.energy.gov/eere/fuelcells/articles/doe-fuel-cell-bus-analysis-finds-fuel-economy-be14-times-higher-diesel.

Perner, A., and J. Vetter. "Lithium-Ion Batteries for Hybrid Electric Vehicles and Battery Electric Vehicles." In Advances in Battery Technologies for Electric Vehicles, edited by Bruno Scrosati, Jürgen Garche, and Werner Tillmetz, 173-90. Woodhead Publishing Series in Energy. Woodhead Publishing. https://doi.org/10.1016/B978-1-78242-377-5.00008-X.

Pesaran, Ahmad, Shriram Santhanagopalan, and Gi-Heon Kim. "Addressing the Impact of Temperature Extremes on Large Format Li-Ion Batteries for Vehicle Applications." Presented at the 30TH INTERNATIONAL BATTERY SEMINAR, Ft. Lauderdale, Florida, March 11, 2013. https://www.nrel.gov/docs/fy13osti/58145.pdf.

Pinto De Moura, Maria Cecilia, and David Reichmuth. 2019. "Inequitable Exposure to Air Pollution from Vehicles | Union of Concerned Scientists." Cambridge, MA: Union of Concerned Scientists. https://www.ucsusa.org/resources/inequitable-exposure-air-pollution-vehicles.

Prohaska, R., K. Kelly, and L. Eudy. 2016. "Fast Charge Battery Electric Transit Bus In-Use Fleet Evaluation.” In 2016 IEEE Transportation Electrification Conference and Expo (ITEC), 1-6. https://doi.org/10.1109/ITEC.2016.7520220.

Proterra. 2018. "Catalyst: 40 Foot Bus Performance Specifications.” Proterra. https://www.proterra.com/wp-content/uploads/2016/08/Proterra-Catalyst-Vehicle-Specs.pdf. 
Quarles, Neil, Kara M. Kockelman, and Moataz Mohamed. 2020. "Costs and Benefits of Electrifying and Automating Bus Transit Fleets.” Sustainability 12 (10): 3977. https://doi.org/10.3390/su12103977.

REN21. 2019. "Renewables 2019 Global Status Report.” ISBN 978-3-9818911-7-1. Paris: REN21 Secretariat. https://www.ren21.net/gsr-2019/.

Rogge, Matthias, Sebastian Wollny, and Dirk Uwe Sauer. 2015. "Fast Charging Battery Buses for the Electrification of Urban Public Transport-A Feasibility Study Focusing on Charging Infrastructure and Energy Storage Requirements.” Energies 8 (5): 4587-4606. https://doi.org/10.3390/en8054587.

RTA Transit. "Howard County Electric Bus Project: Interactive Electric Bus." RTA Transit. August 23, 2018. http://www.transitrta.com/interactive/.

SAE. 2018. "SAE International Releases New Specification (SAE J3068) for Charging of Medium and Heavy-Duty Electric Vehicles." SAE International. April 26, 2018. https://www.sae.org/news/press-room/2018/04/sae-international-releases-new-specification-saej3068-for-charging-of-medium-and-heavy-duty-electric-vehicles.

SCE. n.d. Charge Ready Transport: Clean Energy to Fuel Southern California's Medium- and HeavyDuty Fleets. Southern California Edison. https://www.sce.com/sites/default/files/inlinefiles/25\%20-\%20SCE_CRT_FactSheet_Final_4.16_rem post.pdf.

Shirk, Matthew, and Jeffrey Wishart. 2015. Effects of Electric Vehicle Fast Charging on Battery Life and Vehicle Performance. In. Vol. SAE Technical Paper 2015-01-1190. https://doi.org/10.4271/2015$\underline{01-1190 .}$.

Shuttleworth, Jennifer. "SAE Standards News: Conductive Automatic Charging Recommended Practice Nears Completion.” Automotive Engineering (June 2018).

Tomford, Kate. "Chicago Transit Authority (CTA) Electrification of Mass Transit." Presented at the NextGrid Illinois, February 14, 2018.

Translink. 2019. “Translink.” 2019. https://new.translink.ca/.

Trippe, A. E., R. Arunachala, T. Massier, A. Jossen, and T. Hamacher. 2014. "Charging Optimization of Battery Electric Vehicles Including Cycle Battery Aging." In IEEE PES Innovative Smart Grid Technologies, Europe, 1-6. https://doi.org/10.1109/ISGTEurope.2014.7028735.

UN Environment Programme. "The EMob Calculator." Informational. UN Environment Programme. Last modified August 26, 2020. https://www.unenvironment.org/resources/toolkits-manuals-andguides/emob-calculator.

WDES. 2018. "Contract Summary - Heavy-Duty Mass Transit Vehicles - Pricing and Ordering." Washington State Department of Enterprise Services. August 22, 2018. https://fortress.wa.gov/ga/apps/ContractSearch/ContractSummary.aspx?c=09214.

Vilnius. 2020. Lithuania's Fourth Biennial Report. Ministry of Environment of the Republic of Lithuania Climate Change Management Group. https://unfccc.int/sites/default/files/resource/BR4_2020_LT.pdf. 


\section{Appendix A. BEBs Available in the United States as of 2018}

Table A- 1. BEBs Available in the United States as of 2018

\begin{tabular}{|c|c|c|c|c|c|c|c|c|}
\hline Manufacturer & Model & $\begin{array}{l}\text { Drive } \\
\text { Train }\end{array}$ & $\begin{array}{l}\text { BEB } \\
\text { Size }\end{array}$ & $\begin{array}{l}\text { Charging } \\
\text { Infrastructure }\end{array}$ & $\begin{array}{l}\text { Battery } \\
\text { Type }\end{array}$ & $\begin{array}{l}\text { Battery Storage } \\
\text { Size (kWh) (As } \\
\text { advertised) }\end{array}$ & $\begin{array}{l}\text { Battery Storage } \\
\text { Size (kWh) From } \\
\text { State of the } \\
\text { Practice }^{1}\end{array}$ & $\begin{array}{l}\text { Range as } \\
\text { Advertised } \\
\text { (miles) }\end{array}$ \\
\hline BYD $^{2}$ & K7 & Unavailable & $30^{\prime}$ & $\begin{array}{l}80-\mathrm{kW} \text { Depot } \\
\text { Charge }\end{array}$ & LFP & 195 & 182 & 135 \\
\hline BYD $^{2}$ & K9 & Unavailable & $35^{\prime}$ & $\begin{array}{l}\text { 80-kW Depot } \\
\text { Charge }\end{array}$ & LFP & 350 & 324 & $\geq 230$ \\
\hline BYD $^{2}$ & K9S & Unavailable & $40^{\prime}$ & $\begin{array}{l}\text { 80-kW Depot } \\
\text { Charge }\end{array}$ & LFP & 500 & 324 & $\geq 255$ \\
\hline GILLIG $^{1}$ & Standard LF & Unavailable & $29^{\prime}$ & $\begin{array}{l}\text { Depot/On } \\
\text { Route }\end{array}$ & & Unavailable & 100 & Unavailable \\
\hline Greenpower $^{3}$ & EV250 & Unavailable & $30-32$ & Depot Charge & LFP & 210 & $210-478$ & $>175$ \\
\hline Greenpower $^{3}$ & EV300 & Unavailable & $35^{\prime}$ & Depot Charge & LFP & 260 & Unavailable & $>175$ \\
\hline Greenpower $^{3}$ & EV350 & Unavailable & $40^{\prime}$ & Depot Charge & LFP & 320 & Unavailable & $>185$ \\
\hline Greenpower $^{3}$ & EV 400 & Unavailable & $45^{\prime}$ & Depot Charge & LFP & 320 & Unavailable & $>185$ \\
\hline New Flyer ${ }^{4}$ & $\begin{array}{l}\text { Xcelsior } \\
\text { CHARGE }\end{array}$ & Unavailable & $35^{\prime}$ & $\begin{array}{l}150 \mathrm{~kW} \text { Depot/ } \\
300 \mathrm{~kW} \text { or } 450 \\
\mathrm{~kW} \text { On Route }\end{array}$ & NMC & $\begin{array}{l}\text { Rapid Charge: } \\
\text { 100/150/200, } \\
\text { Long Range } \\
\text { Charge: } 280,454\end{array}$ & Unavailable & Up to 260 \\
\hline New Flyer ${ }^{4}$ & $\begin{array}{l}\text { Xcelsior } \\
\text { CHARGE }\end{array}$ & Unavailable & $40^{\prime}$ & $\begin{array}{l}150 \mathrm{~kW} \text { Depot/ } \\
300 \mathrm{~kW} \text { or } 450 \\
\mathrm{~kW} \text { On Route }\end{array}$ & NMC & $\begin{array}{l}\text { Rapid Charge: } \\
\text { 100/150/200, } \\
\text { Long Range } \\
\text { Charge: } \\
\text { 280/454/545 }\end{array}$ & 99/198/297 & Up to 260 \\
\hline New Flyer ${ }^{4}$ & $\begin{array}{l}\text { Xcelsior } \\
\text { CHARGE }\end{array}$ & Unavailable & $60^{\prime}$ & $\begin{array}{l}150 \mathrm{~kW} \text { Depot/ } \\
300 \mathrm{~kW} \text { or } 450 \\
\mathrm{~kW} \text { On Route }\end{array}$ & NMC & $\begin{array}{l}\text { Rapid Charge: } \\
\text { 250, Long Range } \\
\text { Charge: } 640,818\end{array}$ & 250 & Up to 260 \\
\hline Nova Bus ${ }^{5}$ & LFSe & Unavailable & $40^{\prime}$ & $\begin{array}{l}\text { On Route } \\
\text { Charging } \\
\text { (inverted } \\
\text { pantograph) }\end{array}$ & NMC & 76 & 76 & 25 \\
\hline
\end{tabular}




\begin{tabular}{|c|c|c|c|c|c|c|c|c|}
\hline Manufacturer & Model & $\begin{array}{l}\text { Drive } \\
\text { Train }\end{array}$ & $\begin{array}{l}\text { BEB } \\
\text { Size }\end{array}$ & $\begin{array}{l}\text { Charging } \\
\text { Infrastructure }\end{array}$ & $\begin{array}{l}\text { Battery } \\
\text { Type }\end{array}$ & $\begin{array}{l}\text { Battery Storage } \\
\text { Size (kWh) (As } \\
\text { advertised) }\end{array}$ & $\begin{array}{l}\text { Battery Storage } \\
\text { Size (kWh) From } \\
\text { State of the } \\
\text { Practice }^{1}\end{array}$ & $\begin{array}{l}\text { Range as } \\
\text { Advertised } \\
\text { (miles) }\end{array}$ \\
\hline Proterra $^{6}$ & Catalyst FC & Prodrive & $35^{\prime}, 40^{\prime}$ & $\begin{array}{l}\text { On Route } \\
\text { Charging }\end{array}$ & LTO & 94 & $79-105$ & 55 \\
\hline Proterra $^{6}$ & Catlyst FC+ & Duopower & $35^{\prime}, 40^{\prime}$ & $\begin{array}{l}\text { On Route } \\
\text { Charging }\end{array}$ & LTO & 126 & $79-105$ & 87 \\
\hline Proterra $^{6}$ & Catlyst FC+ & Prodrive & $35^{\prime}, 40^{\prime}$ & $\begin{array}{l}\text { On Route } \\
\text { Charging }\end{array}$ & LTO & 126 & $79-105$ & 72 \\
\hline Proterra $^{6}$ & Catalyst XR & Duopower & $35^{\prime}, 40^{\prime}$ & $\begin{array}{l}\text { Depot/On } \\
\text { Route }\end{array}$ & LTO & 220 & $220-330$ & 164 \\
\hline Proterra $^{6}$ & Catalyst XR & Prodrive & $35^{\prime}, 40^{\prime}$ & $\begin{array}{l}\text { Depot/On } \\
\text { Route }\end{array}$ & LTO & 220 & $220-330$ & 136 \\
\hline Proterra $^{6}$ & $\begin{array}{l}\text { Catalyst } \\
\mathrm{XR}+\end{array}$ & Duopower & $35^{\prime}, 40^{\prime}$ & $\begin{array}{l}\text { Depot/On } \\
\text { Route }\end{array}$ & LTO & 330 & $220-330$ & 238 \\
\hline Proterra $^{6}$ & $\begin{array}{l}\text { Catalyst } \\
\mathrm{XR}+\end{array}$ & Prodrive & $35^{\prime}, 40^{\prime}$ & $\begin{array}{l}\text { Depot/On } \\
\text { Route }\end{array}$ & LTO & 330 & $220-330$ & 193 \\
\hline Proterra $^{6}$ & Catalyst E2 & Duopower & $35^{\prime}, 40^{\prime}$ & Depot Charge & LTO & 440 & $440-660$ & 305 \\
\hline Proterra $^{6}$ & Catalyst E2 & Prodrive & $35^{\prime}, 40^{\prime}$ & Depot Charge & LTO & 440 & $440-660$ & 251 \\
\hline Proterra $^{6}$ & Catalyst E2+ & Duopower & $35^{\prime}, 40^{\prime}$ & Depot Charge & LTO & 550 & $440-660$ & 367 \\
\hline Proterra $^{6}$ & Catalyst E2+ & Prodrive & $35^{\prime}, 40^{\prime}$ & Depot Charge & LTO & 550 & $440-660$ & 303 \\
\hline Proterra $^{6}$ & $\begin{array}{l}\text { Catalyst E2 } \\
\max \end{array}$ & Duopower & $35^{\prime}, 40^{\prime}$ & Depot Charge & LTO & 660 & $440-660$ & 426 \\
\hline Proterra $^{6}$ & $\begin{array}{l}\text { Catalyst E2 } \\
\max \end{array}$ & Prodrive & $35^{\prime}, 40^{\prime}$ & Depot Charge & LTO & 660 & $440-660$ & 350 \\
\hline
\end{tabular}


${ }^{1}$ (NASEM 2018)

${ }^{2}($ ICCT 2018)

3 (Green Power Motor Company 2015)

${ }^{4}$ (New Flyer 2018)

${ }^{5}$ (LTI Bus Research and Testing 2018)

(Proterra 2018)

NOTES: A. Lithium iron phosphate (LFP), lithium-titanate (LTO), and lithium nickel manganese cobalt oxide (NMC). B. All information in the above table comes from manufacturer website, as cited in the manufacturer column, except for the second battery storage column. 


\section{Appendix B. Charging Comparison}

There are many relative advantages and challenges to on-route versus depot charging - the major ones are captured in Table B.

Table B- 1. Comparison of On-Route and Depot Charging

\begin{tabular}{|c|c|c|}
\hline & Advantages & Drawbacks \\
\hline \multirow{6}{*}{ On-Route Charging } & Faster charge time & $\begin{array}{l}\text { Faster charging requires high power = high } \\
\text { impact on the energy grid, thus high } \\
\text { demand charges }\end{array}$ \\
\hline & $\begin{array}{l}\text { Smaller battery }=\text { less weight }= \\
\text { higher efficiency }\end{array}$ & $\begin{array}{l}\text { Less flexible: BEBs must stay on the route } \\
\text { with charging access. Charging locations } \\
\text { make it hard to adjust routes in the future }\end{array}$ \\
\hline & $\begin{array}{l}\text { Can run } 24 \text { hours with no long } \\
\text { break for charging }\end{array}$ & Expensive charging infrastructure \\
\hline & $\begin{array}{l}\text { Smaller battery = Battery } \\
\text { cheaper to buy and replace }\end{array}$ & $\begin{array}{l}\text { Daytime charging can mean expensive } \\
\text { time-of-use charges }\end{array}$ \\
\hline & $\begin{array}{l}\text { One fast charger can serve } \\
\text { multiple routes }\end{array}$ & $\begin{array}{l}\text { Land use/rights must be obtained at } \\
\text { charging locations. May not be owned by } \\
\text { transit agency }\end{array}$ \\
\hline & $\begin{array}{l}\text { Traffic flow at depot is similar } \\
\text { to diesel and would not require } \\
\text { reconfiguration }\end{array}$ & \\
\hline \multirow{7}{*}{ Depot Charging } & $\begin{array}{l}\text { Schedules do not need to change } \\
\text { to allow on-route charge }\end{array}$ & $\begin{array}{l}\text { Traffic flow may not be similar to diesel } \\
\text { due to increase used of bollards and } \\
\text { charging pedestals }\end{array}$ \\
\hline & Off-peak charging is cheaper & Longer charging time \\
\hline & $\begin{array}{l}\text { Less infrastructure and } \\
\text { installation }\end{array}$ & $\begin{array}{l}\text { Requires more space and more chargers at } \\
\text { the depot to charge many buses at once }\end{array}$ \\
\hline & $\begin{array}{l}\text { Simpler grid connection and } \\
\text { more centralized charging } \\
\text { equipment }\end{array}$ & $\begin{array}{l}\text { High grid impact if all buses charge at once } \\
\text { at same place }\end{array}$ \\
\hline & \multirow[t]{3}{*}{$\begin{array}{l}\text { Charging handled by } \\
\text { maintenance staff }\end{array}$} & $\begin{array}{l}\text { Midday charge might be necessary/more } \\
\text { buses might be necessary }\end{array}$ \\
\hline & & Cannot be in service while charging \\
\hline & & $\begin{array}{l}\text { Large battery }=\text { more weight }=\text { decreased } \\
\text { fuel efficiency and increased wear on } \\
\text { suspension }\end{array}$ \\
\hline
\end{tabular}

Source: Adapted from "Peak Demand Charges and Electric Transit Buses," Gallo, Rubin, Tomic, 2014 (Gallo, Bloch-Rubin, and Tomic 2014). For further information on depot and on-route charging visit https://afdc.energy.gov/files/u/publication/ financial analysis be transit buses.pdf. 


\section{Appendix C. Emissions Calculations}

Table C-1. Calculation for the Amount of $\mathrm{CO}_{2}$ Produced by a Single BEB Annually

\begin{tabular}{|c|c|c|c|c|c|c|}
\hline $\begin{array}{l}\text { eGRID } \\
\text { Region }\end{array}$ & $\begin{array}{c}\text { A. } \mathrm{CO}_{2} \\
\text { (lb./MWh) }\end{array}$ & $\begin{array}{c}\text { B. } \\
\text { Assumed } \\
\text { annual } \\
\text { mileage of } \\
\text { bus }\end{array}$ & $\begin{array}{c}\text { C. Fuel } \\
\text { efficiency } \\
\text { (kWh/mile) }\end{array}$ & $\begin{array}{l}\text { D. Annual } \\
\text { energy } \\
\text { consumed } \\
\text { in } \mathrm{kWh} \\
\left(\mathrm{B}^{*} \mathrm{C}\right)\end{array}$ & $\begin{array}{l}\text { E. Annual energy } \\
\text { consumed in MWh } \\
(D / 1000)\end{array}$ & $\begin{array}{l}\text { F. Annual lbs. of } \mathrm{CO}_{2} \\
\text { produced by a } \mathrm{BEB} \\
\left(\mathrm{A}^{*} \mathrm{E}\right)\end{array}$ \\
\hline MRO East & 1668.2 & 40,000 & 2.17 & 86,800 & 86.8 & 144,800 \\
\hline $\begin{array}{c}\text { WECC } \\
\text { California }\end{array}$ & 527.9 & 40,000 & 2.17 & 86,800 & 86.8 & 45,822 \\
\hline U.S. Avg & 998.4 & 40,000 & 2.17 & 86,800 & 86.8 & 86,661 \\
\hline
\end{tabular}

Sources: (EPA 2018a) Table 6; (Eudy et al. 2016)

Table C- 2. Calculation for the Amount of $\mathrm{CO}_{2}$ Produced by a Single Diesel Bus Annually

\begin{tabular}{|c|c|c|c|c|c|c|c|}
\hline & $\begin{array}{l}\text { A. } \mathrm{CO}_{2} \\
\text { (g/gal) }\end{array}$ & $\begin{array}{l}\text { B. Assumed } \\
\text { annual } \\
\text { mileage of } \\
\text { bus }\end{array}$ & $\begin{array}{l}\text { C. Fuel } \\
\text { efficiency } \\
\text { (mi/gal) }\end{array}$ & $\begin{array}{l}\text { D. Annual } \\
\text { energy } \\
\text { consumed in } \\
\text { gal }(B / C)\end{array}$ & $\begin{array}{l}\text { E. g to lb. } \\
\text { conversion } \\
\text { (g/lb.) }\end{array}$ & $\begin{array}{l}\text { F. Annual g of } \\
\mathrm{CO}_{2} \text { produced } \\
\left(A^{*} D\right)\end{array}$ & $\begin{array}{l}\text { G. Annual } \\
\text { lbs. of } \mathrm{CO}_{2} \\
\text { produced } \\
\text { (F/E) }\end{array}$ \\
\hline Diesel & 10210 & 40,000 & 4.2 & 9523.81 & 453.592 & 97238095.24 & 214373 \\
\hline
\end{tabular}

Diesel buses produce 1.48 times more $\mathrm{CO}_{2}$ than MRO East BEBs: $214373.48 \mathrm{lbs}$. of $\mathrm{CO}_{2}$ produced by diesel bus / $144799.76 \mathrm{lbs}$. of $\mathrm{CO}_{2}$ produced by BEB in MRO East $=1.48$. 


\section{www.greeningthegrid.org | www.nrel.gov/usaid-partnership}

Jeremy Foster

U.S. Agency for International Development

Email: jfoster@usaid.gov

Sarah Lawson

U.S. Agency for International Development Email: slawson@usaid.gov

\section{Alexandra Aznar}

National Renewable Energy Laboratory

Email: Alexandra.aznar@nrel.gov
Greening the Grid is a platform for expertly curated information, tools, and technical assistance to support countries in power system transformation and grid modernization. Greening the Grid is supported by the U.S. Agency for International Development.

The USAID-NREL Partnership addresses critical challenges to scaling up advanced energy systems through global tools and technical assistance, including the Renewable Energy Data Explorer, Greening the Grid, the International Jobs and Economic Development Impacts tool, and the Resilient Energy Platform. More information can be found at: www.nrel.gov/usaid-partnership.

\section{(S) USAID RNREL}

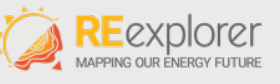

Greening

the Grid

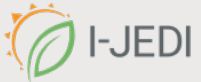

Resilient Energy 